\title{
Structures of Impurity Defects in Lithium Niobate and Tantalate Derived from Electron Paramagnetic and Electron Nuclear Double Resonance Data
}

\author{
Valentin G. Grachev *(D) and Galina I. Malovichko * \\ Physics Department, Montana State University, Bozeman, MT 59717, USA \\ * Correspondence: valentin.g.grachev@gmail.com (V.G.G.); galina.i.malovichko@gmail.com (G.I.M.)
}

Citation: Grachev, V.G.; Malovichko, G.I. Structures of Impurity Defects in Lithium Niobate and Tantalate Derived from Electron Paramagnetic and Electron Nuclear Double Resonance Data. Crystals 2021, 11, 339. https://doi.org/10.3390/ cryst11040339

Academic Editor: Gábor Corradi

Received: 28 February 2021

Accepted: 23 March 2021

Published: 27 March 2021

Publisher's Note: MDPI stays neutral with regard to jurisdictional claims in published maps and institutional affiliations.

Copyright: (c) 2021 by the authors. Licensee MDPI, Basel, Switzerland. This article is an open access article distributed under the terms and conditions of the Creative Commons Attribution (CC BY) license (https:/ / creativecommons.org/licenses/by/ $4.0 /)$.

\begin{abstract}
Point intrinsic and extrinsic defects, especially paramagnetic ions of transition metals and rare-earth elements, have essential influence on properties of lithium niobate, LN and tantalate, LT, and often determine their suitability for numerous applications. Discussions about structures of the defects in LN/LT have lasted for decades. Many experimental methods facilitate progress in determining the structures of impurity centers. This paper gives current bird's eye view on contributions of Electron Paramagnetic Resonance (EPR), and Electron Nuclear Double Resonance (ENDOR) studies to the determination of impurity defect structures in LN and LT crystals for a broad audience of researchers and students. Symmetry and charge compensation considerations restrict a number of possible structures. Comparison of measured angular dependences of ENDOR frequencies with calculated ones for $\mathrm{Li}$ and $\mathrm{Nb}$ substitution using dipole-dipole approximation allows unambiguously to determine the exact location of paramagnetic impurities. Models with two lithium vacancies explain angular dependencies of EPR spectra for $\mathrm{Me}^{3+}$ ions substituting for $\mathrm{Li}^{+}$like $\mathrm{Cr}, \mathrm{Er}, \mathrm{Fe}, \mathrm{Gd}, \mathrm{Nd}$, and $\mathrm{Yb}$. Self-compensation of excessive charges through equalization of concentrations of $\mathrm{Me}^{3+}\left(\mathrm{Li}^{+}\right)$and $\mathrm{Me}^{3+}\left(\mathrm{Nb}^{5+}\right)$ and appearance of interstitial $\mathrm{Li}^{+}$in the structural vacancy near $\mathrm{Me}^{3+}\left(\mathrm{Nb}^{5+}\right)$ take place in stoichiometric $\mathrm{LN} / \mathrm{LT}$ due to lack of intrinsic defects.
\end{abstract}

Keywords: impurity; intrinsic defect; paramagnetic ion; lithium niobate; lithium tantalate; electron paramagnetic resonance; electron nuclear double resonance; lithium vacancy

\section{Introduction}

Point intrinsic and extrinsic defects, especially paramagnetic ions of transition metals and rare-earth elements, belong to the most important defects in lithium niobate (LN, $\left.\mathrm{LiNbO}_{3}\right)$ and tantalate $\left(\mathrm{LT}, \mathrm{LiTaO}_{3}\right)$, because of their essential influence on properties of this material, such as domain structure, electro-optical coefficients, light absorption, refractive indices, birth and evolution of wave-front dislocations ([1,2] and references there), and their consequences for present and potential applications [3-7]. A lot of effort was spent to establish a correlation between the observable data and the crystal composition, and to develop experimentally supported models of the defects: ion charges, identities, and position of the ions in the lattice, their nearest surroundings, ways of charge compensation and recharge mechanisms. Discussions about structures of intrinsic and extrinsic defects in LN/LT have lasted for decades [1]. With time, the proposed structures were evolved and detailed. Some early models were rejected. For instance, after a supposition that effective net charges are about 2.0+ [8], or 1.59+ for $\mathrm{Nb}$ and 1.21+ for $\mathrm{Ta}$ [9], it was natural to assume that divalent and trivalent impurities should preferably substitute for $\mathrm{Nb}$, but not for Li. Later, numerous investigations have shown that the real picture is more complicated and richer.

In the course of the investigation of defect structures in LN/LT the following difficulties take place: 
- $\quad$ high quality conventional samples with crystal composition $x_{C}$ are usually grown from the congruent melt with the composition $x_{m} \approx 48.4 \%$, for LN and $x_{m} \approx 48.7 \%$ for LT $\left(x=[\mathrm{Li}] /([\mathrm{Li}]+[\mathrm{Nb} / \mathrm{Ta}])\right.$; this means that the congruent crystals with $x_{m}=x_{C}$ contain many intrinsic (non-stoichiometric) defects, causing a broadening of the observable spectral lines and ambiguities in their interpretation;

- the crystal composition $x_{C}$ of the undoped samples depends on both melt composition and growth conditions;

- the most probable positions for impurity incorporation, the $\mathrm{Li}$ and $\mathrm{Nb}$ sites as well as the octahedral structural vacancy, have the same local symmetry $\mathbf{C}_{3}$; this means that they are not distinguishable by many spectroscopic techniques.

Techniques for the defect study can be conditionally divided into two groups: direct (Mössbauer spectroscopy [10], Rutherford Backscattering Spectrometry (RBS) [11], Extended X-ray Absorption Fine Structure Analysis (EXAFS), Particle Induced X-ray Emission (PIXE) combined with channeling, X-ray standing wave (XSW) [12], Electron Paramagnetic Resonance (EPR), and Electron Nuclear Double Resonance (ENDOR) [13]) and indirect (optical absorption and luminescence, measurements of electro-optical coefficients, etc.).

Attempts to determine impurity positions by indirect methods often gave contradicting information. Direct methods also have some shortcomings. For instance,

- Mössbauer spectroscopy demands the presence of special nuclei,

- channeling investigations are more successful in the case of heavy, many-electron ions,

- $\quad$ channeling methods are not sensitive to the charge state of the impurity and do not distinguish centers with $\mathbf{C}_{3}$ and $\mathbf{C}_{1}$ symmetry,

- due to the relatively low sensitivity the EXAFS needs high levels of crystal dopants (about 3-5 mol.\%), for which clustering and occupation of both $\mathrm{Li}$ and $\mathrm{Nb}$ positions become very probable,

- $\quad$ EPR/ENDOR techniques are applicable to systems with non-zero spins only.

Investigations of impurity defects were carried out by all direct and indirect techniques in parallel and together, and made invaluable contributions to the problem solution. Let's mention briefly a few of them. The positions of many impurity ions were determined by the EXAFS, PIXE, XSW, and channeling methods. Lithium substitution was found for most elements including Sc, Ti, Mn, Ni, In, Pr, Gd, Ho, Er, Tm, Yb, Lu ([11,14-18], and references there), Nd [19,20], Co, Fe [21-28]. A few ions substitute for Nb in LN (Hf [29], Er [30]) and in LN heavily co-doped by $\mathrm{Mg}$ or $\mathrm{Zn}$ (Sc, In, $\mathrm{Nd}$, Lu [31]). Some of the ions can occupy both positions ( $\mathrm{Cr}$ [32], Gd, Nd). Mössbauer spectroscopy [33,34] gave indirect evidence of $\mathrm{Fe}^{2+}$ and $\mathrm{Fe}^{3+}$ substitution for $\mathrm{Li}^{+}$. Raman spectroscopy data [35] were interpreted on the base of Fe substitution for Li. Magneto-optical and luminescence studies [36,37] identified non-paramagnetic pairs $\mathrm{Cr}_{\mathrm{Li}}-\mathrm{Cr}_{\mathrm{Nb}}$ and established a correlation between optical bands and $\mathrm{Cr}^{3+}$ positions.

Convincing arguments of $\mathrm{Fe}^{3+}$ substitution for $\mathrm{Li}^{+}$were obtained by ENDOR [38-40]: it was shown that spectrum angular dependencies calculated on the base of dipole-dipole interactions of $\mathrm{Fe}^{3+}$ electrons with surrounding Li nuclei are qualitatively different for $\mathrm{Li}$ and $\mathrm{Nb}$ substitution; quantitative agreement calculated and experimental data was achieved for Li substitution.

The huge amount of nonstoichiometric intrinsic defects in congruent LN/LT grown by the conventional Czochralski method [41,42] (we shall call them cLN and cLT) has often undesirable effects on crystal properties. Several techniques were invented in order to reduce the concentration of these defects. Some decrease of their concentration was achieved by using melts with Li excess (with $x_{m}$ up to $60 \%$ ) $[43,44]$. Thin LN/LT samples were enriched with Li by vapor transport equilibrium treatment (VTE [45-50], we shall call them vLN and vLT). Using double crucible growth [51-55] with excess of Li allowed one to obtain nearly stoichiometric samples (nsLN). Crystals grown by the Czochralski method from a melt to which potassium oxide $\mathrm{K}_{2} \mathrm{O}$ has been added ([56-67], and references there) have composition $x_{C} \approx 50 \%\left(\mathrm{LN}_{\mathrm{K}}\right.$, stoichiometric $\left.\mathrm{LN}, \mathrm{sLN}\right)$. The method is scientifically called the High Temperature Top Seeded Solution Growth (HTTSSG). 
The defect elimination in sLN crystals has led to a tremendous narrowing of the resonance lines and a corresponding increase of spectral resolution, and resulted in improved precision of obtained spectroscopic characteristics. Discovery of new centers substituting for $\mathrm{Nb}$ (or Ta in $\mathrm{LiTaO}_{3}$ ) and a change of charge compensation mechanism in sLN was accompanied by a significant progress in understanding the nature and structures of intrinsic and extrinsic defects [68-76]. Several methods of determination of real crystal composition were developed [68,77-80]. It should be mentioned that even crystals with $x_{C}=50 \%$ are not completely free of intrinsic defects. There is a class of intrinsic defects which break the regular order of the $\mathrm{LN}$ lattice without a change of $x_{\mathrm{C}}$ : the permutations $\mathrm{Nb}_{\mathrm{Li}}$ and $\mathrm{Li}_{\mathrm{Nb}}$, and cyclical permutation of $\mathrm{Nb}$ in $\mathrm{Li}$ site, $\mathrm{Li}$ in structural vacancy, and vacancy of $\mathrm{Nb}$. Such defects can cause broadening of spectral lines.

EPR is resonance absorption of microwave quanta by electron spins placed in a swept external magnetic field at definite value of magnetic field $B_{\text {res }}$. Depending on measurement conditions it has usual sensitivity about $10^{12}-10^{15}$ spins $/ \mathrm{cm}^{3}$ or higher. Equipment with wave lengths $3 \mathrm{~cm}$ (X-band, microwave frequency $v \approx 9.5 \mathrm{GHz}$ ) and $8 \mathrm{~mm}$ (Q-band, $v \approx 34 \mathrm{GHz}$ ) are usually used. EPR lines have typical widths about $1-100 \mathrm{MHz}$. This defines the resolution ability of the EPR.

Nuclear magnetic resonance (NMR) is resonance absorption of radiofrequency quanta by nuclear spins. It has worse sensitivity due to thousand time smaller magnetic moments of nuclei. However, NMR has significantly higher resolution ability about $1-100 \mathrm{KHz}$ or less. Only nuclei with large natural abundance of magnetic isotopes (like ${ }^{7} \mathrm{Li}-92.5 \%$, ${ }^{93} \mathrm{Nb}-100 \%,{ }^{181} \mathrm{Ta}-99.99 \%$ ) can be studied by NMR. Due to interactions with electron spins, nuclei in the impurity neighborhood have energy levels and resonance frequencies different from those of bulk nuclei. As their concentrations, which are about impurity concentration, are significantly smaller than concentrations of bulk nuclei, their NMR signals are too weak to be registered directly.

ENDOR is the indirect way to register NMR of nuclei in impurity surrounding via a stimulated change of intensity of the EPR signal in magnetic field $B_{\text {res. }}$ ENDOR has sensitivity that is worse than EPR (about one-two orders of magnitude), but is better than NMR. Its resolution is comparable with NMR resolution. Characteristics of all nuclei (natural abundance of isotopes, their nuclear spins, magnetic and quadrupole moments) are well known and tabulated. This allows to relate observed ENDOR frequencies to interactions of impurity electrons with own nucleus and surrounding nuclei.

For a paramagnetic impurity these techniques are capable of determining: its element, charge, spin state, nearest surrounding (i.e., its location), and many spectroscopic characteristics. Fortunately, most impurities which are useful for optoelectronic application (including transition and rare-earth elements) enter LN and LT in a paramagnetic state. $\mathrm{Li}, \mathrm{Nb}$ and Ta nuclei have significant (93-100\%) natural abundance of magnetic isotopes. The main isotope ${ }^{16} \mathrm{O}$ has no magnetic moment and is invisible in EPR/ENDOR/NMR experiments.

The aim of this paper is to give current bird's eye view on contributions of EPR/ENDOR studies to the determination of impurity defect structures in LN and LT crystals for a broad audience of researchers and students. The name "center" will be used for a complex consisting of the paramagnetic impurity and its surrounding that can have zero, one or more defects besides regular ions.

\section{Materials and Methods}

Most of our measurements presented below were carried out on samples grown by E.P.Kokanyan from Li-rich melt or from the melt with the addition of $\mathrm{K}_{2} \mathrm{O}[56,57]$.

The EPR/ENDOR spectra were measured at microwave frequencies $v \approx 9.4 \mathrm{GHz}$ (X-band) and $v \approx 34.4 \mathrm{GHz}$ (Q-band) on the Bruker ELEXSYS EPR/ENDOR spectrometer at temperatures between 4.2 and $300 \mathrm{~K}$ at Montana State University (Bozeman, MT, USA). 
The treatment and simulation of all spectra and their angular dependencies, as well as the preparation of corresponding figures were carried out with the help of the "Visual EPR" and "Visual ENDOR" program packages [81].

All lattice images were generated using CrystalMaker ${ }^{\circ}$ program [82] and crystallographic data [83-86]. Sizes of oxygen balls were artificially reduced, since nonmagnetic $\mathrm{O}^{2-}$ ions are invisible for EPR/ENDOR. As $\mathrm{LiNbO}_{3}$ and $\mathrm{LiTaO}_{3}$ are isostructural crystals, all figures with lattice and structures of impurity centers are equally applicable to both LN and LT. However, dipole-dipole interactions should be calculated taking into account a difference of their lattice constants.

\section{Basics of EPR and ENDOR Spectra Interpretation}

\subsection{Symmetry Considerations}

The ideal lattice of LN and LT crystals (Figure 1, see also [87]) has two molecules in its rhombohedral elementary unit cell and the space group symmetry is $R 3 c\left(C_{3 v}{ }^{6}, 3 \mathrm{~m}\right)$ at room temperature [8,88-90]. If ionic radii are taken into account, the LT/LN lattices look like consisting mainly of planar layers of closely packed oxygen ions with small voids between them, filled by $\mathrm{Li}$ and $\mathrm{Nb} / \mathrm{Ta}$. There are several electrically non-equivalent positions in the lattice. Some of them-the sites on the $\mathbf{z}$ (or optical c) axis of the crystal, including the sites of $\mathrm{Li}, \mathrm{Nb} / \mathrm{Ta}$ and the octahedral structural void (vacancy), $\mathrm{v}_{\text {oct }}$ - have the symmetry of the point group $C_{3}$. An isolated defect in any of these positions creates a $\mathrm{C}_{3}$ (in the following also labeled "axial") center. The tetrahedral structural void, oxygen sites and all other off axis positions have the lowest possible symmetry, $\mathrm{C}_{1}$.

A complex of two defects has $C_{3}$ symmetry, if both are located on the crystal $\mathbf{z}$ axis, and $C_{1}$ symmetry in all other cases. If the difference in positions of the nearest oxygen ions is ignored, then each unit cell has the following site sequence along the $\mathbf{z}$-axis: $\mathrm{Li}, \mathrm{Ta}, \mathrm{v}_{\text {oct }}$, $\mathrm{Li}, \mathrm{Ta}, \mathrm{v}_{\text {oct }}$. However, oxygen octahedrons and next neighbors for two positions of one type cation are not identical, therefore, the correct assignment of the sequence should be $\mathrm{Li}_{\mathrm{L}}$, $\mathrm{Ta}_{\mathrm{L}}, \mathrm{v}_{\mathrm{Oct}, \mathrm{L}}, \mathrm{Li}_{\mathrm{R}}, \mathrm{Ta}_{\mathrm{R}}, \mathrm{v}_{\mathrm{oct}, \mathrm{R}}$. The surrounding of the "Right" (R) position can be transformed to the "Left" (L) one by a reflection $\mathbf{x} \Leftrightarrow-\mathbf{x}$ and a shift by $\mathrm{c} / 2$, because $\mathbf{z y}$ is a glide mirror plane in the R3c lattice (Figure $1 b$ ). The same consideration is applicable to $C_{1}$ positions also. This means that each axial $\left(C_{3}\right)$ or low-symmetry $\left(C_{1}\right)$ L center has a corresponding $\mathrm{R}$ partner. The $\mathrm{L}$ and $\mathrm{R}$ partners are electrically identical and are not distinguishable by optical or channeling methods, but they are magnetically non-equivalent and can be resolved from each other in favorable cases (high spin value, small line width) by magnetic resonance techniques.

Each $C_{1}$ center in the $\mathrm{R} 3 \mathrm{c}$ lattice has two additional magnetically nonequivalent partners, which can be transformed into each other by a rotation around the $\mathbf{z}$-axis of the crystal by $120^{\circ}$ and $240^{\circ}$. They can be distinguished by the EPR at arbitrary orientations of the magnetic field.

As any crystal characteristic, the EPR spectra must reflect the crystal symmetry and symmetry of all present paramagnetic centers. The best way to determine the defect symmetry is to study angular dependence of the spectra in external magnetic field $\mathbf{B}$ under rotation of the crystal sample around z-axis (shortly speaking, in $\mathbf{x y}$ plane). For a $\mathrm{C}_{3}$ paramagnetic defect with electron spin $S=1 / 2$ the EPR spectrum consists of one resonance at the same position $B_{\text {res }}$ at any orientation of $\mathbf{B}$ with respect to crystallographic axes. A set of up to six lines can be observed at arbitrary orientation of $\mathbf{B}$ for $\mathrm{C}_{1}$ centers; however, some of them coincide for directions of $\mathbf{B}$ along $\mathbf{x}, \mathbf{y}$, or $\mathbf{z}$. If two or more centers present in the sample studied, the spectrum has two or more sets of the lines. If a center has electron spin $S>1 / 2$ multiplets of $2 S$ lines can be observed for every center. 


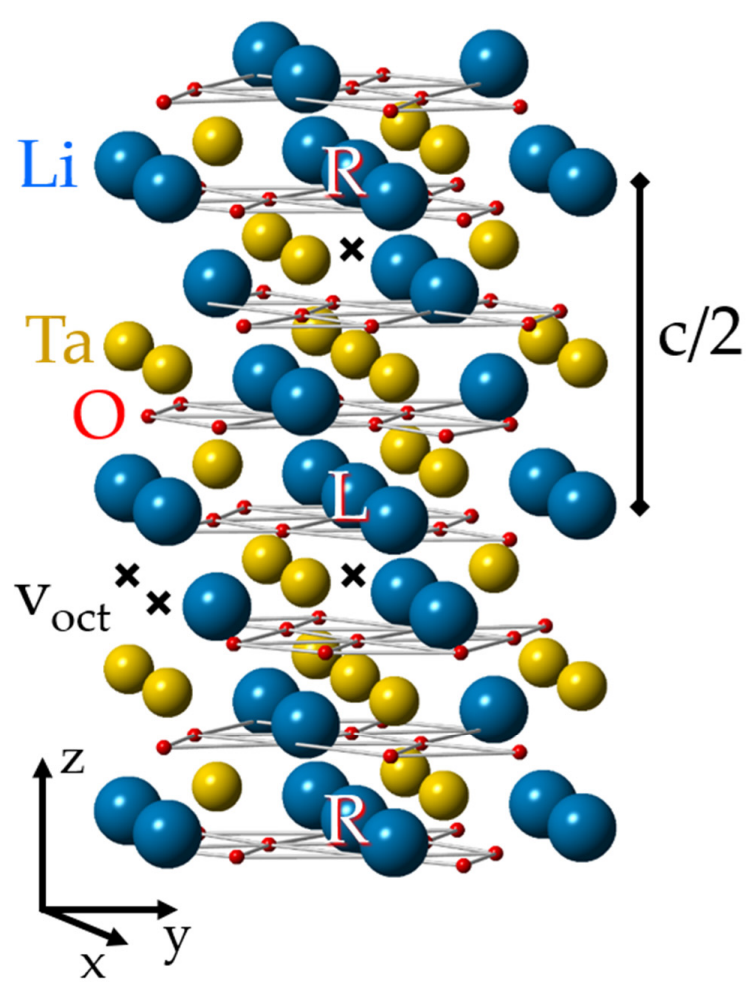

(a)

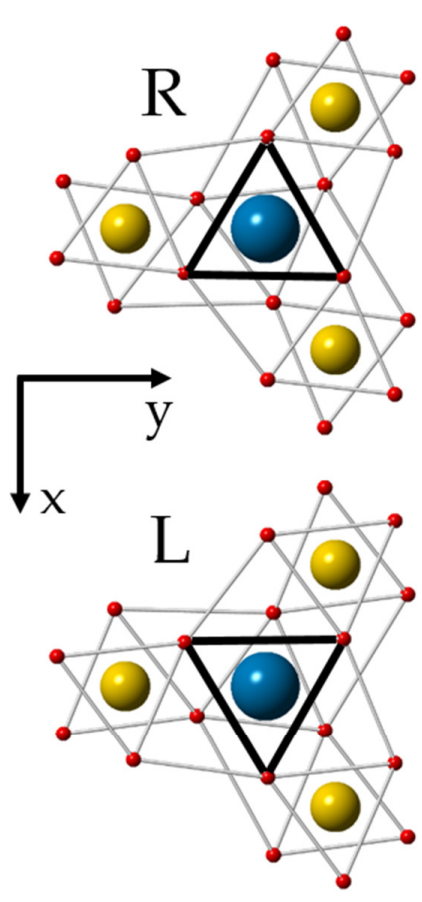

(b)

Figure 1. (a) Ideal lattice of lithium tantalite (LT). To simplify the representation of the lattice and defect structures in it, the sizes of "balls" imitating ions were made intentionally different. The L (Left) and R (Right) positions are distinguished by their different oxygen surroundings. (b) An illustration of local $C_{3}$ symmetry for the nearest surroundings of cation sites and glide mirror zy plane that transforms the $\mathrm{L}$ center to the $\mathrm{R}$ partner; a projection of one $\mathrm{Li}$, Ta layer between two oxygen layers on the xy plane is shown.

For centers with $S=1 / 2$ the resonance line positions can be described using spinHamiltonian

$$
H=\mu_{B} \mathbf{B g S}
$$

Here $\mu_{B}$ is the Bohr magneton, $\mathbf{B}$ is the vector of static magnetic field, $\mathbf{g}$ is the tensor of spectroscopic splitting, and $\mathbf{S}$ is the vector of electron spin.

As an example of the multi-center spectra let's consider ion $\mathrm{Nd}^{3+}$ in $\mathrm{LN}$ [91-93] (Figure 2). Every spectrum consists of a single dominant line labeled with the number 1 and many satellite lines of smaller intensities. The positions of the dominant line have the same value of the resonance field for $\mathbf{B} \mid \mathbf{|} \mathbf{x}$ and $\mathbf{B}|| \mathbf{y}(\varphi=90 \mathrm{deg})$, whereas positions of other lines do not coincide. We have to suppose that the single line \#1 belongs to the axial $\mathrm{C}_{3}$ symmetry center, $\mathrm{Nd}_{1}$.

To make correct labeling of all observed lines a detailed study of angular dependence of EPR line positions is required. For instance, we can rotate magnetic field in xy crystallographic plane, changing azimuthal angle $\varphi$ between $\mathbf{x}$-axis and $\mathbf{B}$. Circular diagram of measured spectra (Figure 3 ) show that dominant line draw a circle, i.e., has no dependence of $B_{\text {res }}(1)$ on $\varphi$. Angular patterns of other lines demonstrate the presence of all elements of the $3 \mathrm{~m}$ group, namely, $C_{3}$ symmetry and the mirror with respect to $\mathbf{y}$-axis at $\varphi=90 \mathrm{deg}$. Measurement of such a diagram is redundant, since $\mathbf{x y}$ plane angular patterns simply repeat themselves with a period $60 \mathrm{deg}$. Due to the glide mirror plane, the 30 degree dependence measured from $\mathbf{x}$ axis contains all information. 
Usually, $90 \mathrm{deg}$ of the measured dependence is plotted (Figure 4). If spectra are measured with small angular steps (said $1 \mathrm{deg}$ ), it is easy to trace every line. The line tracing allows to put labels on every resonance line on Figure 2. Without doubt, at least four groups of angular branches are clearly distinguished on Figure 4: one straight branch of axial $\mathrm{Nd}_{1}$ and three sets of curved branches, which correspond to low-symmetry centers $\mathrm{Nd}_{2}, \mathrm{Nd}_{3}$, and $\mathrm{Nd}_{4}$. Therefore, we can conclude that $\mathrm{Nd}^{3+}$ in $\mathrm{Nd}_{1}$ center occupies one of three possible positions on the $\mathbf{z}$-axis. If $\mathrm{Nd}^{3+}$ has additional defect or defects (charge compensators) in its neighborhood, the defect is located on the same axis. In the case of $\mathrm{Nd}_{2}, \mathrm{Nd}_{3}$, and $\mathrm{Nd}_{4}$ centers with the $\mathrm{C}_{1}$ symmetry, the additional defects are located off the $\mathbf{z}$-axis. It is unlikely that $\mathrm{Nd}^{3+}$ ions occupy sites with $\mathrm{C}_{1}$ symmetry (tetrahedral void or $\mathrm{O}^{2-}$ ) due to large charge misfit.

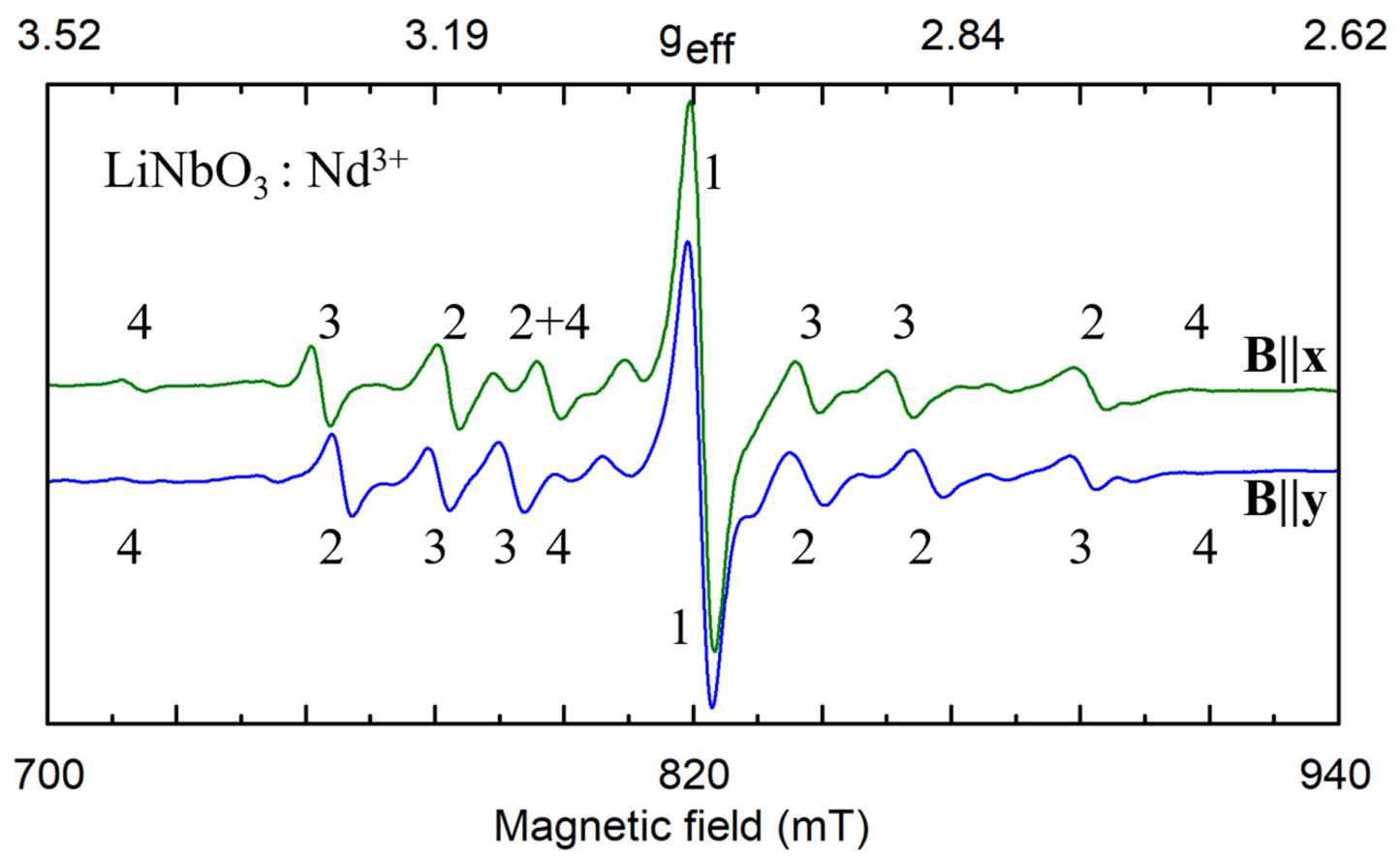

Figure 2. Fragments of electron paramagnetic resonance (EPR) spectra of $\mathrm{Nd}^{3+}$ impurity ions in nearly stoichiometric lithium niobate (LN) for microwave frequency $v=34.445 \mathrm{GHz}, T=19 \mathrm{~K}$. The numbers $1-4$ correspond to four different electrically non-equivalent defects. Lines of magnetically nonequivalent partners have the same number.

Symmetry of any center reflects the symmetry of lattice sites occupied by impurity and charge compensators (if any) and their relative locations. To distinguish the $C_{3}$ and $C_{1}$ symmetries the measurement of angular dependence in $x y$ plane is sufficient. However, to obtain a full set of spectroscopic characteristics of the center (like six components of g-tensor) by fitting measured angular dependence a study of spectra under three rotations in perpendicular planes (road map) is required. 


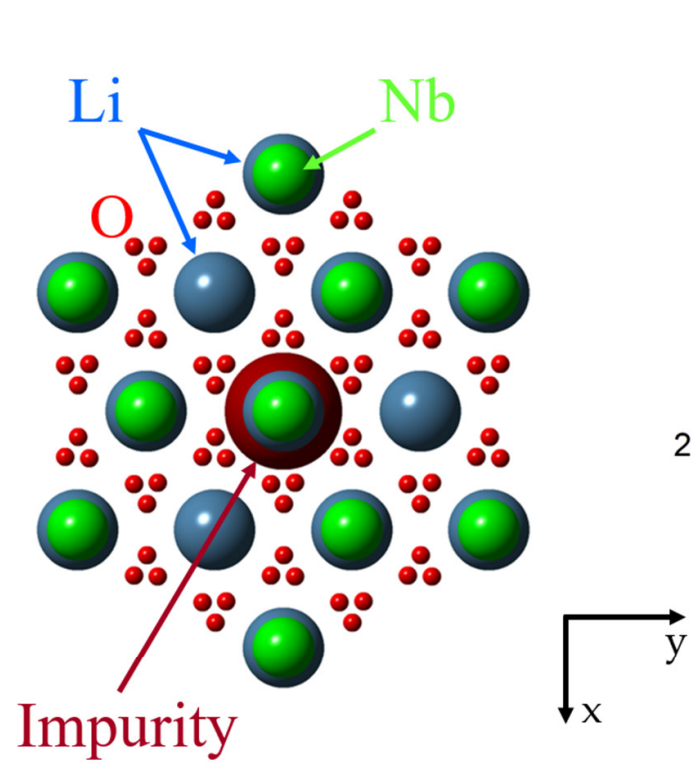

(a)

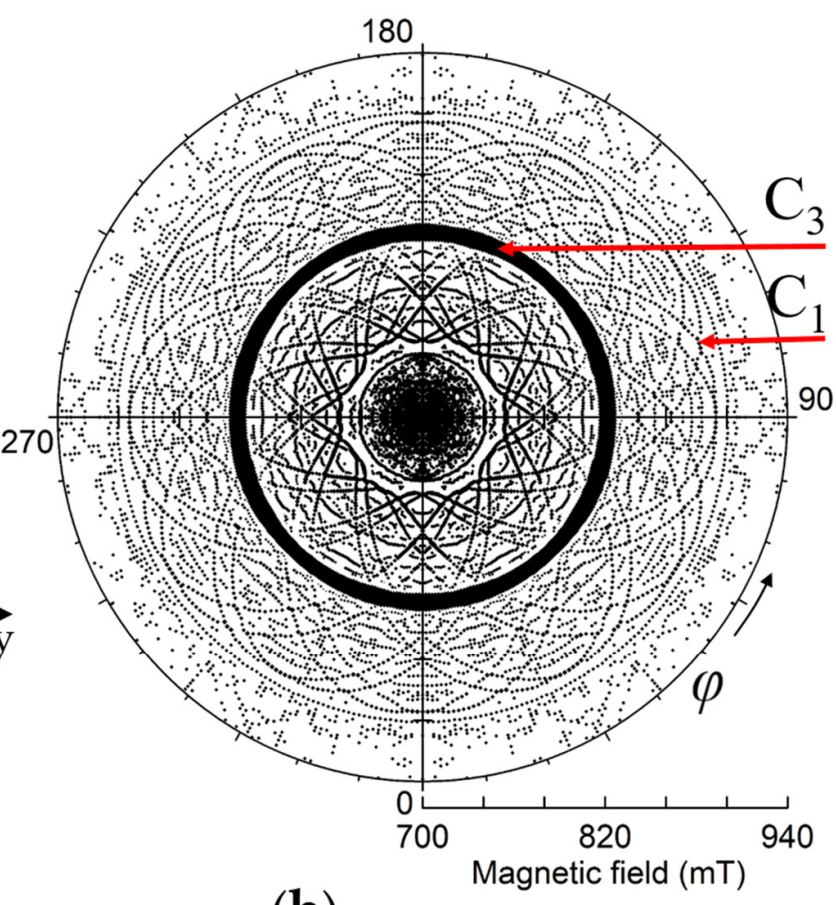

(b)

Figure 3. (a) Projection of ideal lithium niobate lattice with $\mathrm{Nd}^{3+}$ impurity ion on xy plane (artificial sizes of balls are used). (b) Circular diagram of measured angular dependence of electron paramagnetic resonance (EPR) lines of $\mathrm{Nd}^{3+}$ ions in Figure 3. Magnetic field was rotated in xy plane from 0 to $360 \mathrm{deg} . v=34.445 \mathrm{GHz}, \mathrm{T}=19 \mathrm{~K}$. Symbol sizes reflect line intensities.

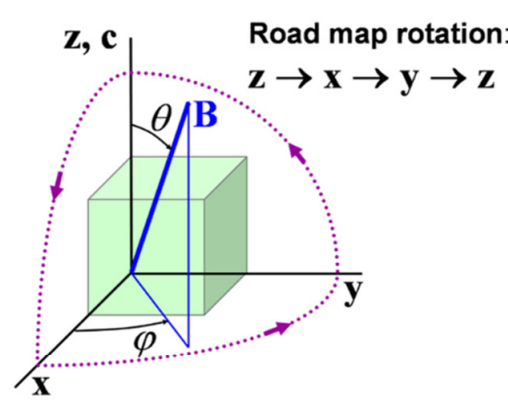

(a)

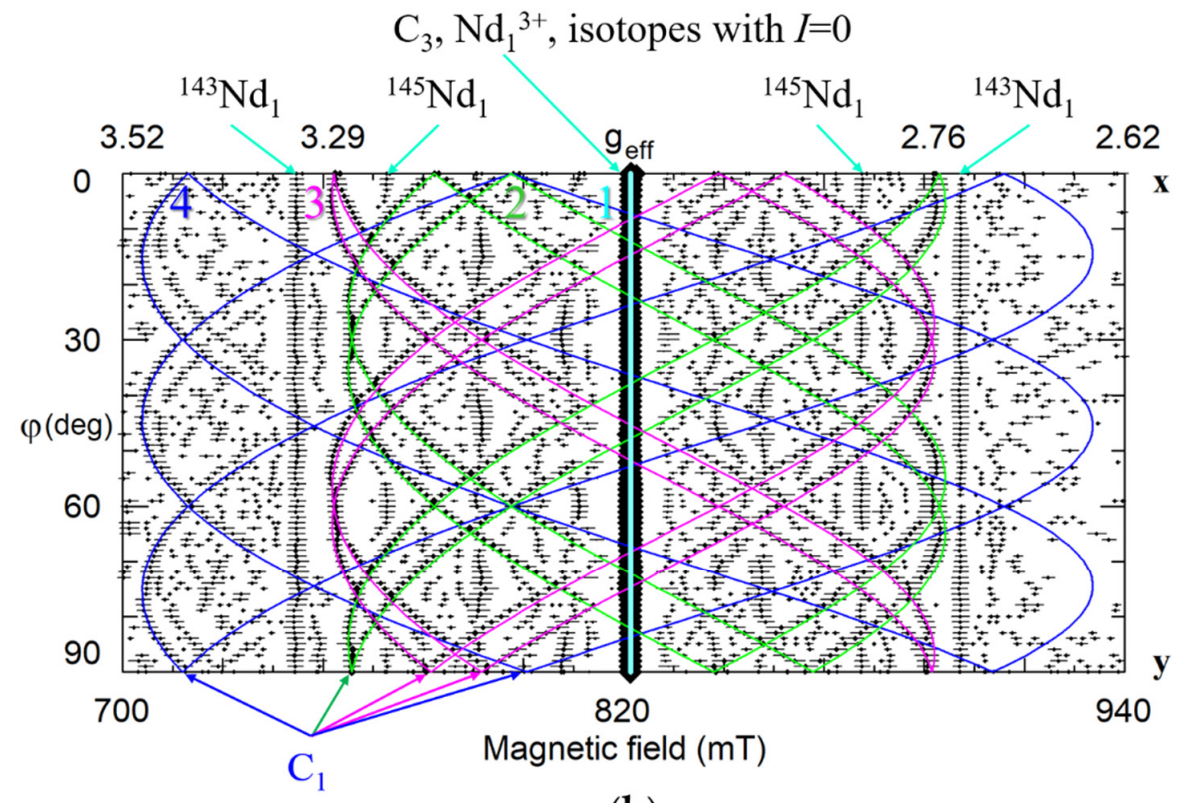

(b)

Figure 4. (a) The road map rotation corresponds to the following changes of the $\theta, \phi$ angles: $\theta=0-90^{\circ}$ at $\phi=0^{\circ} ; \theta=90^{\circ}$, $\phi=0-90^{\circ} ; \theta=0-90^{\circ}$ at $\phi=90^{\circ}$. (b) Angular dependence of the EPR spectra in xy plane for nearly stoichiometric $\mathrm{LN}: \mathrm{Nd}^{3+}$. Rhombs represent experimental line positions for Q-band measurements $(v=34.445 \mathrm{GHz})$, their sizes reflect line intensities. Horizontal whiskers near rhombs represent line widths. Cyan, lime, fuchsia, and blue curves represent simulated dependencies for axial $\mathrm{Nd}_{1}$, and low-symmetry $\mathrm{Nd}_{2}, \mathrm{Nd}_{3}$, and $\mathrm{Nd}_{4}$ centers, respectively. Curves for isotopes with nuclear spin $I \neq 0$ are not shown. 


\subsection{Isotropic and Dipole-Dipole Interactions}

Calculations of the ENDOR frequencies and transition probabilities (i.e., ENDOR line positions and relative intensities) for $i$-th nucleus is usually based on nuclear spinHamiltonians $H_{i}$

$$
H_{i}=-\mu_{n} g_{n}^{(i)} \mathbf{B} \mathbf{I}^{(i)}+\mathbf{S} \mathbf{A}^{(i)} \mathbf{I}^{(i)}+\mathbf{I}^{(i)} \mathbf{Q}^{(i)} \mathbf{I}^{(i)}
$$

where $\mu_{n}$-nuclear magneton, $g_{n}^{(i)}$-nuclear $g$-factor; $\mathbf{A}^{(i)}, \mathbf{Q}^{(i)}$ —tensors of hyperfine and quadrupole interactions.

In many cases there are two dominant contributions to the hyperfine tensor $\mathbf{A}^{(i)}$ : isotropic (contact) hyperfine interaction, $a^{(i)} \mathbf{S I}{ }^{(i)}$ and dipole-dipole interaction of vectors of electron $\mu_{B} g \mathbf{S}$ and nuclear $-\mu_{n} g_{n}^{(i)} \mathbf{I}^{(i)}$ magnetic moments. The dipole-dipole interaction can be described by

$$
A_{j m}^{(i) d d}=\frac{\mu_{B} \mu_{n}}{\left(R^{(i)}\right)^{3}} g_{n}^{(i)}\left[\frac{3}{\left(R^{(i)}\right)^{2}}\left(\sum_{p=x, y, z} g_{j p} R_{p}^{(i)}\right)\left(\sum_{l=x, y, z} R_{l}^{(i)} \delta_{l m}\right)-g_{j m}\right]
$$

where $\mathbf{R}^{(i)}$ is the vector from paramagnetic impurity to the $i$-th nucleus. Most characteristics in Equation (3) are known: $\mu_{B}, \mu_{n}, g_{n}^{(i)}$ are tabulated, $g_{j m}$ components of $\mathbf{g}$-tensor are determined from EPR measurements. Therefore, comparison of measured angular dependences of ENDOR frequencies with calculated ones on the base of Equations (2) and (3) can be used for determination of $\mathbf{R}^{(i)}$, i.e., the position of the paramagnetic impurity relative to surrounding nuclei.

Nuclei at the same distance from impurity ions are usually called a shell. The first shell of an impurity in a Li site has six nearest Li nuclei off the $\mathbf{z}$-axis at the distance $R^{(1)}$ (Figure 5a). Three of them are located above the impurity (the subshell 1a), other threebelow the impurity (the sub-shell 1b); if the impurity is shifted from regular Li site then $R^{(1 \mathrm{a})} \neq R^{(1 \mathrm{~b})}$. The second shell consist of six Li nuclei in the $\mathbf{x y}$ plane of the impurity at the distance $R^{(2)}$ (subshells 2a, 2b).The first shell of an impurity in a $\mathrm{Nb}$ site has one $\mathrm{Li}$ nucleus on $\mathbf{z}$-axis, the second shell has three Li nuclei (the nuclei are labelled 1 and 2 on Figure 5b). As directions from the impurity to the nuclei in a shell are different, their hyperfine interactions are magnetically non-equivalent, i.e., produce different branches in angular dependences of ENDOR spectra.

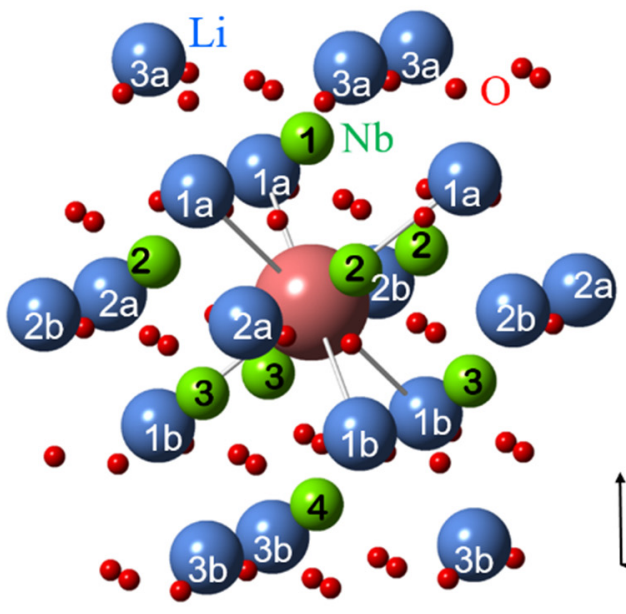

(a)

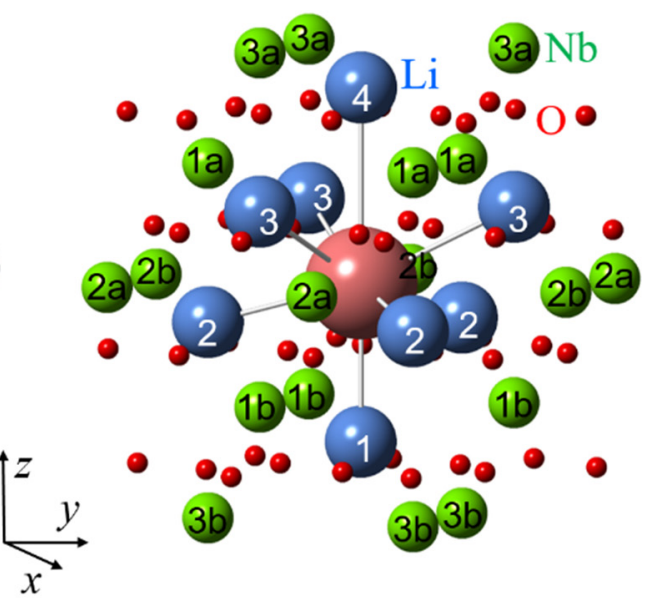

(b)

Figure 5. Surroundings of impurity ions substituted for $\mathrm{Li} \mathrm{(a)} \mathrm{and} \mathrm{Nb}(\mathbf{b})$ in $\mathrm{LN}$ crystal lattice with corresponding shell numbers. Large blue balls represent $\mathrm{Li}^{+}$ions, medium green balls- $\mathrm{Nb}^{5+}$ ions, small red balls- $\mathrm{O}^{2-}$ ions, and the largest magenta ball—the impurity ion. 
The simplest way to determine the impurity lattice site is:

- $\quad$ to calculate $A_{j m}^{(i) d d}$ for the several nearest nuclei around the impurity taking lattice distances from X-ray data and $g_{j m}$ from EPR measurements,

- to calculate ENDOR frequencies, to plot patterns of their angular dependencies, and

- $\quad$ to compare the patterns with measured angular dependencies of ENDOR for a definite EPR line [13,38,39].

Due to different surroundings for impurities in the $\mathrm{Li}$ and $\mathrm{Nb}$ sites, the calculated patterns are completely different (Figure 6). ENDOR frequencies for the first shell of Li nuclei for the Li site vary with rotation of magnetic field in xy plane(Figure 6a), whereas for the single Li nucleus of the first shell for $\mathrm{Nb}$ site two straight branches should be observed in angular dependence (Figure 6c). As Li nuclei of the all corresponding shells are closer to the impurity ion in the $\mathrm{Nb}$ site than in the Li site, the range of angular variation for $\mathrm{Nb}$ site is larger than for Li site. The branches of the 2nd and 3rd shells for Li site practically coincide with measured angular dependencies for $\mathrm{Nd}_{1}$ center (Figure $6 \mathrm{~b}$ ), whereas no branch for $\mathrm{Nb}$ site is close to observed one. The branches of the 1st shell for Li substitution also agree with observed ones after small correction due to isotropic hyperfine interaction (Figure 6b). Based on clear agreement of hundred measured values of ENDOR frequencies for the dominant EPR line \#1 with calculated frequencies for Li site and obvious disagreement with calculated ones for $\mathrm{Nb}$ site, we can definitely conclude that the $\mathrm{Nd}_{1}$ line in EPR spectra (Figure 2) belongs to $\mathrm{Nd}^{3+}$ ion substituted for $\mathrm{Li}$.

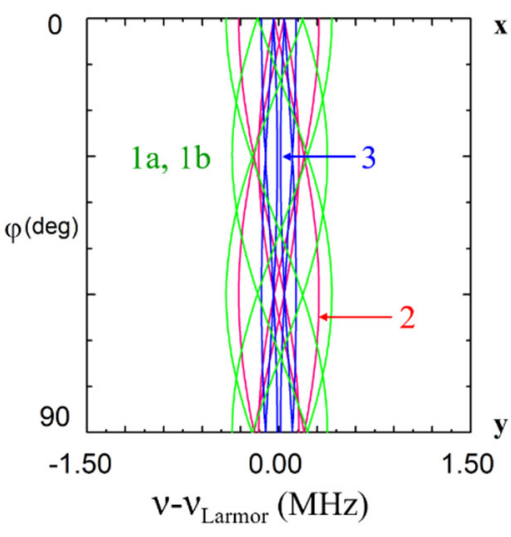

(a)

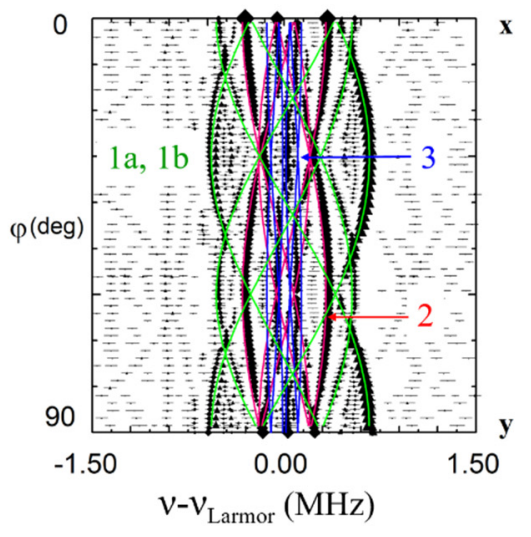

(b)

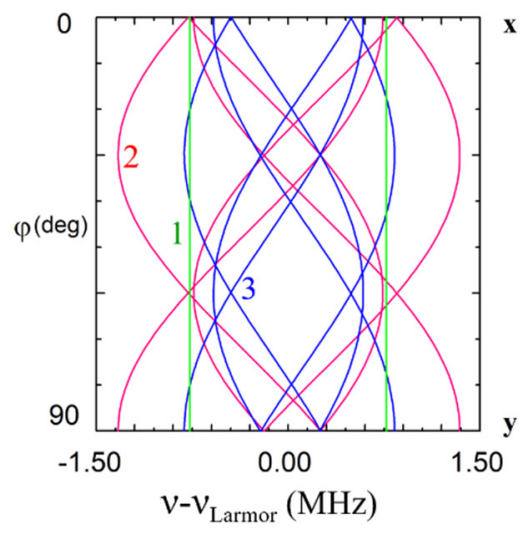

(c)

Figure 6. Angular dependence of electron nuclear double resistance (ENDOR) frequencies of Li nuclei in $\mathbf{x y}$ plane for the $\mathrm{Nd}_{1}{ }^{3+}$ center in $\mathrm{LiNbO}_{3}$. The green, red and blue curves-calculated frequencies for Li nuclei of the 1st, 2nd and 3rd shells based on dipole-dipole interaction for $\mathrm{Nd}^{3+} \mathrm{Li}(\mathbf{a}, \mathbf{b})$, and $\mathrm{Nd}^{3+} \mathrm{Nb}(\mathbf{c})$. ENDOR frequencies represented on the part (b) were measured at magnetic fields corresponding to the position of dominant EPR line \#1 on Figure 2 ( $B=820 \mathrm{mT}$ for $v=34.445 \mathrm{GHz}$, rhombs, and $B=228 \mathrm{mT}$ for $v=9.500 \mathrm{GHz}$, triangles). $v_{\text {Larmor }}$ is Larmor frequency of ${ }^{7} \mathrm{Li}$ nuclei.

The simulation of dipole-dipole interactions for the $\mathrm{Li}$ and $\mathrm{Nb}$ sites has no fitting parameter. Therefore, the described qualitative and quantitative approach for the determination of impurity positions gives reliable results. Note that hyperfine interactions for $\mathrm{Nb} /$ Ta nuclei have additional contributions due to a polarization of inner electron shells of oxygen and niobium ions (transferred hyperfine interaction).

The characteristic of isotropic hyperfine interaction $a^{(i)}$ is related to a density of electron cloud at the location of $i$-nucleus $\mathbf{R}^{(i)}$. For the isotropic g-factor:

$$
a^{(i)}=\frac{8 \pi}{3} g \mu_{B} g_{n}^{(i)} \mu_{n}\left|\psi\left(\mathbf{R}^{(i)}\right)\right|^{2}
$$

The isotropic hyperfine interaction often (but not always) exponentially decreases with the distance from impurity. The largest value $a^{(i)} / g_{n}^{(i)}$ should correspond to nuclei nearest 
to the impurity. It allows to determine nuclei of the nearest surrounding by comparison of $a^{(i)} / g_{n}^{(i)}$ for $\mathrm{Li}$ and $\mathrm{Nb}$ nuclei, and therefore, to find the impurity location. Impurities substituted for $\mathrm{Li}$ have $\mathrm{Nb}$ nucleus on $\mathbf{z}$-axis in the nearest surrounding, whereas ions substituted for $\mathrm{Nb}$ have Li nucleus (Figure 6, shell \#1).

Another way to use contact and dipole-dipole interactions is:

- to measure the road map of angular dependencies in three perpendicular planes (Figure 4a),

- to determine all components of $\mathbf{A}^{(i)}$ tensors by fitting observed angular dependencies,

- to separate isotropic and anisotropic parts,

- to find principal values of the anisotropic part, and finally,

- to compare these principal values with calculated ones on the base of Equation (3).

\subsection{Charge Compensation and Intrinsic Defects}

The structure of a center, in which a lattice site is occupied by an extrinsic impurity ion having a charge different from that of the respective lattice ion (in the following labeled "non-isocharged replacement"), depends on the charge of the impurity and the mechanism of charge compensation. Because of non-stoichiometry, the real lattice of conventional congruent $\mathrm{LN}$ contains many intrinsic defects, the relative concentrations of which have not yet been determined reliably. The following entities have been considered (their charges with respect to the lattice being given by Kröger-Vink notation in brackets): $\mathrm{Nb}^{5+}{ }_{\mathrm{Li}}^{+}\left(\mathrm{Nb}_{\mathrm{Li}}{ }^{4 \bullet}\right)$ antisite defect, $\mathrm{v}_{\mathrm{Li}}{ }^{+}\left(\mathrm{v}_{\mathrm{Li}}{ }^{\prime}\right)$ lithium vacancy, $\mathrm{v}_{\mathrm{Nb}}{ }^{5+}\left(\mathrm{v}_{\mathrm{Nb}}{ }^{5}\right)$ niobium vacancy, $\mathrm{Nb}^{5+}{ }_{\mathrm{v}}\left(\mathrm{Nb}_{\mathrm{v}}{ }^{5 \bullet}\right)$ niobium on structural vacancy, $\mathrm{Li}^{+}{ }_{\mathrm{v}}\left(\mathrm{Li}_{\mathrm{v}}{ }^{\bullet}\right)$ lithium on structural vacancy, $v_{O}$ oxygen vacancy. During recent years the existence of the following charge compensated complexes has been postulated most often: $\mathrm{Nb}_{\mathrm{Li}}+4 \mathrm{v}_{\mathrm{Li}}[90,94,95]$ (including three-dimensional complexes $\left.3 \mathrm{v}_{\mathrm{Li}}+\mathrm{Nb}_{\mathrm{Li}}+\mathrm{v}_{\mathrm{Li}}[96,97]\right), 5 \mathrm{Nb}_{\mathrm{Li}}+4 \mathrm{v}_{\mathrm{Nb}}[98,99], 2 \mathrm{Nb}_{\mathrm{Li}}+2 \mathrm{Nb}_{\mathrm{v}}$ $+3 \mathrm{v}_{\mathrm{Li}}+3 \mathrm{v}_{\mathrm{Nb}}$ [96] and some others [100]. Some features accompanying the crystal growth $\left(\mathrm{Li}_{2} \mathrm{O}\right.$ evaporation, variation of oxygen deficiency in $\mathrm{Nb}_{2} \mathrm{O}_{5-\mathrm{x}}$ [101]) and specific changes of some crystal properties after thermal oxidation and/or reduction definitely indicate that the oxygen sub-lattice is not always perfect and stable as well; therefore the oxygen non-stoichiometry has been also discussed for a long time [102-105]. The intrinsic defects by themselves or complexes of them, which are not charge compensated, can furthermore serve as local or distant charge compensators for non-isocharged extrinsic or radiation defects. Due to the high concentration of the intrinsic defects the congruent LN and LT crystals are very tolerant to substitutional or interstitial impurities, including non-controlled ones, because the necessary charge compensators (local or distant) can be easily found among the non-stoichiometric defects. Real crystals often contain $\mathrm{H}, \mathrm{Cu}, \mathrm{Co}, \mathrm{Mn}$, Fe, etc. in concentrations about $0.00 \mathrm{X}-0.0 \mathrm{X}$.

Non-isovalent cation $\mathrm{Me}^{\mathrm{n}+}(\mathrm{n}>1)$ substituted for $\mathrm{Li}^{+}$requires negative charge compensator like lithium vacancy or interstitial $\mathrm{O}^{2-}$. If $\mathrm{Me}^{\mathrm{n}+}(\mathrm{n}<5)$ substituted for $\mathrm{Nb}^{5+}$ or $\mathrm{Ta}^{5+}$ the $\mathrm{n}-5$ negative charge can be compensated by antisite ions, oxygen vacancies, $\mathrm{v}_{\mathrm{O}}$ or interstitial $\mathrm{H}^{+}$and $\mathrm{Li}^{+}$.

In some cases, a self-compensation of impurity charges takes place. For instance, no additional charge is required if two $\mathrm{Me}^{3+}$ ions substitute for both $\mathrm{Li}^{+}$and $\mathrm{Nb}^{5+}$ in nearest neighbor or next neighbor sites (local self-compensation) or even relatively far one from another (distant self-compensation). There are two critical parameters, which stimulate the self-compensation: total concentration of possible charge compensation defects, [D] and the total concentration of $\mathrm{Me}^{3+}$ ions in the sample, [Me]. The [D] includes a dominant contribution due to a deviation of the crystal composition from stoichiometry, concentrations of $\mathrm{H}^{+}$ions and $\mathrm{v}_{\mathrm{O}}$, as well as contributions due to non-controlled impurities $(\mathrm{Mg}, \mathrm{C}, \mathrm{Si}, \mathrm{Cl}$, $\ldots$ ), which are always present in real crystal in concentrations about 1-500 ppm. If [D] $>>$ $[\mathrm{Me}]$ the isolated centers with additional intrinsic defects are dominating. If $[\mathrm{D}]<<[\mathrm{Me}]$ then the self-compensation is preferable due to lack of charge compensators.

Distant charge compensators produce small distortions of the crystal field at the impurity site, what normally causes EPR line broadening, and an asymmetry of their 
shapes, but do not change the center symmetry revealed in the observed positions and splitting of EPR lines. Defects in the immediate neighborhood (local charge compensation) cause strong changes of the center characteristics ( $\mathbf{g}$ and $\mathbf{A}$ tensors in the case of $\mathrm{Nd}^{3+}$ ) and lowering of center symmetry.

\subsection{Di-Vacancy Models for Trivalent Impurities}

Many impurities in LN/LT crystals create a family of paramagnetic centers that includes dominant axial center and several satellite low-symmetry centers with EPR lines of smaller intensities (like presented on Figure 2). It would be reasonable to look for center models which are able to describe the whole family.

Low-symmetry $C_{1}$ centers appear in three cases:

1. Impurity ion like $\mathrm{Nd}^{3+}$ has an off-axis lattice defect (charge compensator) in the immediate neighborhood.

2. Impurity ion substitutes for $\mathrm{O}^{2-}$ (this is very improbable for cations).

3. Impurity ion incorporates into a small tetrahedral void (this is possible, but often unlikely due to larger charge misfit than for Li substitution).

For axial centers, the directions of principal axes of the g-tensor are dictated by crystal symmetry: the 3rd axis of the center coincides with the crystal axis and the directions of the 1st and 2nd axes are arbitrary. For low-symmetry centers, there are no symmetry restrictions on the orientation of principal axes. However, if the symmetry lowering is related to an off-axis lattice defect, it is reasonable to expect that directions of the center axes are related to the distortion created by the off-axis defect. The 3rd axis will have some inclination from the $\mathbf{z}$-axis to the defect, and projections of the 1 st or 2 nd axis will be close to the projection of line from the impurity ion to the defect. The distortion should decrease with the distance from the impurity ion to the defect.

ENDOR data for the dominant EPR line have confirmed that $\mathrm{Nd}^{3+}$ substitutes for $\mathrm{Li}^{+}$ and only $\mathrm{Li}$ and $\mathrm{Nb}$ nuclei were found in the neighborhood. Therefore, intrinsic defects without nuclear spin should be considered for the required 2-charge compensation. The size $\mathrm{O}^{2-}$ is comparatively large to be placed into small octahedral or tetrahedral voids. Nearly stoichiometric crystals have significantly reduced concentration of $\mathrm{v}_{\mathrm{Li}}$. Nevertheless, their concentration often exceeds the impurity concentration. Sufficient concentration of $\mathrm{V}_{\mathrm{Li}}$ can be also created in the process of growth of samples with non-isocharged impurities.

A key to the identification of models which describe all varieties of $\mathrm{Nd}^{3+}$ centers with minimal assumptions was obtained from the analysis of angular dependencies of the $\mathrm{Nd}_{4}$ center. The extrema in the xy plane and, correspondingly, projections of one principal axis of the g-tensor, are close to $\phi$ values of 15,45 , and 75 degrees (Figure $4 \mathrm{~b}$ ). In the projection of the LN lattice onto the xy plane (Figure 7, after [93]) there are no similar values of $\phi$ from $\mathrm{Nd}^{3+}$ to any ion in the lattice: directions from the $\mathrm{Nd}^{3+}$ site to all cation sites have azimuthal angles equal to $n \times 30^{\circ}$. Therefore, the simplest model, that has a single lattice defect, like a $\mathrm{Li}^{+}$vacancy, $\mathrm{v}_{\mathrm{Li}}$, cannot explain the observed angular dependencies of $\mathrm{Nd}_{4}$ centers. However, if two $\mathrm{Li}^{+}$vacancies are located in the first and second shells of the surroundings of an $\mathrm{Nd}^{3+}$ ion substituted for a $\mathrm{Li}^{+}$, the three defects are organized into a triangle. The longest side of the triangle connected two $\mathrm{v}_{\mathrm{Li}}$ has a perpendicular oriented in the required direction (Figure 7).

The hypothesis that $\mathrm{Nd}^{3+}$ substituted for $\mathrm{Li}^{+}$has two $\mathrm{V}_{\mathrm{Li}}$ as charge compensators allows for consistent models for the whole family of $\mathrm{Nd}^{3+}$ centers in $\mathrm{LN}$ crystals with a low concentration of neodymium doping. After analysis of principal values and axes of g-tensors it was concluded $[92,93]$ that $\mathrm{Nd}^{3+}$ centers have lithium vacancies in sites described in Table 1. Some of possible structures are presented on Figures 7 and 8.

The di-vacancy models can explain EPR spectra of many other (but not all) trivalent impurities $\mathrm{Me}^{3+} \mathrm{Li}$. 


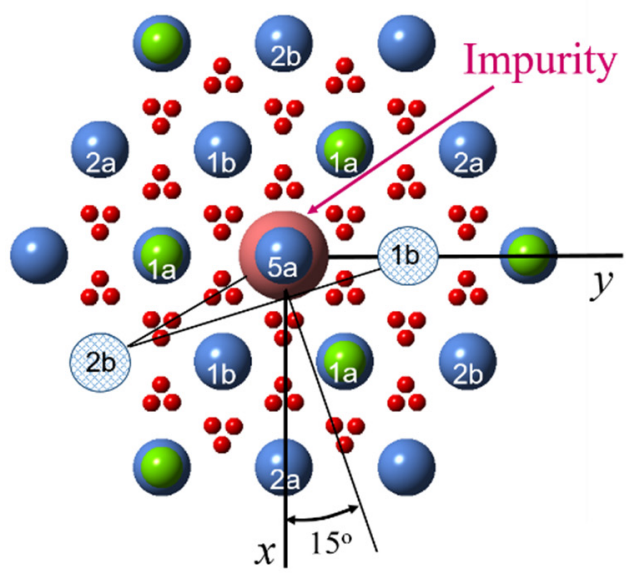

(a)

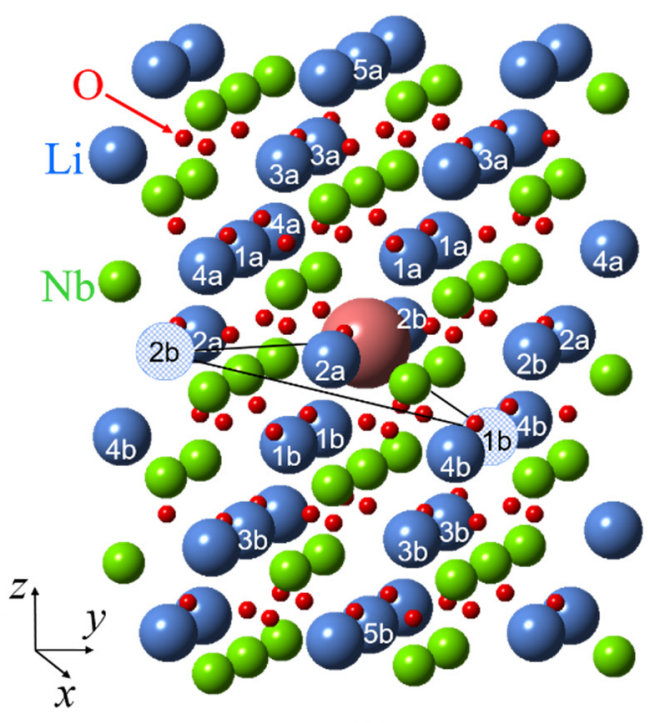

(b)

Figure 7. A projection of lithium niobate crystal lattice on xy plane (a) and 3D model (b) with shell numbers for an impurity substituted for $\mathrm{Li}^{+}$ion (sizes of all ions were artificially changed in order to make clear positions of cation ions). Hatched circles represent two vacancies of $\mathrm{Li}^{+}$ions for $\mathrm{Nd}_{4}$ center.

Table 1. Sites for lithium vacancies, $\mathrm{v}_{\mathrm{Li}}$ in the surroundings of $\mathrm{Me}^{3+} \mathrm{Li}$ centers in $\mathrm{LiNbO}_{3}$.

\begin{tabular}{ccccccccc}
\hline $\begin{array}{c}\text { Center } \\
\mathbf{v}_{\mathbf{L i}} \text { Site }\end{array}$ & $\mathbf{M e}_{\mathbf{1}}$ & $\mathbf{M e}_{2}$ & $\mathbf{M e}_{3}$ & $\mathbf{M e}_{4}$ & $\mathbf{M e}_{5}$ & $\mathbf{M e}_{6}$ & $\mathbf{M e}_{7}$ & $\mathbf{M e}_{8}$ \\
\hline First & $5 \mathrm{a} / 5 \mathrm{~b}$ & $1 \mathrm{a} / 1 \mathrm{~b}$ & $2 \mathrm{a} / 2 \mathrm{~b}$ & $1 \mathrm{a}$ & $1 \mathrm{~b}$ & $1 \mathrm{a} / 1 \mathrm{~b}$ & $2 \mathrm{a} / 2 \mathrm{~b}$ & $5 \mathrm{a}$ \\
Second & distant & $5 \mathrm{a} / 5 \mathrm{~b}$ & $5 \mathrm{~b} / 5 \mathrm{~b}$ & $2 \mathrm{a}$ & $2 \mathrm{~b}$ & $3 \mathrm{a} / 3 \mathrm{~b}$ & $3 \mathrm{a} / 3 \mathrm{~b}$ & $5 \mathrm{~b}$ \\
\hline
\end{tabular}

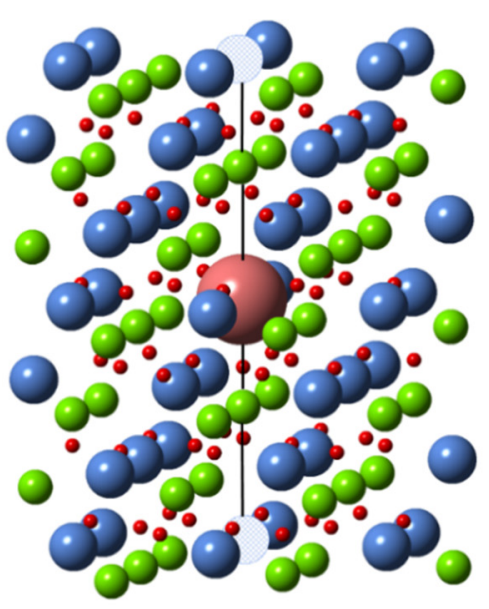

(a)

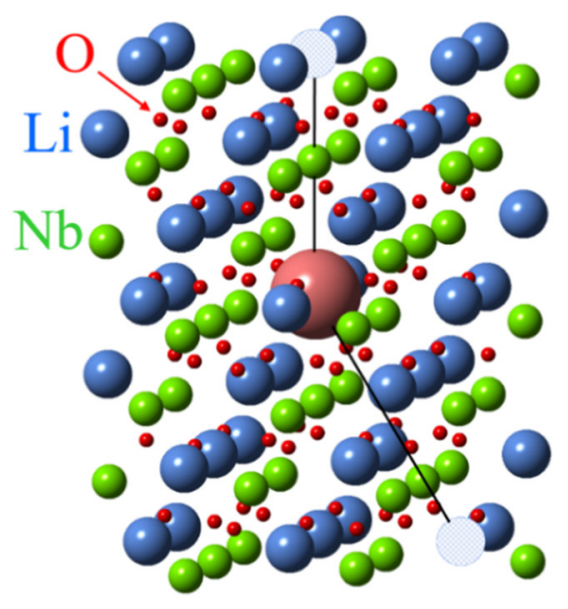

(b)

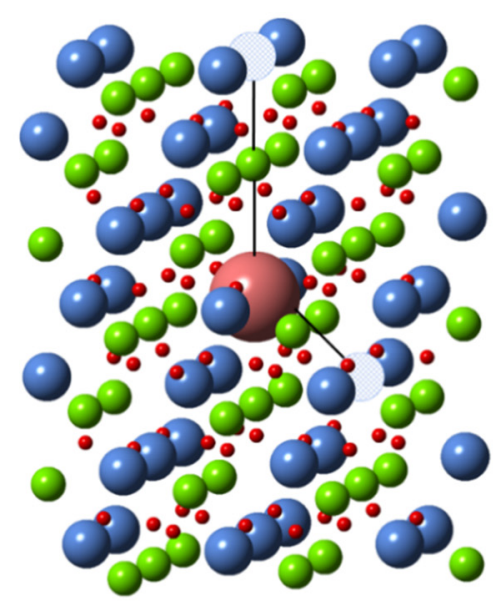

(c)

Figure 8. Divacancy models for an impurity substituted for $\mathrm{Li}^{+}$ion in $\mathrm{LN}$ crystal lattice. Hatched circles represent two $\mathrm{v}_{\mathrm{Li}}$. (a) Axial center, (b) nearly axial center, (c) low-symmetry center.

\section{Structures of Impurity Centers}

\subsection{Monovalent Cations}

The most probable incorporations of $\mathrm{Me}^{+}$is the substitution for $\mathrm{Li}^{+}$. No charge compensation is required in this case. The $\mathrm{Me}_{\mathrm{Li}}{ }^{+}$center should have axial $\mathrm{C}_{3}$ symmetry. 
Proton $\mathrm{H}^{+}$. This is an example of off-site position: protons occupy positions between two oxygen ions in an oxygen plane. The non-paramagnetic $\mathrm{OH}^{-}$centers were studied by infrared and NMR spectroscopies [80,106-108].

A hydrogen associated paramagnetic center $(g=2.0028, A=3 \mathrm{mT}$ at $77 \mathrm{~K})$ was identified as an $\mathrm{OH}^{2-}$ ion, produced because of an electron capture by a diamagnetic $\mathrm{OH}^{-}$ ion, substituting the $\mathrm{O}^{2-}$ ion in LN [109].

$\mathrm{Ni}^{+}\left(3 \mathrm{~d}^{9}, \mathrm{~S}=1 / 2\right)$. Observed EPR spectra of the $\mathrm{Ni}^{+}$have axial symmetry at room temperature $[110,111]$. That excludes interstitial position in tetrahedral structural vacancies. However, at low temperatures the $\mathrm{Ni}^{+}$center has $\mathrm{C}_{1}$ symmetry, as up to six lines were observed at arbitrary orientation of magnetic field (Figure 9a, after [111]).

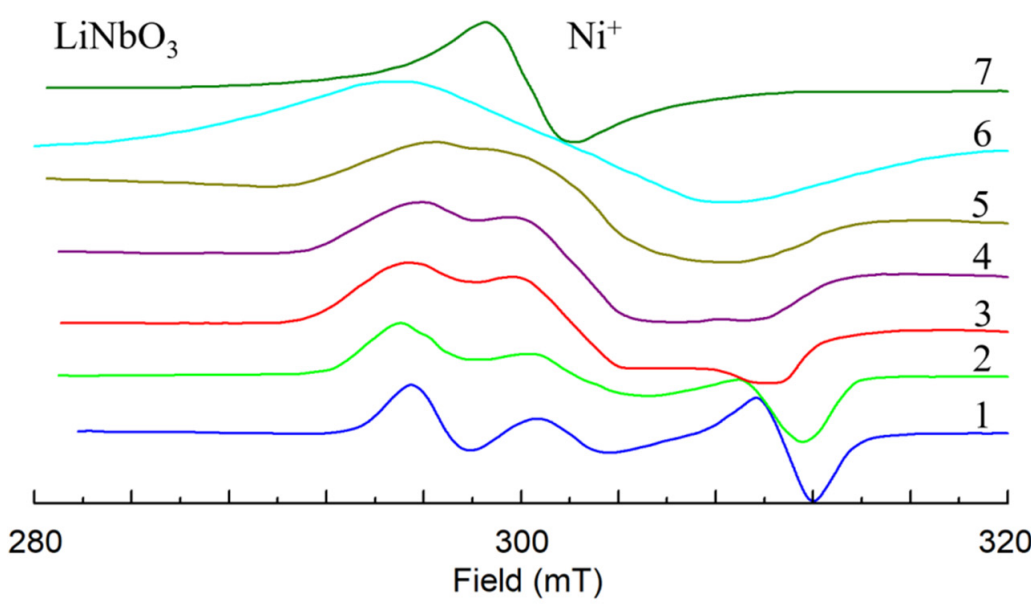

(a)

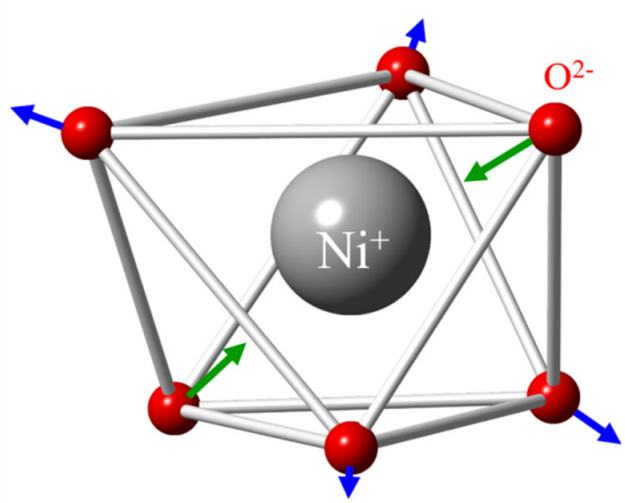

(b)

Figure 9. (a) $\mathrm{X}$-band EPR spectra of $\mathrm{Ni}^{+}$in $\mathrm{LiNbO}_{3}$ at $\theta=25 \mathrm{deg}$ in zy plane at various temperatures $\mathrm{T}$ : 1-40 K, 2-90 K, 3-151 K, 4-206 K, 5-244 K, 6-300 K. The spectrum 7 was measured at $\theta=0 \mathrm{deg}, T=300 \mathrm{~K}$. (b) Distortion of oxygen octahedron due to the Jahn-Teller effect.

The center was characterized by anisotropic $\mathbf{g}$-tensor with principal values $g_{1}=2.246$, $g_{2}=2.217$ and $g_{3}=2.061$; principal axes of the g-tensor are rotated with respect to crystallographic axes by Euler angles $\alpha=\gamma \approx 0, \beta \approx 55^{\circ}$. As the 3 rd principal axis is directed approximately to one of the nearest oxygen ions, the reason for the low symmetry is a static Jahn-Teller effect for $3 \mathrm{~d}^{9}$ ions in $\mathrm{Ni}^{+} \mathrm{O}_{6}{ }^{2-}$ complexes (Figure 9b, [111,112]), and not a presence of an intrinsic defect in the neighborhood. Dynamic averaging due to center reorientation leads to the axial symmetry of observed EPR spectra at room temperatures [111].

$\mathrm{Mg}^{+}\left(3 \mathrm{~s}^{1}, S=1 / 2\right)$. Following vacuum reduction at $1000{ }^{\circ} \mathrm{C}, \mathrm{LN}$ crystals heavilydoped with $\mathrm{Mg}$ exhibit an optical absorption spectrum that can be decomposed into two bands peaking near 760 and $1200 \mathrm{~nm}$, and a broad EPR spectrum with $g_{c}=1.82$ [113]. The 1200-nm band and ESR signal are associated with an electron trap (identical to the one produced during the irradiations). This electron trap is suggested to be a $\mathrm{Mg}^{+}$complex. There is an alternative interpretation of this spectrum [114].

\subsection{Divalent Cations}

For divalent $\mathrm{Me}^{2+}$ impurities a substitution for $\mathrm{Li}^{+}$ions and incorporation in structural vacancies has essentially less charge misfit than a substitution for $\mathrm{Nb}^{5+}$. Since the $\mathrm{Li}-\mathrm{Li}$ distance is much larger than $\mathrm{Li}-\mathrm{Nb}$ or $\mathrm{v}_{\text {oct }}-\mathrm{Li}, \mathrm{v}_{\text {oct }}-\mathrm{Nb}$, the $\mathrm{Me}^{2+}{ }_{\mathrm{Li}}+\mathrm{v}_{\mathrm{Li}}$ centers should be slightly distorted by the presence of a local charge compensator. For $\mathrm{v}_{\mathrm{Li}}$ located on $\mathrm{C}_{3}$ axis and for distant cation vacancies (local and distant charge compensation) axial centers should be observed.

$\mathrm{Co}^{2+}\left(3 \mathrm{~d}^{7}, S=1 / 2, I=7 / 2\right)$. Dominant axial $\mathrm{Co}^{2+}$ center with $g_{\|}=2.6$ and $g_{\perp}=$ $4.96 \div 5.04, A_{\|} \approx 0,\left|A_{\perp}\right|=0.0154 \mathrm{~cm}^{-1}$, as well as low-intensity low-symmetry satellite centers were observed in cLN $[115,116]$ and vLN [117]. Similar g- and A-values were 
reported for $\mathrm{LiTaO}_{3}: \mathrm{Co}^{2+}[116]$. The picture agrees with $\mathrm{Co}^{2+}$ substitution for $\mathrm{Li}^{+}$in the dominant axial center $\left(\mathrm{Co}_{\mathrm{Li}}\right)$ and excess charge compensation by $\mathrm{v}_{\mathrm{Li}}\left(\right.$ the $\mathrm{Co}^{2+} \Leftrightarrow 2 \mathrm{Li}^{+}$ substitution mechanism). A small EPR line of axially symmetric cluster of $\mathrm{Co}^{2+}$ ions appeared in sLN [118] (Figure 10a). To explain it the substitution mechanism $4 \mathrm{Co}^{2+} \Leftrightarrow 3 \mathrm{Li}^{+}$ $+\mathrm{Nb}^{5+}$ [119] was considered. The four $\mathrm{Co}^{2+}$ ions can occupy nearest possible cation sites by occupying one $\mathrm{Nb}$ site and three neighbor Li sites, creating a trigonal pyramid with $\mathrm{C}_{3}$ symmetry (Figure 10b).

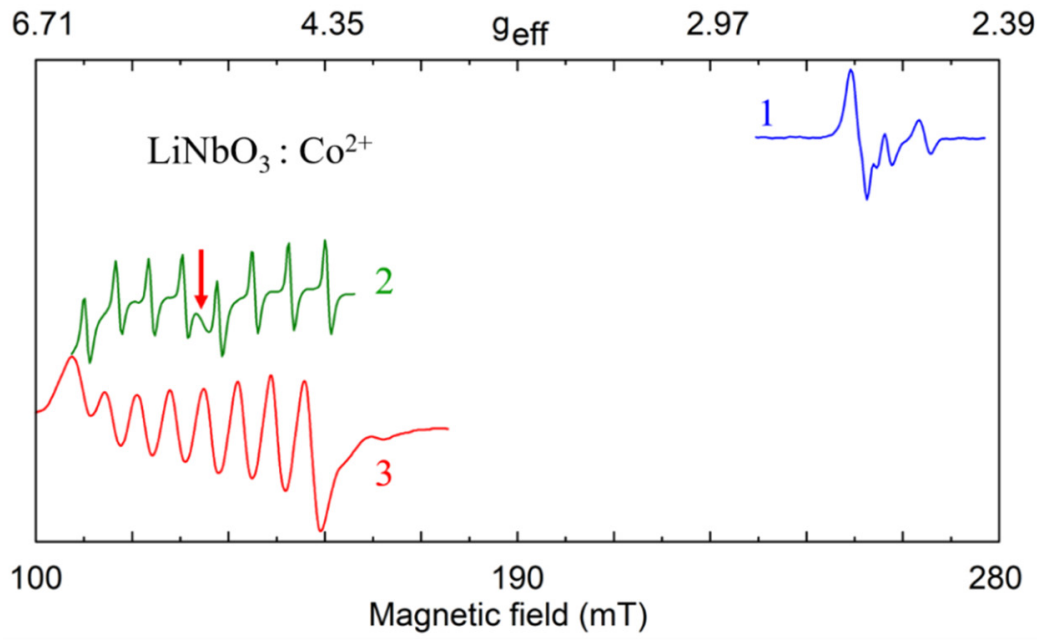

(a)

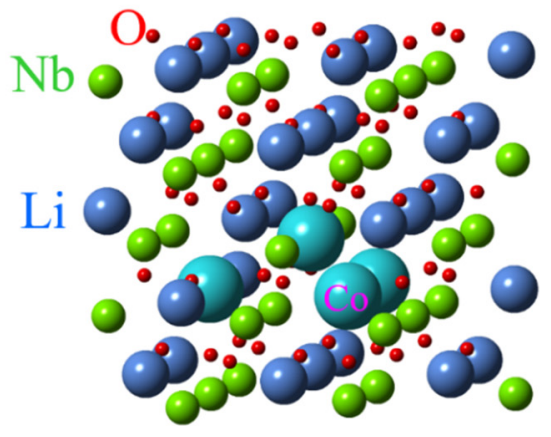

(b)

Figure 10. (a) Measured EPR spectra of $\mathrm{Co}^{2+}, \mathrm{X}$-band, $T=5 \mathrm{~K} .1-\mathrm{sLN}, \mathbf{B}|| \mathbf{z} ; 2-\mathrm{sLN}, \mathbf{B}|| \mathbf{x} ; 3-\mathrm{cLN}$, B || $\mathbf{x}$. The red arrow indicates an additional line assigned to clusters of $\mathrm{Co}^{2+}$ ions. (b) Possible model for a cluster of four $\mathrm{Co}^{2+}$ ions substituted for one $\mathrm{Nb}^{5+}$ and three $\mathrm{Li}^{+}$ions.

From comparison of measured and calculated characteristics it was found that $\mathrm{Co}^{2+}$ does not occupy exactly the host $\mathrm{Li}^{+}$site but undergoes an off-center displacement $0.006 \mathrm{~nm}$ away from the oxygen octahedron center in $\mathrm{LiNbO}_{3}\left(\right.$ or $\left.\mathrm{LiTaO}_{3}\right)[120,121]$.

$\mathrm{Cu}^{2+}\left(3 \mathrm{~d}^{9}, S=1 / 2\right)$. Copper nuclei have two isotopes ${ }^{63} \mathrm{Cu}\left(I=3 / 2, g_{\mathrm{n}}=1.484\right.$, natural abundance $69.2 \%)$ and ${ }^{65} \mathrm{Cu}\left(I=3 / 2, g_{\mathrm{n}}=1.588,30.8 \%\right)$. Hyperfine interaction of $\mathrm{Cu}^{2+}$ electrons with their own nucleus leads to splitting of its single EPR line into a quartet ([110,111], and references there; [122-124]). As magnetic moments of ${ }^{63} \mathrm{Cu}$ and ${ }^{65} \mathrm{Cu}$ are very close, the quartets from the two isotopes overlap in cLN (Figure 11a). The $\mathrm{Cu}^{2+}$ center in $\mathrm{LN}$ was characterized by anisotropic g-tensor $\left(g_{1}=2.095, g_{2}=2.111\right.$ and $g_{3}=2.428 ; \alpha=\gamma$ $\approx 0, \beta \approx 51^{\circ}$ ) [111]. At low temperatures a static Jahn-Teller effect for $3 \mathrm{~d}^{9}$ ions in $\mathrm{Cu}^{2+} \mathrm{O}_{6}{ }^{2-}$ complexes reduces the center symmetry to $\mathrm{C}_{1}$ (Figure $11 \mathrm{~b}$ ). At room temperature, the $\mathrm{Cu}^{2+}$ center has axial symmetry due to center reorientation and motional averaging. The EPR parameters of the impurity $\mathrm{Ni}^{+}, \mathrm{Cu}^{2+}$, and $\mathrm{Ni}^{3+}$ in $\mathrm{LiNbO}_{3}$ were theoretically studied from the perturbation formulas for $3 \mathrm{~d}^{9}$ ions $[112,122]$.

$\mathrm{Ni}^{2+}\left(3 \mathrm{~d}^{8}, S=1\right)$. Several additional terms, which describe zero field splitting (ZFS) of energy levels, should be added to the spin-Hamiltonian (1) for paramagnetic centers with $S>1 / 2$ :

$$
H_{Z F S}=\sum_{k=2,4,6} f_{k}\left[\sum_{q=0}^{k} b_{k}^{q} O_{k}^{q}(\mathbf{S})+\sum_{q=1}^{k} c_{k}^{q} \Omega_{k}^{q}(\mathbf{S})\right]
$$

Here $f_{2}=1 / 3, f_{4}=1 / 60, f_{6}=1 / 1260 ; O_{k}^{q}, \Omega_{k}^{q}(\mathbf{S})$-Stevens operators, which are nonzero for $k \geq 2 S$. For $C_{3}$ symmetry only $q$ equal to 0,3 , and 6 are allowed. For $S=1$ only terms with $k=2$ are present in Equation (5).

The $\mathrm{Ni}^{2+}$ centers in LN exhibit the EPR spectra of $\mathrm{C}_{3}$ symmetry. Therefore, the sum in (5) turns into one term $b_{2}^{0} O_{2}^{0} / 3$. It was found that $b_{2}^{0}=-5.31 \mathrm{~cm}^{-1}$ and $\Delta g=g_{\|}-g_{\perp}$ $=0.04[115,125]$. Since EXAFS data supports $\mathrm{Ni}^{2+}$ substitution for $\mathrm{Li}^{+}[24]$, the reasonable 
choice for the charge compensator is one $\mathrm{v}_{\mathrm{Li}}$ that is located on the $\mathrm{C}_{3}$ axis or very far of $\mathrm{Ni}^{2+}$.

A cluster substitution $4 \mathrm{Ni}^{2+} \Leftrightarrow \mathrm{Ta}^{5+}+3 \mathrm{Li}^{+}$was considered for LT [126]. Note that an agreement of measured and calculated spin-Hamiltonian parameters [127] was obtained for $\mathrm{Ni}^{2+}$ substitution for $\mathrm{Nb}^{5+}$ in $\mathrm{LN}$ without a charge compensator.

The charge excess of one interstitial $\mathrm{Me}^{2+}$ or two $\mathrm{Me}^{2+} \mathrm{Li}$ could be exactly compensated by an additional $\mathrm{O}^{2-}$ ion. However, such a compensation looks unlikely, as the ionic radius of $\mathrm{O}^{2-}$ (about $1.4 \AA$ ) is larger than the sizes of octahedral or tetrahedral vacancies.

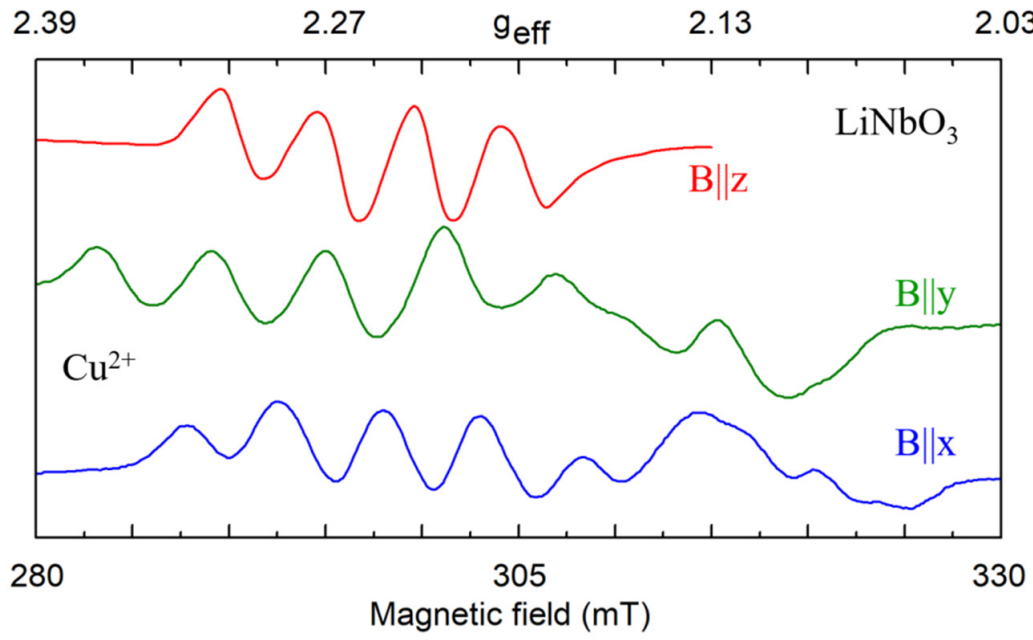

(a)

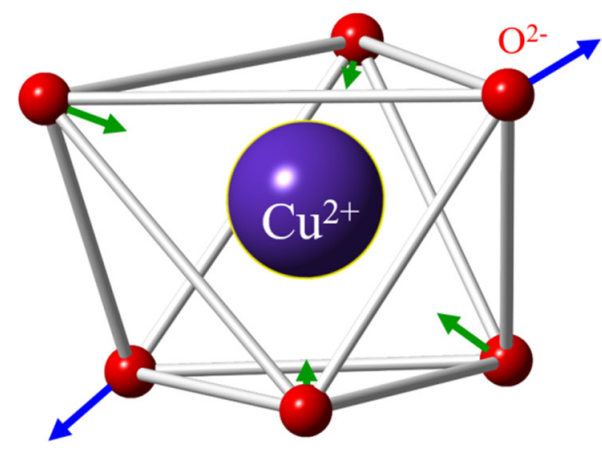

(b)

Figure 11. (a) Measured EPR spectrum of $\mathrm{Cu}^{2+}$ in $\mathrm{LN}, \mathrm{X}$-band, $\mathrm{T}=7 \mathrm{~K}$. (b) Distortion of oxygen octahedron due to Jahn-Teller effect.

$\mathrm{Mn}^{2+}\left(3 \mathrm{~d}^{5}, S=5 / 2, I=5 / 2\right)$. For $S=5 / 2$ the ZFS causes splitting into $2 S=5$ components of fine structure, each of them additionally splits into $2 I+1=6$ lines due to the hyperfine interaction of $\mathrm{Mn}^{2+}$ electrons with their own nucleus (Figure 12).

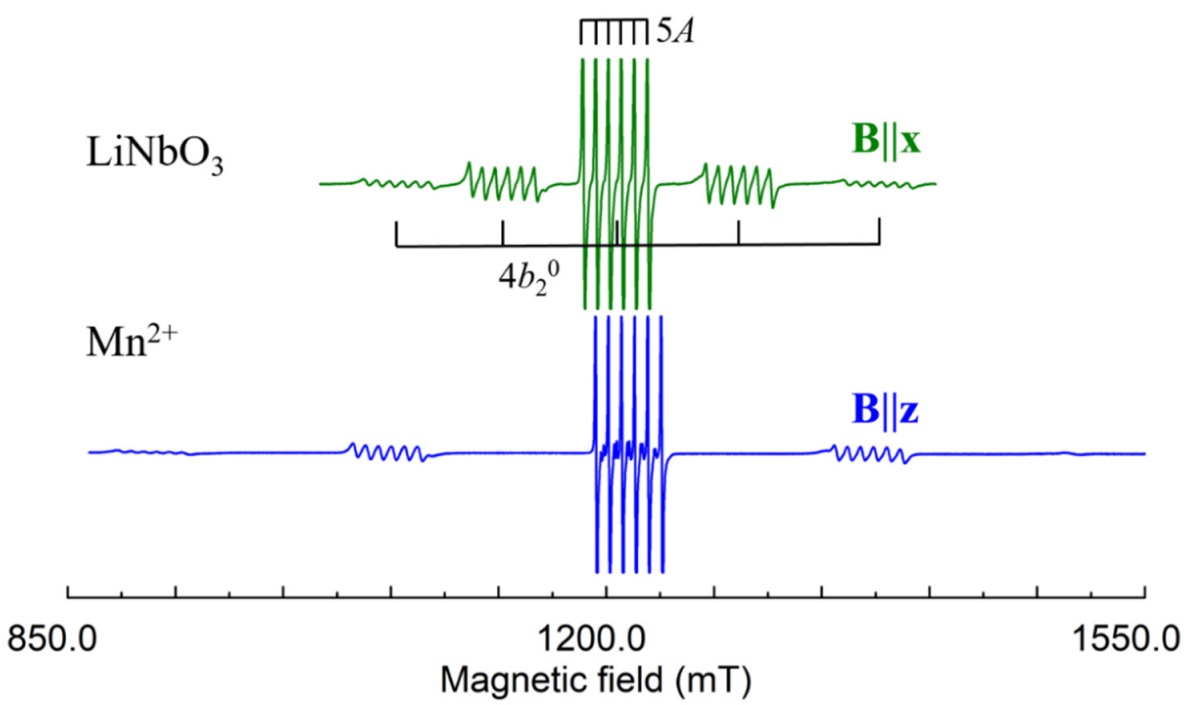

(a)

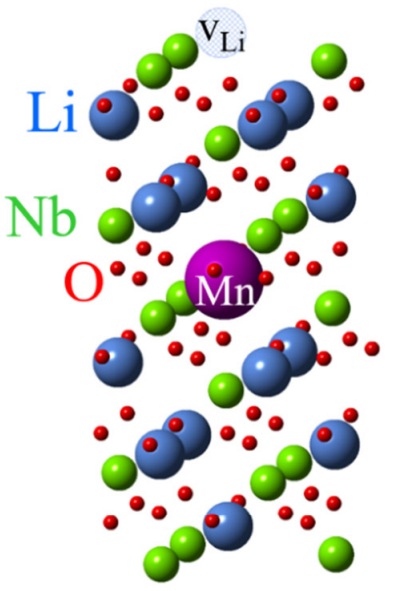

(b)

Figure 12. (a) Measured EPR spectrum of $\mathrm{Mn}^{2+}$ in $\mathrm{LN}_{\mathrm{K}}, v=34.45 \mathrm{GHz}$. (b) Model of axial $\mathrm{Mn}^{2+}{ }_{\mathrm{Li}}$ center with $\mathrm{v}_{\mathrm{Li}}$. 
Angular dependences of $\mathrm{Mn}^{2+}$ in both LN and LT are described by spin-Hamiltonian of axial symmetry with $g \approx 2.0$, and $A \approx-0.008, b_{2}^{0}=0.0731(\mathrm{LN}), b_{2}^{0}=0.1694(\mathrm{LT})$, all in $\mathrm{cm}^{-1}$, [128-138]. Our spectra (Figure 12) were fitted with $b_{2}^{0}=0.074(\mathrm{LN}), b_{2}^{0}=0.175$ (LT).

Hyperfine interactions with four $\mathrm{Li}$ and two $\mathrm{Nb}$ shells of surrounding nuclei were determined by ENDOR study in LN [139]. For isotropic g-tensor, the principal values of dipole-dipole interaction (3) can be described by:

$$
b_{d d}^{(i)}=\frac{g \mu_{B} g_{n}^{(i)} \mu_{n}}{\left(R^{(i)}\right)^{3}}
$$

Comparison of measured values of $b_{d d}^{(i)}$ with values calculated by Equation (6) for Li and $\mathrm{Nb}$ substitution has definitely shown that $\mathrm{Mn}^{2+}$ ions occupy Li site [139].

\subsection{Trivalent Cations}

Most transition metals (including iron, titanium, and chromium) and rare-earth elements enter $\mathrm{LN}$ in this valence. If $\mathrm{Me}^{3+}$ substitutes $\mathrm{Li}^{+}$there are three possibilities to compensate its $2+$ excess charge: $\mathrm{v}_{\mathrm{Li}}, \mathrm{v}_{\mathrm{Nb}}$ and self-compensation with $\mathrm{Me}^{3+} \mathrm{Nb}^{5+}$ in the nearest or distant neighborhood. Every $\mathrm{Me}^{3+} \mathrm{Li}$ can be compensated by two $\mathrm{v}_{\mathrm{Li}}$; every five $\mathrm{Me}^{3+} \mathrm{Li}^{+}$ions-by two niobium vacancies. The positive antisite defect $\mathrm{Nb}_{\mathrm{Li}}$ can serve as a charge compensator for $\mathrm{Me}^{3+}$ replacing $\mathrm{Nb}^{5+}$ (but not $\mathrm{Me}^{3+} \mathrm{Li}^{+}$or $\mathrm{Me}^{3+}{ }_{\mathrm{v}}$ ). It is remarkable that one $\mathrm{Nb}^{5+}{ }_{\mathrm{Li}}{ }^{+}$exactly compensates the excess charge of two $\mathrm{Me}^{3+} \mathrm{Nb}^{5+}$ ions. Since $\mathrm{V}_{\mathrm{Li}}{ }^{+}$ has only one negative charge relative to the ideal lattice, it produces a 4-5 times weaker perturbation of the crystal field than $\mathrm{Nb}^{5+} \mathrm{Li}^{+}$or $\mathrm{v}_{\mathrm{Nb}}{ }^{5+}$. Therefore the centers with $\mathrm{VLi}^{+}$at distances of about $6 \AA$ should probably are not distinguishable from axial centers with non-local charge compensation.

Interstitial $\mathrm{Li}^{+}$ions should be considered as charge compensators for $\mathrm{Me}^{3+} \mathrm{Nb}{ }^{5+}$ in Li-rich, VTE treated, and stoichiometric crystals. The association of $\mathrm{Me}^{3+} \mathrm{Nb}^{5+}$ with one $\mathrm{Li}^{+}$ ion in the nearest vacancy (partial local charge compensation) leads to an axial center, the second $\mathrm{Li}^{+}$in the next vacancies can decrease symmetry to $\mathrm{C}_{1}$, if located off center axis and near the impurity. $\mathrm{Mg}^{2+}$ or $\mathrm{Zn}^{2+}$ ions substituted for $\mathrm{Li}^{+}$can be also suitable compensators for $\mathrm{Me}^{3+} \mathrm{Nb}$.

Distances between the replaced ion and shells of possible location of compensators, various configurations of Me and charge compensators, as well as the symmetries of the corresponding complexes are given in References [87,140-142].

$\mathrm{Cr}^{3+}\left(3 \mathrm{~d}^{3}, S=3 / 2\right)$. In congruent and Li-rich LN samples, the EPR lines of dominant axial $\mathrm{Cr}^{3+}$ center, characterized with $\mathrm{ZFS} b_{2}^{0} \approx 0.39 \mathrm{~cm}^{-1}$, are accompanied with small satellite lines (Figure 13). Initial discussion with plausible but contradictory arguments about $\mathrm{Li}^{+}$or $\mathrm{Nb}^{5+}$ substitution [134,143-148] should be ended after PIXE [32] and detailed ENDOR [140] studies have shown that $\mathrm{Cr}^{3+}$ substitutes for $\mathrm{Li}^{+}$and slightly shifted from regular Li site. ENDOR measurements confirmed that $\mathrm{Cr}^{3+}$ substitutes for $\mathrm{Li}^{+}$also in all satellite centers. Therefore, the whole family of these $\mathrm{Cr}^{3+}$ centers can be described as $\mathrm{Cr}^{3+} \mathrm{Li}$ with location of charge compensator on $\mathrm{C}_{3}$ axis for axial or off it for low-symmetry centers.

The ENDOR measurements [140] found that hyperfine interactions with $\mathrm{Nb}$ nuclei of the 2nd and 3rd shells (Figure 5a) are stronger than with Li nuclei (Figure 14, bottom). However, lines of $\mathrm{Nb}$ nuclei on the center axis (1st and 4th shells) were not identified. It can be caused by unfortunate conditions of their observation, petal distribution of electron density for the $3 \mathrm{~d}^{3}$ ion or absence of $\mathrm{Nb}$ ion in one of these sites, i.e., $\mathrm{v}_{\mathrm{Nb}}$. Two $\mathrm{v}_{\mathrm{Nb}}$ can serves as the charge compensator for five $\mathrm{Cr}^{3+} \mathrm{Li}$. Although the presence of $\mathrm{v}_{\mathrm{Nb}}$ in undoped LN looks unlikely, the charge compensation defects in doped crystals (especially, if dopant concentrations exceed $0 . \mathrm{X} \%$ ) can differ from dominant intrinsic defects in undoped LN or LT. During the growth process, the required compensators can organize themselves around impurities or enter from air in order to minimize the creation energy for the impurity center. This is why structures with $\mathrm{v}_{\mathrm{Nb}}$ were proposed for satellite centers of $\mathrm{Cr}^{3+} \mathrm{Li}$ [87]. 


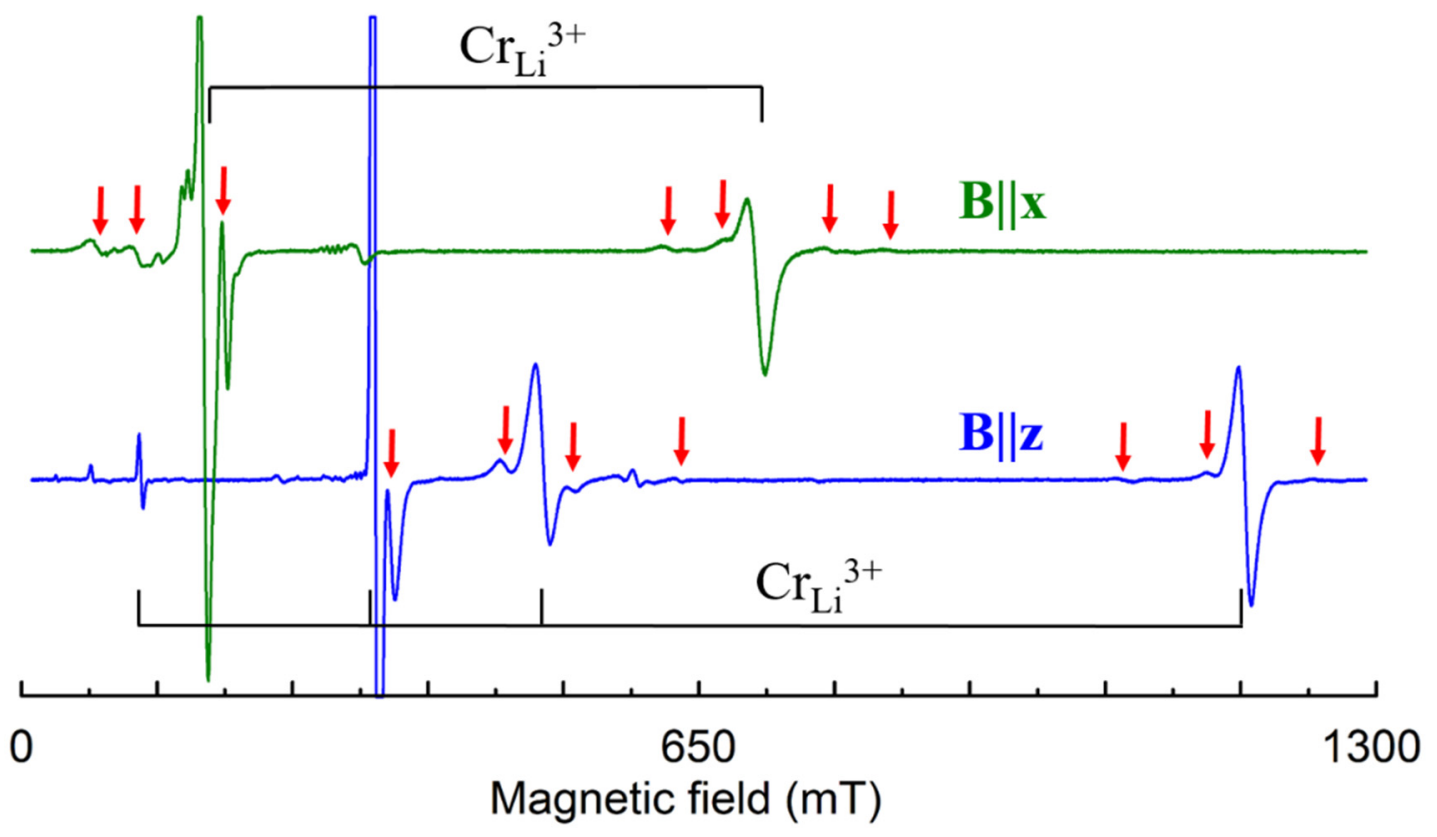

Figure 13. Measured EPR spectrum of $\mathrm{Cr}^{3+}$ in LN grown from the melt with $x_{m} \approx 60 \%$ and $0.1 \mathrm{wt} . \%$ of $\mathrm{Cr}$ (room temperature, $v=9.84 \mathrm{GHz}$ ). Black braces indicate lines of dominant $\mathrm{Cr}^{3+}$ center, red arrows-lines of satellite centers.

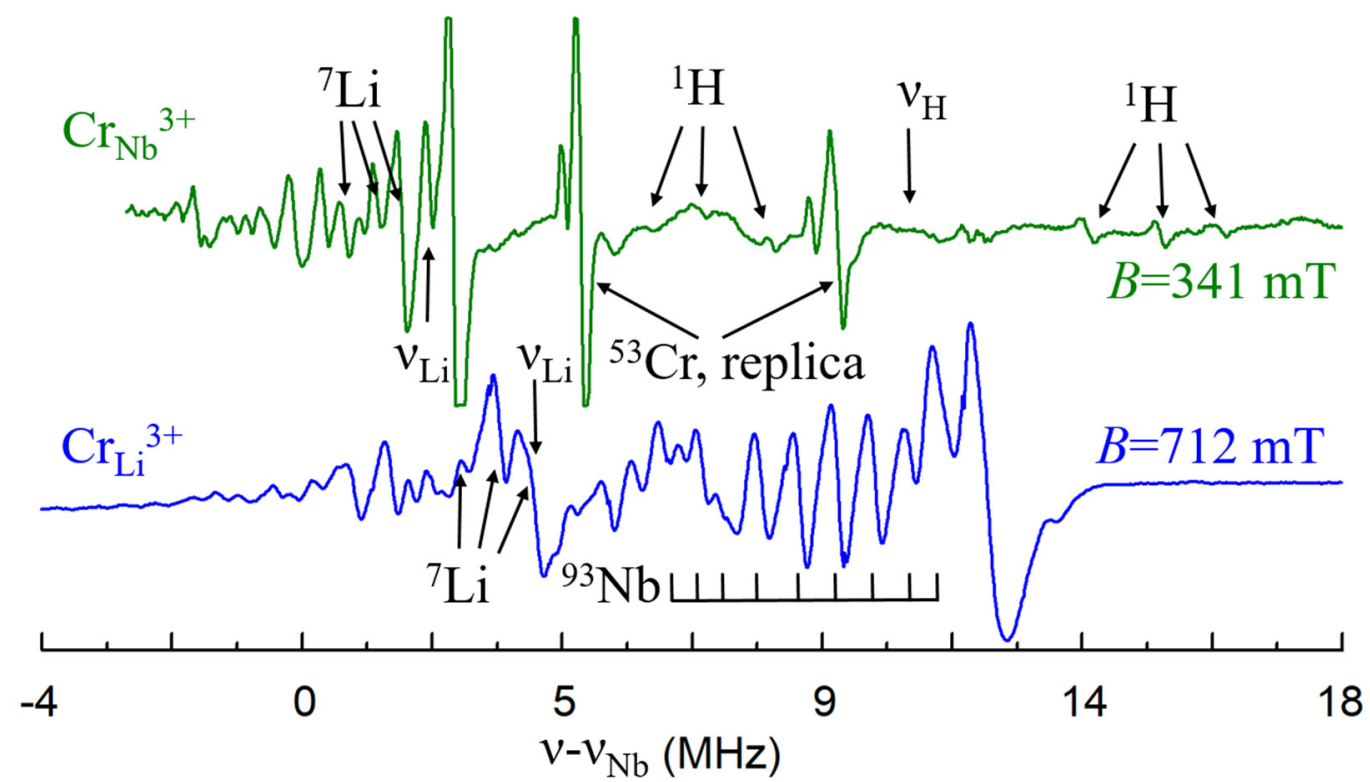

Figure 14. The ENDOR spectra of $\mathrm{Cr}^{3+} \mathrm{Li}$ (high-field EPR transition) and $\mathrm{Cr}^{3+} \mathrm{Nb}$ (central EPR transition) at $\mathbf{B}|| \mathbf{x}, T=5 \mathrm{~K}$. To facilitate a comparison of the spectra, they were shifted to the ${ }^{93} \mathrm{Nb}$ Larmor frequencies.

On the other hand, $\mathrm{v}_{\mathrm{Li}}$ are considered as dominant intrinsic defects in LN and LT. Angular dependencies of EPR spectra for the dominant $\left(C_{3}\right)$ and satellite $\left(C_{1}\right.$ symmetry) $\mathrm{Cr}^{3+}$ centers (Figure 15) are pretty similar to observed patterns for $\mathrm{Nd}^{3+}$ (Figure 4). Therefore, two vacancy models for trivalent impurities (Table 1) and structures on Figures 7 and 8 can be viable alternatives for $\mathrm{Cr}^{3+}$ family. 


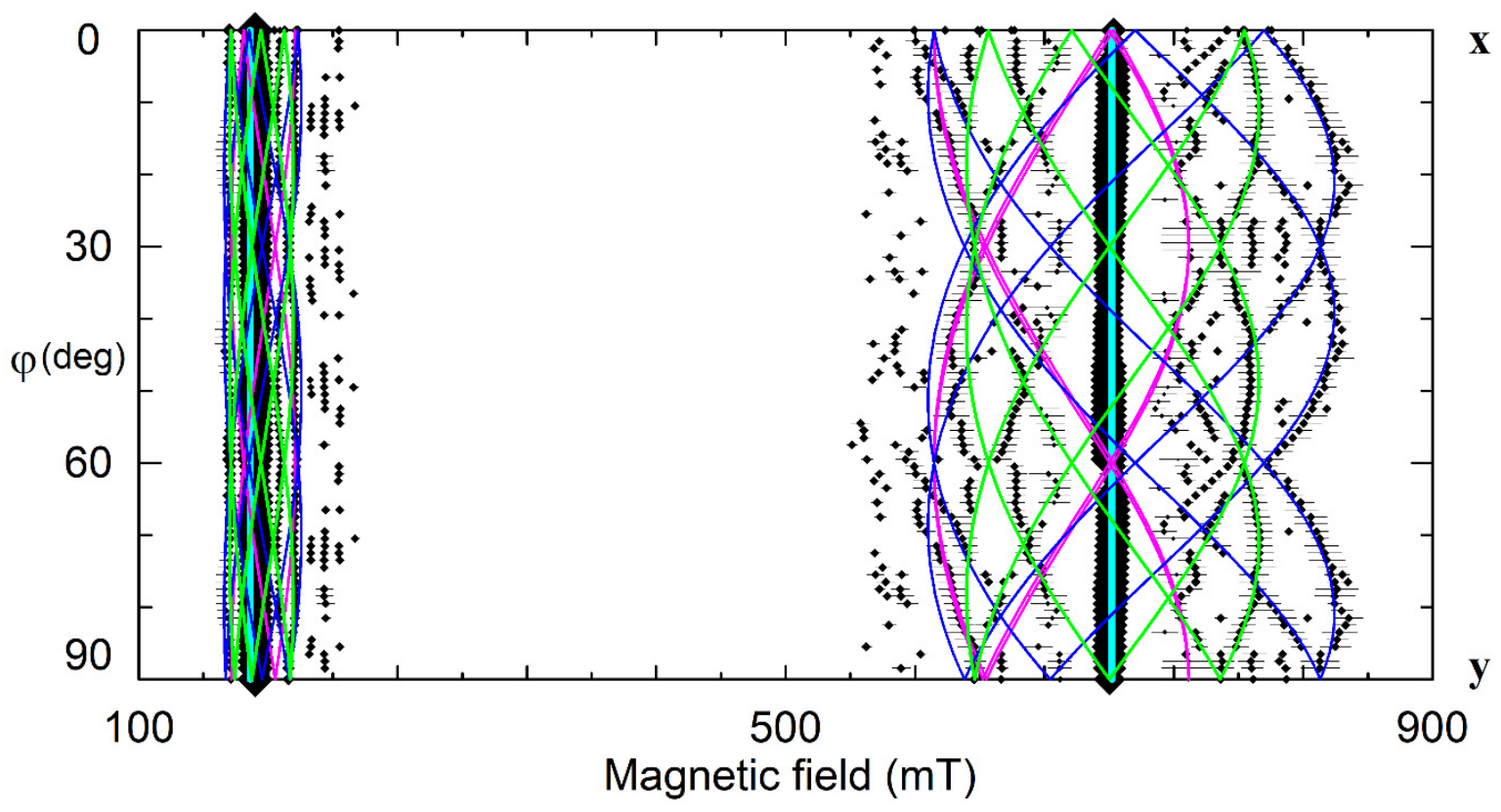

Figure 15. The angular dependencies of EPR spectra in the xy plane for LN:Cr ${ }^{3+}$ grown from the melt with $x_{m} \approx 60 \%$, $v=9.26 \mathrm{GHz}$. Rhombs represent line positions; their sizes are proportional to line intensities. Horizontal whiskers near rhombs represent line widths. Cyan, lime, fuchsia, and blue curves represent simulated dependencies for axial $\mathrm{Cr}_{1}$, and low-symmetry $\mathrm{Cr}_{2}, \mathrm{Cr}_{3}$, and $\mathrm{Cr}_{4}$ centers, respectively.

A lack of intrinsic defects in stoichiometric samples leads unavoidably to a change of charge compensation mechanism for trivalent impurities, and substitution for $\mathrm{Nb}^{5+}$ becomes possible. An axial $\mathrm{Cr}^{3+}$ center with significantly smaller ZFS $b_{2}^{0}=0.0215 \mathrm{~cm}^{-1}$ (Figure 16a) was found in $\mathrm{LN}_{\mathrm{K}}$ samples [142]. ENDOR study has shown that hyperfine interactions with $\mathrm{Li}$ nuclei significantly larger than with $\mathrm{Nb}$ nuclei for this center, i.e., the nearest surrounding consist of $\mathrm{Li}$ nuclei. This means that $\mathrm{Cr}^{3+}$ substitutes for $\mathrm{Nb}^{5+}$ in this center. As lines of protons, $\mathrm{H}^{+}$, were found in the ENDOR spectra (Figure 14, top), they compensate the negative charge of $\mathrm{Cr}^{3+} \mathrm{Nb}^{5+}$ (Figure 16b).

Exchange interaction $\mathbf{S}^{\mathrm{A}} \mathbf{J} \mathbf{S}^{\mathrm{B}}$ between spins of $\mathrm{Cr}^{3+}$ ions $\left(S^{\mathrm{A}}=S^{\mathrm{B}}=3 / 2\right)$ leads to gaps between states with values of total spin $S=S^{\mathrm{A}}+S^{\mathrm{B}}$ equal to $0,1,2$, and 3 . The state with $S=0$ is non paramagnetic. For pairs at a close distance the gaps can exceed energies of microwave quantum $\left(36 \mathrm{GHz} \approx 1.2 \mathrm{~cm}^{-1}\right.$ ). It was found by magneto-optical study that for $\mathrm{Cr}^{3+} \mathrm{Li}^{-} \mathrm{Cr}^{3+} \mathrm{Nb}$ substituted for nearest $\mathrm{Li}$ and $\mathrm{Nb}$ sites (at the distance about $0.3 \mathrm{~nm}$ ) the exchange interaction is antiferromagnetic and $J \approx 480 \mathrm{~cm}^{-1}$. As $1 \mathrm{~K} \times k_{\mathrm{B}} \approx$ $0.7 \mathrm{~cm}^{-1}$ the upper states of such pairs with non-zero $S$ are not populated even at room temperatures, and the pairs are EPR silent. However, the pairs of the next orders with the isotropic exchange coupling parameter $J \approx 1.5 \mathrm{~cm}^{-1}$ were observed by EPR at relatively low concentration of chromium in LN (less than 0.1 at.\%) [87,134,148-150]. 


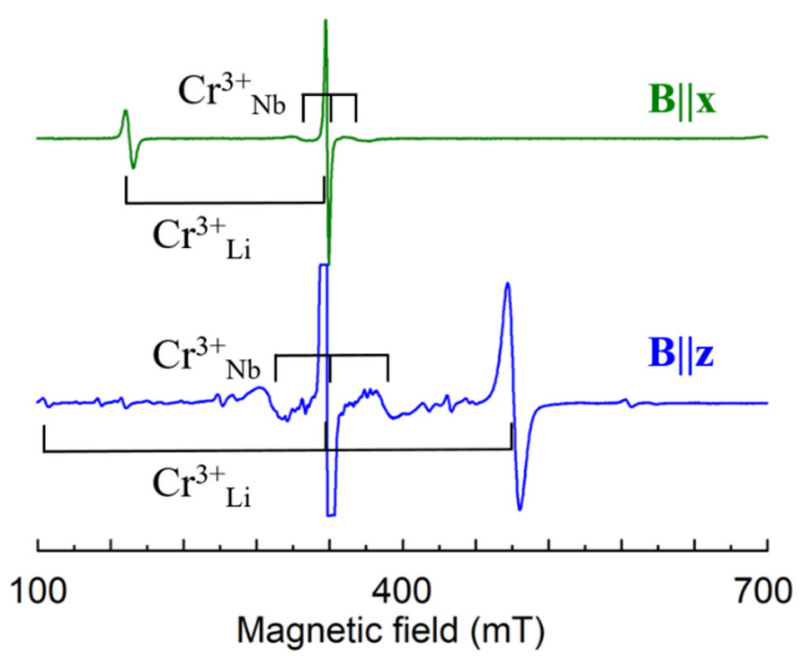

(a)

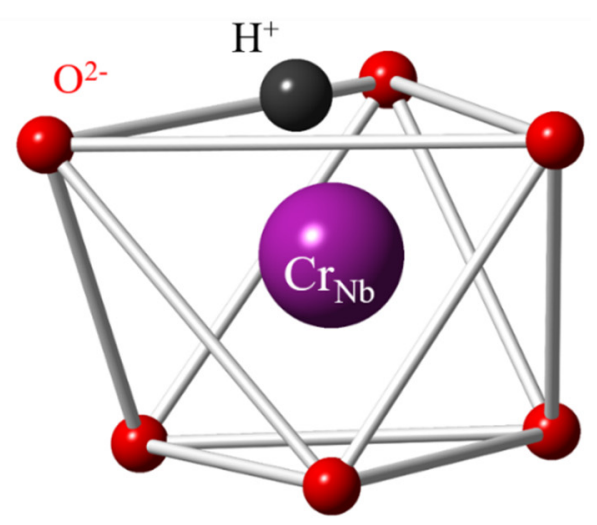

(b)

Figure 16. (a) Measured EPR spectra of $\mathrm{Cr}^{3+}$ in LN grown from the melt with addition of $\mathrm{K}_{2} \mathrm{O}$ and 1 wt. $\%$ of $\mathrm{Cr}$; room temperature, $v=9.445 \mathrm{GHz}$. (b) Model of $\mathrm{Cr}^{3+}{ }_{\mathrm{Nb}}$ center.

PIXE/channeling study [32] revealed that chromium ions occupy both regular cation sites $(60 \%$ on Li sites and $40 \%$ on $\mathrm{Nb}$ sites) in congruent $\mathrm{LN}$ doped with $0.1 \mathrm{~mol} . \%$ of $\mathrm{Cr}$. This means that the majority of chromium ions enter CLN as non-paramagnetic pair centers. The EPR observes only a top of iceberg in cLN: dominant $\mathrm{Cr}^{3+} \mathrm{Li}$ and small signals of non-nearest paramagnetic pairs.

ENDOR study of $\mathrm{Cr}^{3+}$ centers in LN heavily doped with $\mathrm{Mg}$ and co-doped with Cr has unambiguously shown that $\mathrm{Cr}^{3+}$ in the dominant center has ZFS $b_{2}^{0}$ close to zero (nearly isotropic case) and substitute for $\mathrm{Nb}$ [151-155]. Measured anisotropic hyperfine interactions of $\mathrm{Cr}^{3+}$ with for four Li shells were close to $b_{d d}^{(i)}$ for $\mathrm{Nb}$ site. From comparison of data obtained by EPR, ENDOR, optical absorption, fluorescence, fluorescence line narrowing, selective excitation and radiative lifetime measurements [156-162] it has been concluded that the addition of $\mathrm{Mg}^{2+}$ ions to $\mathrm{LN}$ does not create new $\mathrm{Cr}^{3+}$ complexes, but changes the relative concentrations of the $\mathrm{Cr}^{3+} \mathrm{Li}_{\text {and }} \mathrm{Cr}^{3+} \mathrm{Nb}$ centers.

The measured value of ZFS for dominant $\mathrm{Cr}^{3+}$ in $\operatorname{cLT} b_{2}^{0} \approx 0.444 \mathrm{~cm}^{-1}$ [144] is very close to the value for $\mathrm{Cr}^{3+} \mathrm{Li}$ in LN. EPR spectra of this center together with signals of weaker intensities of a second center $[163,164]$ were explained in a supposition that they originate from $\mathrm{Cr}^{3+}$ ions located at $\mathrm{Li}^{+}$sites and that two $\mathrm{v}_{\mathrm{Li}}$ play the role of a divalent charge compensator for both centers. EPR study of $\mathrm{Cr}^{3+}$ in nsLT and superposition model analysis [165] are in good agreement with the $\mathrm{Cr}^{3+}$ substitution for Li. The temperature dependence of $b_{2}{ }^{0}$ term showed a non-monotonic behavior in the region of $40 \mathrm{~K}$.

Finally, a lot of studies were devoted to various properties of $\mathrm{Cr}^{3+}$ in LN and LT crystals of different compositions in order to clarify relations of optical characteristics with structures of chromium centers [166-175] etc.

$\mathrm{Dy}^{3+}\left(4 \mathrm{f}^{9}\right)$. The observed Zeeman splitting [143] was described with g-tensor of axial symmetry: $g_{\|}=8.7$ and $g_{\perp}=1.3$. The single EPR line had width about $8-10 \mathrm{mT}$ at $\mathbf{B}|| \mathbf{z}$ and became broader at $\mathbf{B} \perp \mathbf{z}$. Such a behavior can be related to unresolved splitting due to satellite centers, if $\mathrm{Dy}^{3+}$ occupies $\mathrm{Li}$ position and its charge is compensated by $\mathrm{v}_{\mathrm{Li}}$. Two $\mathrm{Dy}^{3+}$ centers with $g_{x x}(1)=2.56(1), g_{z z}(1)=4.43(1)$, and $g_{x x}(2)=6.67(1), g_{z z}(2)=1.23(1)$ and linewidth about $20 \mathrm{mT}$ were registered in LN after $\gamma$-irradiation [176]. Both centers were attributed to $\mathrm{Dy}^{3+} \mathrm{Li}$. A broad line of the third center with $g_{z z}(3) \approx 1.2$ appeared only at $\mathbf{B}$ close to the $\mathbf{z}$-axis. Weak hyperfine lines due to isotopes ${ }^{161}$ Dy (natural abundance $19 \%$ ), ${ }^{163} \mathrm{Dy}(2.49 \%)$ was observed in single crystal of LN [177].

$\mathrm{Er}^{3+}\left(4 \mathrm{f}^{11}\right)$. Due to fast spin-lattice relaxation, the EPR signals of $\mathrm{Er}^{3+}$ are observable at low-temperatures only. Earlier studies claimed that $\mathrm{Er}^{3+}$ ions in cLN create an axial 
center with $g_{\|} \approx 15.1-15.4$ and $g_{\perp} \approx 2.1[143,178]$ or $g_{\text {zz }} \approx 15.5$ and $g_{x x} \approx g_{y y} \approx 0.8$ [179]. A proposed model with lithium vacancies statistically distributed around $\mathrm{Er}^{3+} \mathrm{Li}^{[179]}$ supposed that the center with no vacancies in surrounding, i.e., the center with axial $\mathrm{C}_{3}$ symmetry, should give a dominant (54\%) line in the EPR spectra. Note that angular dependences of EPR spectra in $x y$-plane were not measured in these studies. Later measurements in all three principal planes [180-183] have shown that there is no line without angular dependence in the xy-plane, i.e., dominant $\mathrm{Er}^{3+}$ center in $\mathrm{CLN}$ has $\mathrm{C}_{1}$ symmetry. This does not agree with statistically distributed $\mathrm{v}_{\mathrm{Li}}$ around $\mathrm{Er}^{3+}{ }_{\mathrm{Li}}$ [179].

Significant narrowing of EPR lines in $\mathrm{LN}_{\mathrm{K}}$ (Figure 17a) allowed us to trace two different $\mathrm{Er}_{1}{ }^{3+}$ and $\mathrm{Er}_{2}{ }^{3+}$ centers with extrema at about 15, 45 and 75 degrees in xy plane (Figure 17b) [184,185]. The divacancy model (Figure 7) gives a possible explanation if a shift of $\mathrm{Er}^{3+} \mathrm{Li}$ from regular Li site is taken into account: RBS, XSW and ion-beam/channeling studies have determined that Er occupies Li sites, but is shifted from the ferroelectric $\mathrm{Li}$ position by 0.03 [186], 0.046 [187], and $0.02 \mathrm{~nm}$ [188]. In this case, distances from $\mathrm{Er}_{\mathrm{Li}}$ to the $\mathrm{v}_{\mathrm{Li}}$ in the $1 \mathrm{a}$ and $1 \mathrm{~b}$ shells (Figures $5 \mathrm{a}$ and $7 \mathrm{~b}$ ) are completely different, and these centers have one charge compensating $\mathrm{v}_{\mathrm{Li}}$ in the nearest neighborhood (the shell $1 \mathrm{a}$ for $\mathrm{Er}_{1}$, and $1 \mathrm{~b}$ for $\mathrm{Er}_{2}$ ), and the second $\mathrm{v}_{\mathrm{Li}}$ in the next nearest neighborhood (shells $2 \mathrm{a}, 2 \mathrm{~b}$, Figure 7).

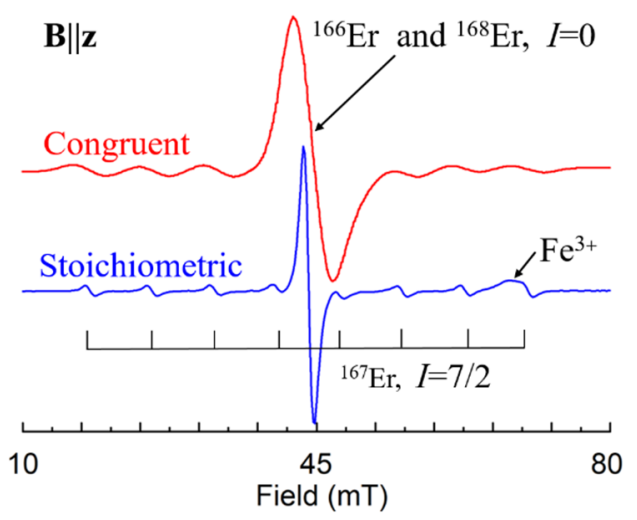

(a)

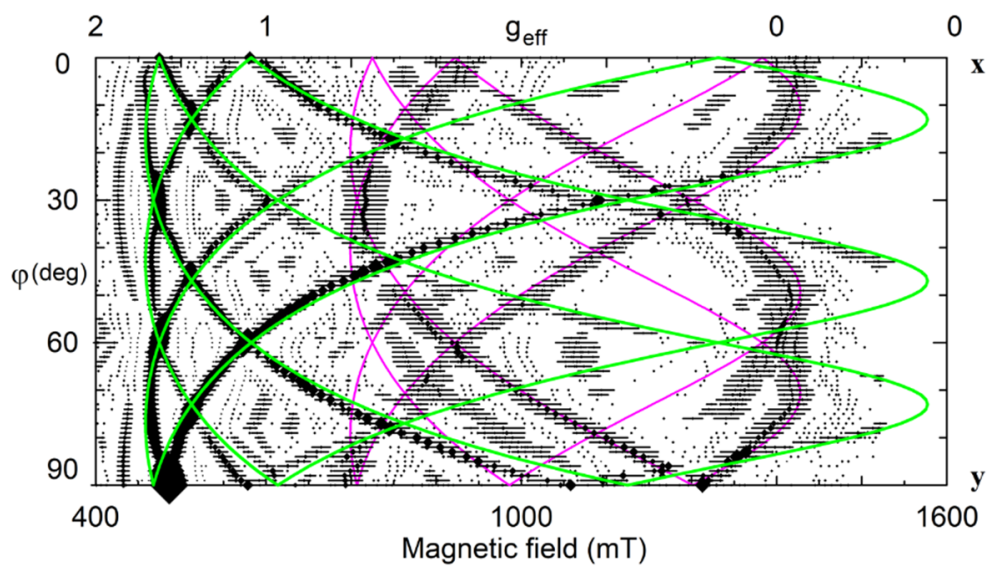

(b)

Figure 17. (a) EPR spectra of $\mathrm{Er}^{3+}$ in congruent and stoichiometric $\mathrm{LN}$ at $\mathbf{B}|| \mathbf{z}, \mathrm{X}$-band. (b) Calculated angular dependence of EPR spectra in xy plane for the $\mathrm{Er}_{1}{ }^{3+}$ (green lines) and $\mathrm{Er}_{2}{ }^{3+}$ (fuchsia lines) centers in sLN. Symbols with horizontal whiskers represent line position and widths.

Magnetic moments $\mu_{B} g \mathbf{S}$ for both $\mathrm{Er}^{3+}$ centers are very large and strongly anisotropic. At low temperatures their interactions lead to magnetic ordering for Er concentration about 0.5 at. $\%$ in sLN [189].

Various models with two $\mathrm{v}_{\mathrm{Li}}$ were also extensively discussed in papers devoted to site-selective spectroscopy [190-196] and references there. Note that models with one of two $\mathrm{v}_{\mathrm{Li}}$ on $\mathbf{z}$-axis (Figure 8) do not agree with the EPR spectra for dominant lines and hyperfine satellites on Figure 17a. However, such centers can probably be associated with weaker lines or may have no EPR lines at all, if they are non-paramagnetic.

EPR spectra detected in cLN heavily doped with Mg or Zn and co-doped with Er were described with $g_{\|}=4.3, g_{\perp}=7.6$ for the Mg-doped samples and $g_{\|}=4.26, g_{\perp}=7.8$ for the $\mathrm{Zn}$-doped ones [197]. The spectra can be attributed to $\mathrm{Er}^{3+}$ located at the $\mathrm{Nb}^{5+}$ site of LN, as they are compared to additional centers observed for some trivalent transition metal ions (particularly $\mathrm{Cr}^{3+}$ ) in LN: $\mathrm{Mg}$ or $\mathrm{LN}: \mathrm{Zn}$.

$\mathrm{Fe}^{3+}\left(3 \mathrm{~d}^{5}, S=5 / 2\right)$. EPR studies have shown that the dominant iron center, $\mathrm{Fe}_{1}$ in cLN has axial symmetry with the ZFS $b_{2}^{0}$ about $0.1680 \mathrm{~cm}^{-1}[131,133,134,198-208]$. Calculations of optical and EPR characteristics based on the superposition models or generalized crystal field theory gave a preference for $\mathrm{Nb}$ substitution [209], no definite conclusion for $\mathrm{Li}$ 
or $\mathrm{Nb}$ substitution [210-213] or some preference for Li site [214,215]. Mössbauer [33,34] and Raman [35] spectroscopy data, Stark effect [216] were interpreted on the base of Fe substitution for Li. Iron clusters were observed at high Fe concentration [33]. Comparison of calculated dipole-dipole interactions of $\mathrm{Fe}^{3+}$ electrons with surrounding Li nuclei for $\mathrm{Li}$ and $\mathrm{Nb}$ substitution (Equation (6)) with measured ENDOR spectra [38-40] has shown that $\mathrm{Fe}^{3+}$ is undoubtedly located in Li site in both cLN and cLT (Figure 5a). Independently, XSW [12,28], EXAFS [21-26], and ion beam/channeling [18,27] confirmed $\mathrm{Fe}^{3+}$ substitution for $\mathrm{Li}^{+}$. It was concluded also that $\mathrm{Fe}^{3+}$ ions can be shifted from regular Li-site; however, the obtained values for the shift were very different: $0.006 \mathrm{~nm}$ [21] or $0.05 \mathrm{~nm}$ from octahedron center [24], less than $0.012 \mathrm{~nm}$ [25], about $0.01 \mathrm{~nm}$ [26], $0.018 \pm 0.007 \mathrm{~nm}$ [28], less than $0.005 \mathrm{~nm}$ [39]. Fitting observed ENDOR data in LN crystals grown from Li-rich melt $\left(x_{m} \approx 55 \%\right)$ was obtained with the shift $0.009 \mathrm{~nm}$ from Li site [217].

$\mathrm{Fe}^{3+}$ center with small ZFS, $\mathrm{Fe}_{2}$ observed in congruent $\mathrm{LN}$ doped with $\mathrm{Mg}[104,218-222]$, In [223], and $\mathrm{Zn}$ [224] was assigned to $\mathrm{Fe}^{3+}{ }_{\mathrm{Nb}}$.

Comparison of EPR spectra of congruent (Figure 18a, 1), near-stoichiometric grown from Li enriched melts (Figure 18a, 2) and grown from congruent melt with the addition of $\mathrm{K}_{2} \mathrm{O}, \mathrm{LN}_{\mathrm{K}}$ samples (Figure 18a, 3) shows ${ }^{\mathrm{a}}$ :

- $\quad$ Lines of allowed transitions in $\mathrm{LN}_{\mathrm{K}}$ become symmetric-intensities of left (up) and right (down) wings become equal.

- $\quad$ Lines of forbidden transitions (see yellow box on Figure 18) disappear in $\mathrm{LN}_{\mathrm{K}}$.

In $\mathrm{LN}_{\mathrm{K}}$ the EPR lines become narrower (up to dozen times at some magnetic field orientation). The narrowing strongly increases spectral resolution. This allows to register even trace impurities in undoped (nominally pure) $\mathrm{LN}_{\mathrm{K}}$ samples (see lines of $\mathrm{Fe}^{3+}$ and $\mathrm{Mn}^{2+}$ on Figure 18a, 3).

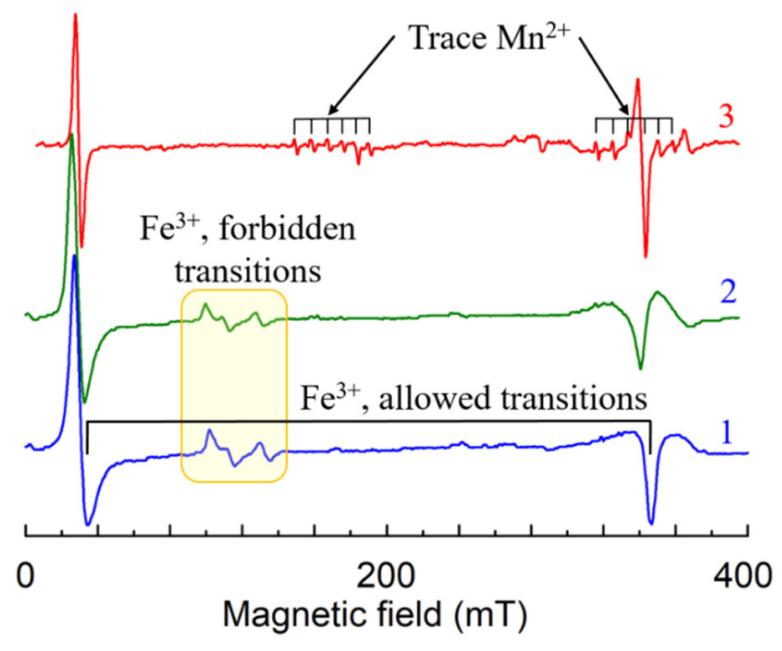

(a)

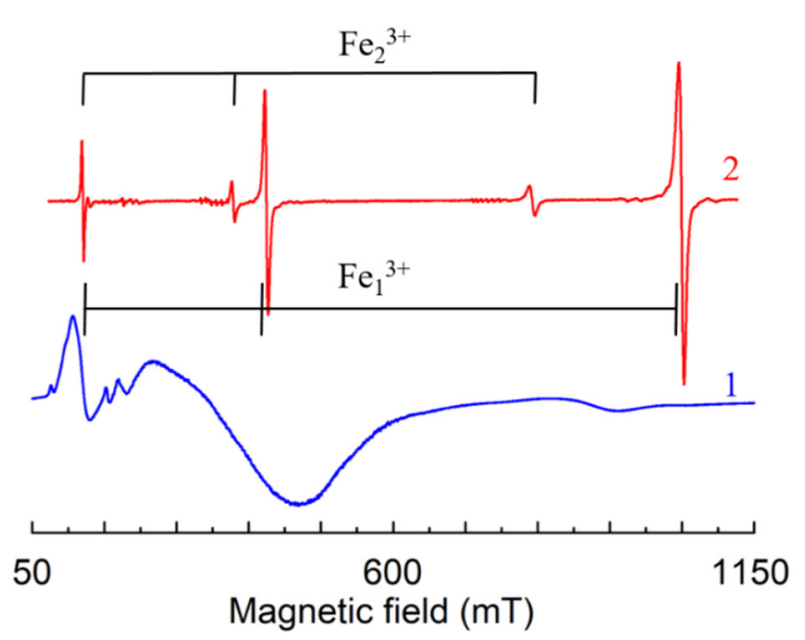

(b)

Figure 18. Normalized spectra of $\mathrm{Fe}^{3+}$ in LN (a) and LT (b), X-band. (a) Congruent (1), grown with $x_{m}=0.545$ (2), undoped sample grown from congruent the melt with $6 \mathrm{wt} \%$ of $\mathrm{K}_{2} \mathrm{O}$ (3), B I I z. (b) Congruent (1), vapor transport equilibrium (VTE) treated sample (2), $\mathbf{B}|| \mathbf{x}$.

${ }^{a}$ A brief glance on history of sLN for curios researchers. Looking for better crystals, G. I. Malovichko asked crystal growers for different samples of LN and LT. Dr. E. P. Kokanyan (at that time, one of the engineers in the group of Dr. V. T. Gabrielyan) was interested to grow crystals under various conditions (melt composition $x_{m}$, growth under applied electric field, variation of temperature, etc.). He has prepared for her a set of non-stoichiometric LN samples grown from melts with $x_{m}$ from $43 \%$ to $60 \%$. During her PhD research of LN and LT of different compositions, Malovichko found that EPR lines become narrower and more symmetric in samples grown with larger $x_{m}$. Dr. V. G. Grachev has simulated 
EPR spectra with random distributions of non-axial components of ZFS, $b_{2}^{q}(q \neq 0)$ for $\mathrm{Cr}^{3+}$ and $\mathrm{Fe}^{3+}$ and confirmed that line width and asymmetry, as well as intensities of forbidden transitions are related to intrinsic defects in non-stoichiometric samples [43]. In 1991, on Malovichko's request Dr. Kokanyan has grown several congruent samples with 2,4 , and $6 \%$ of $\mathrm{K}_{2} \mathrm{O}$ in the melt $\left(\mathrm{LN}_{\mathrm{K}}\right)$. First EPR measurement has surprisingly shown narrow symmetrical lines in $\mathrm{LN}_{\mathrm{K}}$ with traces of $\mathrm{Fe}^{3+}$ (Figure 18a, 3). Based on the experience of studies of Li-rich samples, it was concluded that the concentration of intrinsic defects in $\mathrm{LN}_{\mathrm{K}}$ is smaller than in $\mathrm{LN}$ grown from the melt with $x_{m}=60 \%$, and that $\mathrm{K}_{2} \mathrm{O}$ may serve as a catalyst in electrochemical reaction of crystal growth [56]. As abilities of research techniques in Ukraine were limited, Dr. Malovichko asked Prof. O. F. Schirmer (Osnabrueck University, Germany) for an international collaboration. Prof. Schirmer was very enthusiastic and has quickly managed to involve many of his colleagues in the investigation of $\mathrm{LN}_{\mathrm{K}}$ properties. K. Betzler, B. Faust, B. Gather, F. Jermann, S. Klauer, U. Schlarb, M. Wesselmann, M. Woehlecke and others participated in the $\mathrm{LN}_{\mathrm{K}}$ study by different techniques resulting in publications [57,69,77].

All these features are the result of significant reduction of intrinsic defects in $\mathrm{LN}_{\mathrm{K}}$ samples. Estimations of crystal composition $x_{C}$ made by different methods $[59,68,77,79]$ have shown that $x_{C}$ can exceed $49.8-49.9 \%$, i.e., $\mathrm{LN}_{\mathrm{K}}$ is really a stoichiometric crystal.

As for other impurities, the lack of intrinsic defects in $\mathrm{LN}_{\mathrm{K}}$ :Fe has led to the appearance of centers where impurities substitutes for $\mathrm{Nb}$. Two additional axial $\mathrm{Fe}^{3+}$ centers named $\mathrm{Fe}_{3}$ and $\mathrm{Fe}_{4}$ were observed in $\mathrm{LN}_{\mathrm{K}}$ [69]. Their ZFS are $b_{2}^{0}=0.0495$ and $b_{2}^{0}=0.0688 \mathrm{~cm}^{-1}$. Compared with $\mathrm{Fe}_{2}$, the $\mathrm{Fe}_{3}$ and $\mathrm{Fe}_{4}$ centers were also assigned to $\mathrm{Fe}^{3+}$ in $\mathrm{Nb}$ sites with different charge compensation. The $\mathrm{Fe}^{3+}$ center with $b_{2}^{0}=0.0656 \mathrm{~cm}^{-1}$ (that is very close to $b_{2}^{0}$ for $\mathrm{Fe}_{4}$ ) was observed in VTE treated stoichiometric LN [76]. Therefore, $\mathrm{Fe}_{4}, \mathrm{Fe}_{3}$, and $\mathrm{Fe}_{2}$ were attributed to $\mathrm{Fe}_{\mathrm{Nb}}$ with different charge compensator ions in nearest structural vacancy $\mathrm{v}_{\text {oct }}: \mathrm{Fe}_{4}$-non-regular, interstitial $\mathrm{Li}^{+}{ }_{\mathrm{v}}$ (Figure $19 \mathrm{a}$ ), $\mathrm{Fe}_{3}-\mathrm{K}^{+}{ }_{\mathrm{v}}$, and $\mathrm{Fe}_{2}-\mathrm{Mg}^{2+}{ }_{\mathrm{v}}$. Two $\mathrm{Li}^{+}{ }_{\mathrm{v}}$ (Figure 19b), or interstitial $\mathrm{Mg}^{2+}{ }_{\mathrm{v}}$ or two $\mathrm{Mg}^{2+} \mathrm{Li}^{+}$are required for full charge compensation of $\mathrm{Fe}^{3+}{ }_{\mathrm{Nb}}{ }^{5+}$. Our measurements of EPR in LN:Mg show angular patterns with extrema at 15,45 and 75 degrees in xy plane. It is why we think that models with two differently located $\mathrm{Mg}^{2+} \mathrm{Li}^{+}$(Figure 19c,d) are more suitable for $\mathrm{Fe}_{\mathrm{Nb}}$ (similar to models with two $\mathrm{v}_{\mathrm{Li}}$ for $\mathrm{Fe}_{\mathrm{Li}}$ ). ENDOR measurements could confirm some of these reasonable assignments.

Dominant $\mathrm{Fe}_{1}{ }^{3+}$ center in cLT has $b_{2}^{0}=0.33 \mathrm{~cm}^{-1}[38,225]$ (Figure 18b, 1), and according to ENDOR data [38] it is definitely $\mathrm{Fe}^{3+}{ }_{\mathrm{Li}}$. Line narrowing in nsLT grown by double crucible Czochralski method from an Li rich melt composition (about $60 \mathrm{~mol} \% \mathrm{Li}_{2} \mathrm{O}$ ) allowed to determined $b_{2}{ }^{0}$ more accurately [226].

The main features of the spectra in SLT obtained by VTE treatment are strong line narrowing, higher resolution, and a clear presence of the second axial $\mathrm{Fe}_{2}{ }^{3+}$ center with $b_{2}^{0}=0.205 \mathrm{~cm}^{-1}$ (Figure 18b, 2) [75]. Comparison of calculated angular dependences of ENDOR frequencies for $\mathrm{Li}$ and $\mathrm{Nb}$ substitution using Equation (6) with measured ones (Figure 20) obviously shows that in the case of $\mathrm{Fe}_{2}$ center the $\mathrm{Fe}^{3+}$ ion substitutes for $\mathrm{Nb}$. Both $\mathrm{Fe}_{1}$ and $\mathrm{Fe}_{2}$ centers in sLT have $\mathrm{C}_{3}$ symmetry. No foreign nuclei in the nearest neighborhood were detected for $\mathrm{Fe}_{1}$. As sLT still have some residual concentration of $\mathrm{v}_{\mathrm{Li}}$, the charge compensators for $\mathrm{Fe}_{1}$ centers are one $\mathrm{v}_{\mathrm{Li}}$ on center axis (shells $5 \mathrm{a}, 5 \mathrm{~b}$ on Figure 7) and probably one other distant $\mathrm{v}_{\mathrm{Li}}$ (any vacancy cannot be directly detected by ENDOR). 


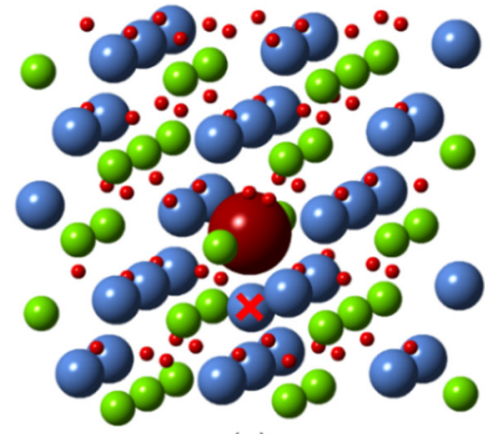

(a)

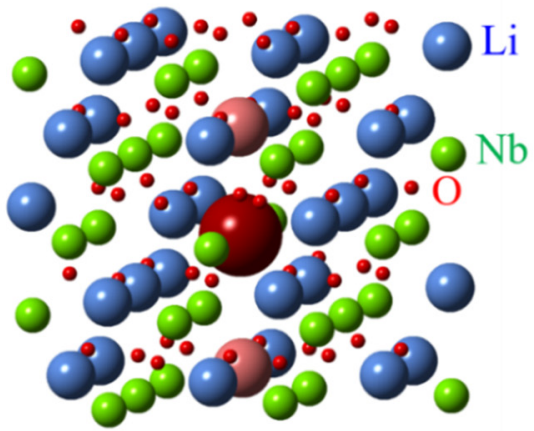

(c)

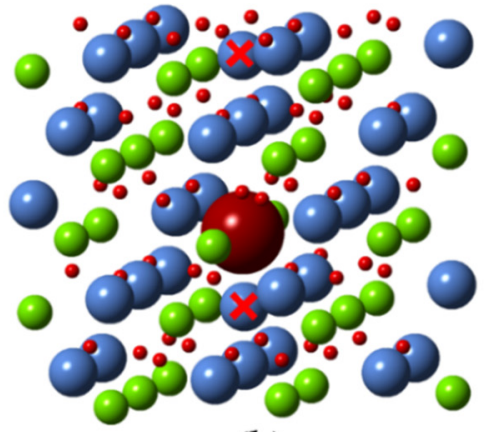

(b)

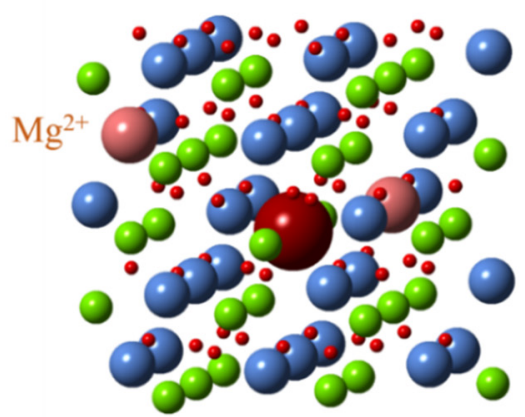

(d)

Figure 19. Possible structures of $\mathrm{Me}^{3+} \mathrm{Nb}^{5+}$ (large magenta ball) centers in LN. Structure with one (a) and two (b) additional $\mathrm{Li}$ ions in $\mathrm{v}_{\text {oct }}$ (marked with red crosses). Axial (c) and low-symmetry (d) structures with two $\mathrm{Mg}^{2+} \mathrm{Li}^{+}$ions.

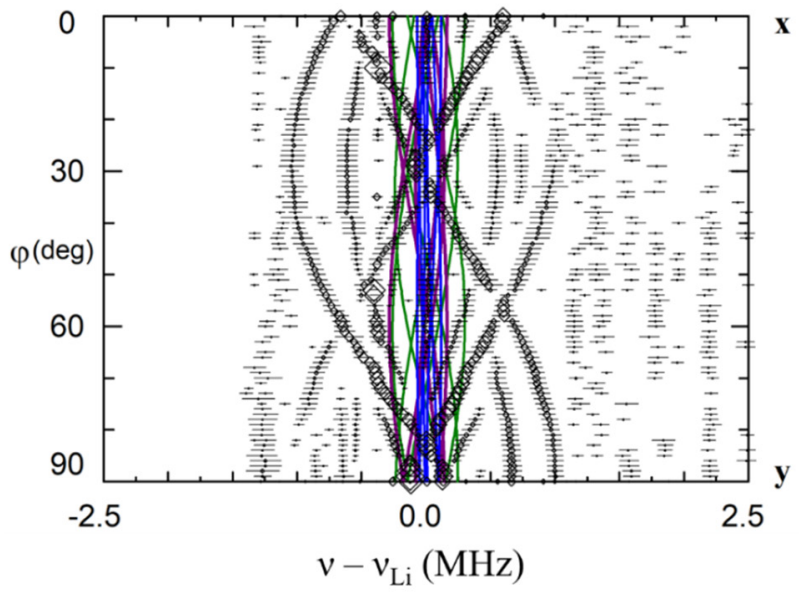

(a)

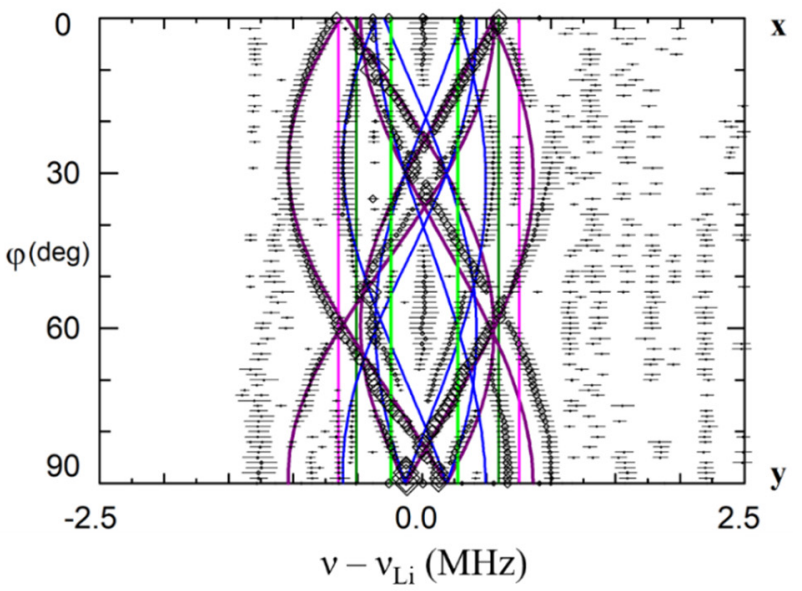

(b)

Figure 20. Angular dependence of ENDOR frequencies of Li nuclei in xy plane for the $\mathrm{Fe}_{2}{ }^{3+}$ center in $\mathrm{LiTaO}_{3}$. The green, magenta, blue and lime curves-calculated frequencies for Li nuclei of the 1st, 2nd, 3rd and 4th shells based on dipole-dipole interaction for $\mathrm{Fe}^{3+} \mathrm{Li}(\mathbf{a})$, and $\mathrm{Fe}^{3+} \mathrm{Nb}(\mathbf{b})$. Fuchsia lines on (b) - calculated frequencies for the additional Li nucleus in the nearest $\mathrm{v}_{\mathrm{oct}}$ on the axis of $\mathrm{Fe}^{3+} \mathrm{Nb}$ center. ENDOR frequencies represented by rhombs were measured on the EPR line at $\mathrm{B}=1162 \mathrm{mT}(v \approx 34.5 \mathrm{GHz})$.

A pair of ENDOR lines for $\mathrm{Fe}_{2}$ (fuchsia line on Figure 20b) were attributed to the additional $\mathrm{Li}^{+}{ }_{\mathrm{v}}$ in the nearest $\mathrm{v}_{\text {oct }}$ at the distance about $0.277 \mathrm{~nm}$ from $\mathrm{Fe}^{3+} \mathrm{Nb}$. It is difficult to make a choice between two models on Figure $19 a, b$ as lines of the second $\mathrm{Li}^{+}{ }_{i}$ in the next or next-next $\mathrm{v}_{\text {oct }}$ are not identified yet. The ratio of concentrations of $\mathrm{Fe}_{2}$ and $\mathrm{Fe}_{1}$ centers changed from less than 0.2 for Fe concentrations $1.1 \times 10^{19} \mathrm{~cm}^{-3}$ to about 1 for $6.7 \times 10^{19} \mathrm{~cm}^{-3}$ in the crystals. Therefore, there are three different mechanisms for 
excessive charge compensation: distant $\mathrm{v}_{\mathrm{Li}}$ for small concentrations of $\mathrm{Fe}^{3+} \mathrm{Li}^{+}$, partial self-compensation of charges of $\mathrm{Fe}^{3+} \mathrm{Li}^{+}$by $\mathrm{Fe}^{3+} \mathrm{Nb}^{5+}$ and partial compensation of $\mathrm{Fe}^{3+} \mathrm{Nb}^{5+}$ by $\mathrm{Li}^{+}$in $\mathrm{v}_{\text {oct }}$ for $\mathrm{Fe}^{3+}$ concentrations, which exceed the concentration of $\mathrm{v}_{\mathrm{Li}}$.

$\mathrm{Gd}^{3+}\left(4 \mathrm{f}^{7}, S=7 / 2\right)$. The EPR spectrum for every $\mathrm{Gd}^{3+}$ center consists of $2 S+1=8$ strong lines of fine structure and many low intensity lines of so called forbidden transitions due to nearly equal values of Zeeman splitting and ZFS. Results of the first EPR study [227], were interpreted as a presence of two axial $\mathrm{Gd}_{1}$ and $\mathrm{Gd}_{2}$ centers with $b_{2}^{0}=0.118$ and $b_{2}^{0}=0.126 \mathrm{~cm}^{-1}$. From the viewpoint of charge compensation, a preference was given to $\mathrm{Gd}^{3+}$ substitution for $\mathrm{Nb}^{5+}$. A small rhombic distortion $\left(b_{2}^{2} \approx 0.004\right)$ determined for $\mathrm{Gd}_{2}$ [228] was attributed to an off axis charge compensator, while for $\mathrm{Gd}_{1}$ the charge compensator may either be absent or must lie on the same threefold axis as $\mathrm{Gd}^{3+}$. However, no decision on whether $\mathrm{Gd}^{3+}$ substitutes for $\mathrm{Li}^{+}$or $\mathrm{Nb}^{5+}$ or for both was made. Similar results with slightly smaller $b_{2}^{2} \approx 0.002$ were also reported [229].

At least four different $\mathrm{Gd}^{3+}$ centers were identified in our study of Li-rich LN doped with $1 \mathrm{wt} . \% \mathrm{Gd}_{2} \mathrm{O}_{3}$ in the melt. As patterns for every EPR transition in xy-plane (Figure 21) are very similar to presented on Figures $4 \mathrm{~b}$ and 15 , the divacancy model is suitable for $\mathrm{Gd}^{3+}$ in $\mathrm{LN} . \mathrm{Gd}^{3+}$ substitutes for $\mathrm{Li}^{+}$in all centers. The dominant axial $\mathrm{Gd}_{1}$ center and low-symmetry $\mathrm{Gd}_{2}, \mathrm{Gd}_{3}$, and $\mathrm{Gd}_{4}$ centers have $\mathrm{v}_{\mathrm{Li}}$ in positions described in Table 1 . This assignment agrees with the Gd substitution for Li found by RBS and PIXE channeling [31].

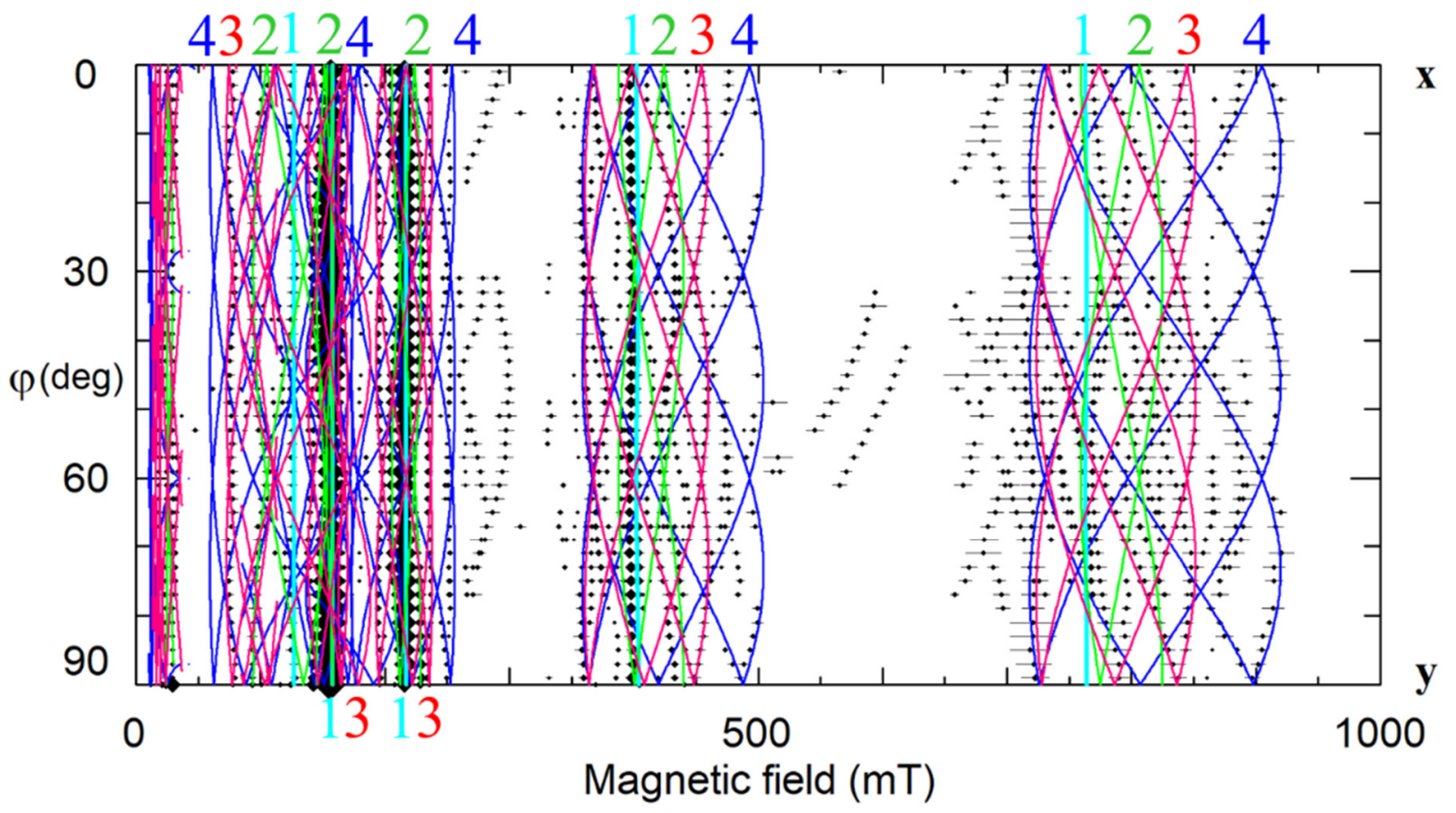

Figure 21. The angular dependencies of EPR spectra in xy plane for Li-rich LN:Gd ${ }^{3+}, v=9.26 \mathrm{GHz}$. Rhombs represent line positions; horizontal whiskers-line widths. Cyan, lime, fuchsia, and blue curves are simulated dependencies for axial $\mathrm{Gd}_{1}$, and low-symmetry $\mathrm{Gd}_{2}, \mathrm{Gd}_{3}$, and $\mathrm{Gd}_{4}$ centers, respectively.

$\mathbf{N d}^{3+}\left(4 \mathrm{f}^{3}\right)$ First EPR spectra have shown that in $\mathrm{CLN} \mathrm{Nd}{ }^{3+}$ creates an axial center with $g_{\|} \approx 1.43$ and $g_{\perp} \approx 2.95\left(\mathrm{Nd}_{1}\right)[143,144,230]$ and second center with $g_{\|} \approx 1.33$ and $g_{\perp} \approx 2.95$ $\left(\mathrm{Nd}_{2}\right)$ [143]. EPR/ENDOR studies in sLN [91-93] has established that $\mathrm{Nd}^{3+}$ substitutes for $\mathrm{Li}^{+}$, and resolved eight different $\mathrm{Nd}^{3+}$ centers. Divacancy models explain angular dependencies of EPR spectra for the whole family of $\mathrm{Nd}^{3+}$ centers [93], and Section 3.1 of this paper.

It is supposed that $\mathrm{Nd}^{3+}$ center found in $\mathrm{LN}: \mathrm{Mg}$ and $\mathrm{LN}: \mathrm{Zn}$ belong to $\mathrm{Nd}^{3+}$ substituted for $\mathrm{Nb}$ [231].

$\mathrm{Ti}^{3+}\left(3 \mathrm{~d}^{1}, S=1 / 2\right)$ EPR spectrum of $\mathrm{Ti}^{3+}$ consist of one line with $g_{\|} \approx 1.961$ and $g_{\perp} \approx 1.840$ in LN [232-234], and $g_{\|}=1.948$, and $g_{\perp}=1.827$ in reduced LT [235]. An axial 
EPR signal observed in vacuum annealed $\mathrm{LiNbO}_{3}$ single crystals doped with $8 \mathrm{~mol} . \% \mathrm{Mg}$ and $0.05 \mathrm{~mol} \%$ Ti has $g_{\|}=1.760$ and $g_{\perp}=1.786$ for $\mathrm{T}=5 \mathrm{~K}$ and $g_{\|}=g_{\perp}=1.893$ for $\mathrm{T}=74 \mathrm{~K}$. The signal has been attributed to $\mathrm{Ti}^{3+}$ on $\mathrm{Nb}$ site [236-240]. The $\mathbf{g}$ tensor components of these centers were explained by a model calculation involving a dynamic pseudo JahnTeller effect. Spin-orbit coupling, lattice vibration, pseudo Jahn-Teller interaction, and the Zeeman term were treated on equal footing. Electron transfer from the observed $\mathrm{Ti}^{3+} \mathrm{Nb}$ center to lattice niobiums, resulting in $\mathrm{Nb}^{4+}$ trapped polarons, has been stimulated by illumination in the near UV region.

$\mathbf{Y b}^{3+}\left(4 \mathrm{f}^{13}\right)$ The EPR lines of $\mathrm{Yb}^{3+}$ in congruent LN are very broad (Figure 22a,c) [241]. The axial center $\mathrm{Yb}_{1}$ with $g_{\|} \approx 4.7-4.86$ and $g_{\perp} \approx 2.7$ was observed in cLN with $0.5-1.2$ wt.\% $\mathrm{Yb}_{2} \mathrm{O}_{3}$ in the melt $[144,230,241]$. The second $\mathrm{Yb}_{2}{ }^{3+}$ center with $g_{\|} \approx 1.9$ and $g_{\perp} \approx 2.8$ was found in LN:Mg [241]. By comparison of these observations with EPR data for $\mathrm{Cr}^{3+}$, $\mathrm{Er}^{3+}, \mathrm{Fe}^{3+}$, and $\mathrm{Ti}^{3+}$ in $\mathrm{LN}$ and $\mathrm{LN}: \mathrm{Mg}$ the $\mathrm{Yb}_{1}$ center was tentatively assigned to $\mathrm{Yb}^{3+} \mathrm{Li}$ and $\mathrm{Yb}_{2}$ center to $\mathrm{Yb}^{3+} \mathrm{Nb}$. A variation of lattice parameters found in $\mathrm{CLN}: \mathrm{Yb}$ supported $\mathrm{Yb}^{3+}$ substitution for Li compensated by $\mathrm{Li}^{+}$vacancy [242].

Complicated EPR spectra without 60 deg repetitions in $x y$ plane were registered in cLN doped with $1 w$ t.\% Yb, and cLN doubly doped with 0.8 wt.\% of $\mathrm{Yb}$ and 0.1 wt.\% of $\operatorname{Pr}$ [243-247]. Some of the spectra were attributed to $\mathrm{Yb}^{3+}$ pairs with the parameter of isotropic exchange interaction $J=-0.0283 \mathrm{~cm}^{-1}$.

Our study of $\mathrm{LN}_{\mathrm{K}}$ crystals doped with 0.02 wt.\% $\mathrm{Yb}_{2} \mathrm{O}_{3}$ has shown that the broad line observed in cLN belongs in reality to a family of at least 8 different centers (Figure 22b,d) $[92,248,249]$. Hyperfine structures from isotopes ${ }^{171} \mathrm{Yb}(I=1 / 2$, natural abundance $14.4 \%)$ and $173(I=5 / 2,16.6 \%)$ that are barely distinguished in cLN, were well resolved in $\mathrm{LN}_{\mathrm{K}}$ (see Figures 22 and 23). The dominant $\mathrm{Yb}_{1}$ line that represents even isotopes with $I=0$ (even $\mathrm{Yb}, 69 \%$ ) was described with $g_{\|}=4.46, g_{\perp}=2.706$. Intensities of the $\mathrm{Yb}^{3+}$ lines were proportional to natural abundances of isotopes and their spins: $\mathcal{I}$ (even): $\mathcal{I}(171): \mathcal{I}(173)$ $=0.69: 0.144 / 2: 0.166 / 6=0.69: 0.072: 0.028$. It was found for $\mathrm{Yb}_{1}$ that ${ }^{171} A_{\|}=0.119 \mathrm{~cm}^{-1}$, and ${ }^{171} A_{\perp}=0.0715 \mathrm{~cm}^{-1}$. Branches of angular dependencies of the $\mathrm{Yb}_{5}$ center (fuchsia lines on Figure 22) were described with spin-Hamiltonian for $S=1$ and anisotropic $\mathbf{S}^{\mathrm{A}} \mathbf{J S}^{\mathrm{B}}$ interaction $\left(J_{i k} \approx 0.012-0.066 \mathrm{~cm}^{-1}\right)$. They were assigned to low-symmetry $\mathrm{Yb}^{3+}-\mathrm{Yb}^{3+}$ pairs. The presence of additional lines of hyperfine structure with similar angular dependence (indicated by red arrows in Figure 23) supports the assignment, as their intensities are proportional to probabilities to meet two even $\mathrm{Yb}$, or one even $\mathrm{Yb}$ and one ${ }^{171} \mathrm{Yb}$, or one even $\mathrm{Yb}$ and one ${ }^{173} \mathrm{Yb}$ in such pairs. A self-compensated pair consisted of $\mathrm{Me}^{3+} \mathrm{Li}$ and $\mathrm{Me}^{3+} \mathrm{Nb}$ in the nearest sites $(\mathrm{Nb}$ shell 1 at a distance $0.3 \mathrm{~nm}$ on the crystal axis, Figure $5 \mathrm{a})$ creates an axial center with rather strong exchange interaction (Jiso $\left.>300 \mathrm{~cm}^{-1}\right)$. Therefore, the observed low-symmetry pairs were attributed to the $\mathrm{Yb}^{3+}-\mathrm{Yb}^{3+}$ ions in next neighbor or next-next neighbor positions (shells 2 and 3 on Figure 5a).

One of the satellite centers $\left(\mathrm{Yb}_{6}\right)$ has axial symmetry; all others are low-symmetry centers. ENDOR measurements has revealed that $\mathrm{Yb}^{3+}$ substitutes for $\mathrm{Li}$ : at the first, comparison of measured angular dependencies with calculated ones on the base of dipoledipole interactions (Equation (3)) gave undisputable preference for Li site, and at the second, the strongest axial hyperfine interaction was found for ${ }^{93} \mathrm{Nb}$ on the $\mathbf{z}$-axis (the first shell on Figure 5a). The most reasonable explanation for the existence of the whole family of ytterbium centers is that $\mathrm{Yb}^{3+} \mathrm{Li}$ is compensated by one or two $\mathrm{v}_{\mathrm{Li}}$ in different configurations. 


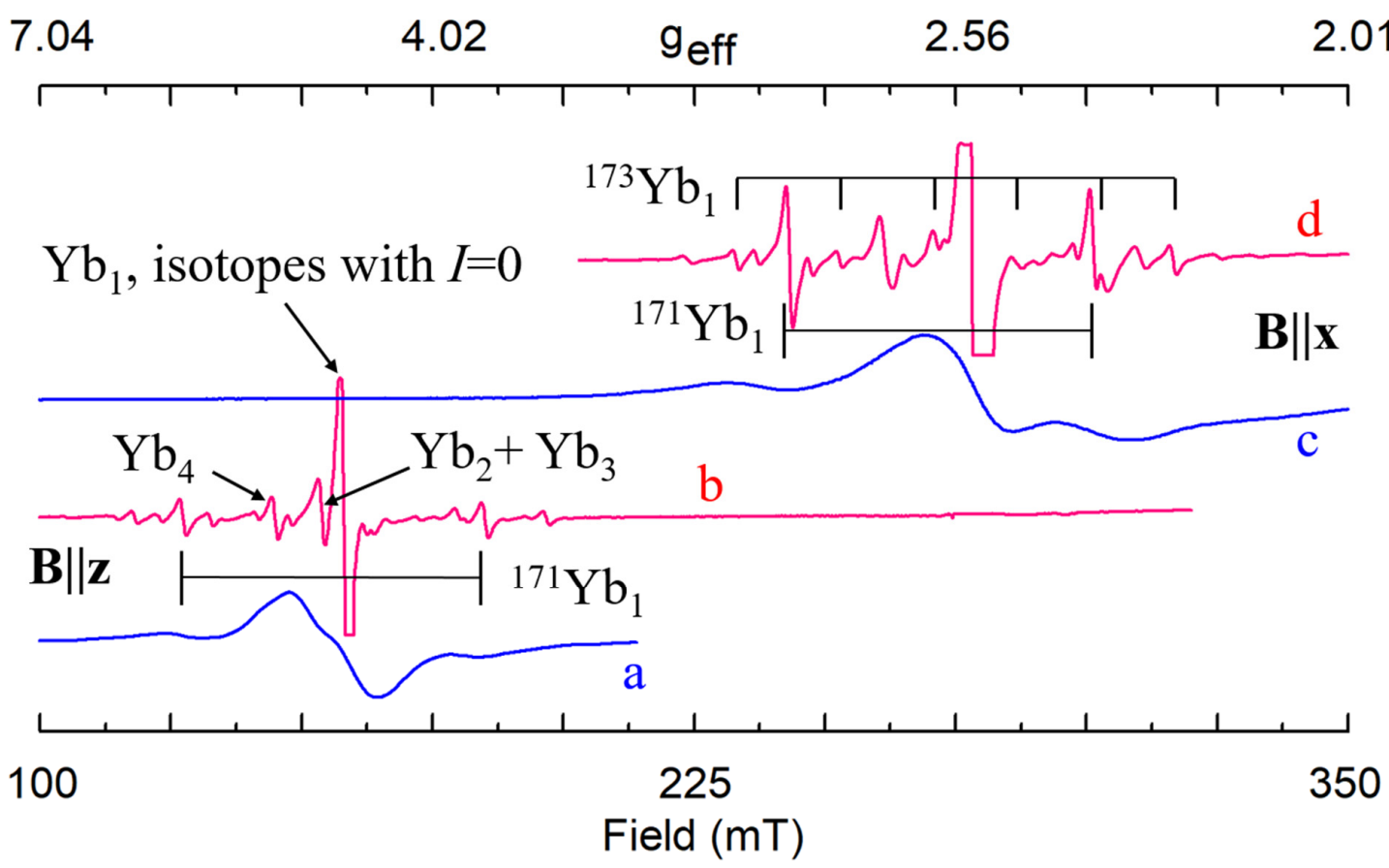

Figure 22. EPR spectra of $\mathrm{Yb}^{3+}$ in congruent $(\mathrm{a}, \mathrm{c})$ and stoichiometric $(\mathrm{b}, \mathrm{d}) \mathrm{LN}$.

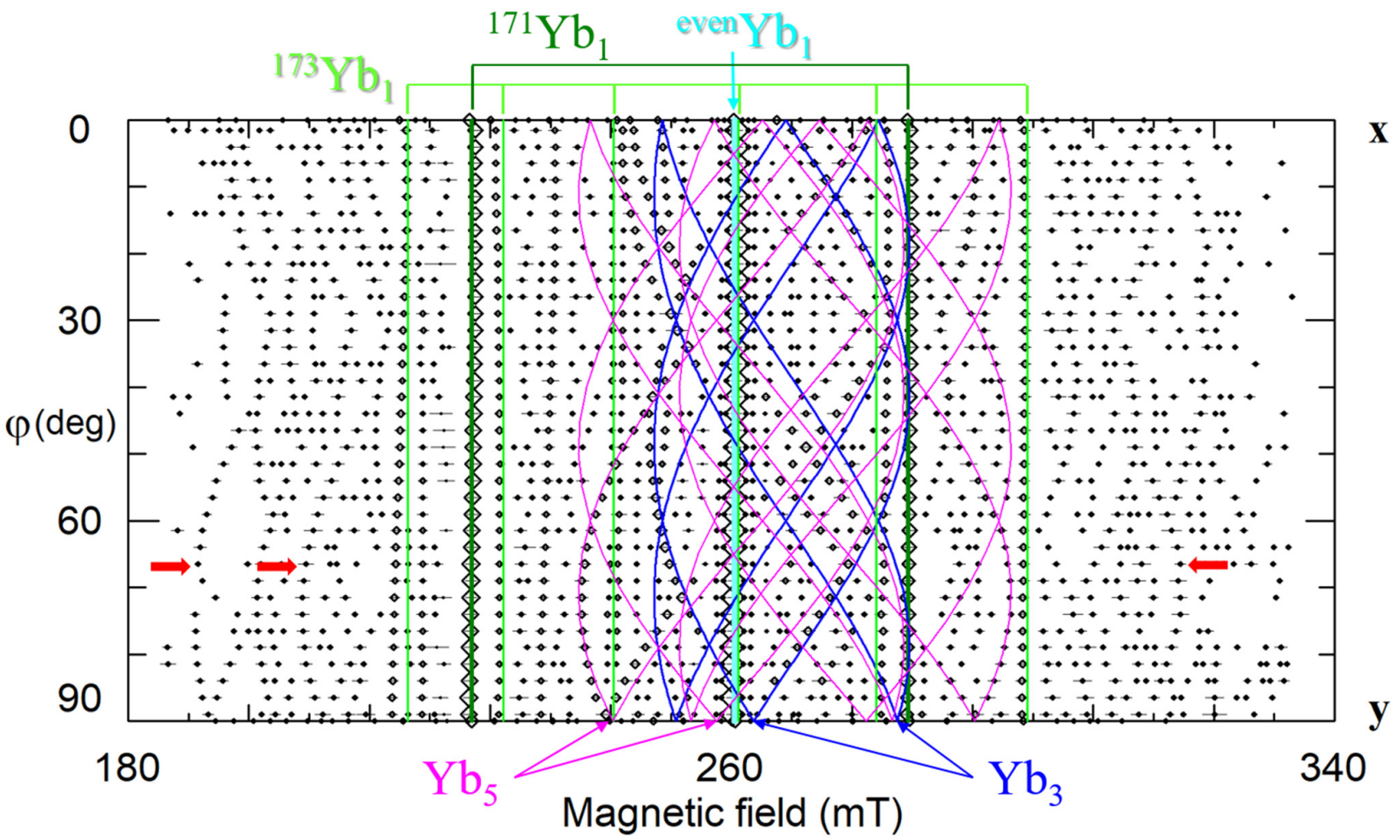

Figure 23. Angular dependence of EPR spectra of $\mathrm{Yb}^{3+}$ in stoichiometric LN, xy plane, $v=9.86 \mathrm{GHz}$. Red arrows-lines of hyperfine structure for $\mathrm{Yb}_{5}$ centers. 


\subsection{Tetra-, Penta- and Heptavalent Cations}

The non-paramagnetic tetravalent impurities (C and $\mathrm{Si}$ ) are always present in $\mathrm{LN}$ in rather high concentrations (about 50-500 ppm). Since determined concentrations of chlorine $\mathrm{Cl}$ (50-500 ppm) and manganese $\mathrm{Mg}$ (1-100 ppm) have the same order of magnitudes, no other charge compensators are necessary if $\mathrm{C}$ or Si substitutes for $\mathrm{Nb}$ creating $\mathrm{C}^{4+} \mathrm{Nb}$ $\mathrm{Cl}^{-} \mathrm{O}^{2-}$ or $\mathrm{C}^{4+}{ }_{\mathrm{Nb}}-\mathrm{Mg}^{2+} \mathrm{Li}$. The additional possibilities for the charge compensation supply $\mathrm{H}^{+}$and $\mathrm{Li}^{+}{ }_{\mathrm{v}}$ ions. It is supposed that $\mathrm{Ti}^{4+}$ substitutes for $\mathrm{Nb}^{5+}$; however, at present a mechanism of its charge compensation is not well established.

Due to the lithium deficiency of congruent lithium niobate crystals, $\mathrm{v}_{\mathrm{Li}}$ have been considered as possible charge compensators for $\mathrm{Nb}^{5+} \mathrm{Li}^{+}$or $\mathrm{Ta}^{5+} \mathrm{Li}^{+}$antisites for a long time. Models with plane and space configurations of $\mathrm{v}_{\mathrm{Li}}$ for non-stoichiometric defects were proposed $[96,97]$ and used for calculations of stability of intrinsic defects and defect clusters in LN [250-253] and LN:Mg [254]. The antisites become paramagnetic ions $\mathrm{Nb}^{4+} \mathrm{Li}^{+}$or $\mathrm{Ta}^{4+} \mathrm{Li}^{+}$after irradiation (see Section 4.5 below).

The $\mathrm{Ta}^{5+}$ substitution for $\mathrm{Nb}^{5+}$ in $\mathrm{LN}$ causes minor lattice distortions only. The heptavalent ions (Mo, $\mathrm{W}$ ) probably substitute for $\mathrm{Nb}^{5+}$ having lithium vacancies as charge compensators.

$\mathrm{U}^{5+}\left(5 \mathrm{f}^{1}\right)$. EPR spectra of $\mathrm{U}^{5+}$ were studied in $\mathrm{LiNbO}_{3}$ powders doped with natural $\mathrm{U}_{3} \mathrm{O}_{8}$ and ${ }^{233} \mathrm{U}_{3} \mathrm{O}_{8}$. A hyperfine sextet of EPR line for ${ }^{233} \mathrm{U}(I=5 / 2)$ was described with $A_{\|}=0.0145$ and $A_{\perp}=0.0128 \mathrm{~cm}^{-1} \cdot g_{\|}=0.71, g_{\perp}=0.724$ were determined for the line of natural $\mathrm{U}^{5+}$ (even isotopes with $I=0$ have total natural abundance about $99 \%$ ). It was observed that $\mathrm{U}^{5+}$ takes part in photoinduced valence change which is the basic mechanism for photorefraction.

\subsection{Radiation and Reduction Defects}

A radiation usually recharges of regular lattice, interstitial and impurity ions or produces interstitial ions. Two kinds of recharged defects were observed in LN: electron traps like $\mathrm{Nb}^{4+}$ and hole traps like $\mathrm{O}^{-}$ions $[236,255,256]$.

$\mathrm{Nb}^{4+}\left(4 \mathrm{~d}^{1}\right)$. Hyperfine interaction of the unpaired $4 \mathrm{~d}^{1}$ electron with the ${ }^{93} \mathrm{Nb}$ nuclear spin $I=9 / 2$ splits its EPR line into ten components. The ten-line EPR spectrum $\left(g_{\|}=1.90\right.$ and $g_{\perp}=1.72$ ) has been described for congruent $\mathrm{LiNbO}_{3}$ after ionizing radiation [257]. Later this spectrum has been reproduced in vacuum-reduced and UV bleached crystals [258-261] (Figure 24, 1) and ascribed to antisite $\mathrm{Nb}$ [255]). It is remarkable that at least part of the $\mathrm{Nb}^{4+}$ centers has $\mathrm{C}_{1}$ symmetry [262], although the main possible positions for $\mathrm{Nb}$ (regular $\mathrm{Nb}$ and $\mathrm{Li}$ site, $\mathrm{v}_{\mathrm{oct}}$ ) have $\mathrm{C}_{3}$ symmetry. It means that compensating defects for $\mathrm{Nb}^{4+}$, most probably lithium vacancies, are located in the nearest neighborhood (Figure 25a,b).

Similar spectra were observed in $\mathrm{LiNbO}_{3}$ doped with 6 mol.\% $\mathrm{Mg}$ (Figure 24, 2) after $\mathrm{X}$-irradiation or vacuum reduction treatments and were related to $\mathrm{Nb}^{4+}$ centers on niobium sites $[104,113,114]$, obviously with nearby defects. The $\mathrm{Nb}^{4+}$ center in $\mathrm{LiNbO}_{3}$ doped with $10 \mathrm{~mol} \% \mathrm{Mg}$ belongs to $\mathrm{Nb}$ in regular position, but with $\mathrm{Mg}^{2+} \mathrm{Li}$ in neighborhood (Figure 24,3) $[238,263]$. The neighboring $\mathrm{Mg}^{2+}$ ion redistributes a cloud of $\mathrm{Nb}^{4+}$ electrons and changes the hyperfine splitting. 


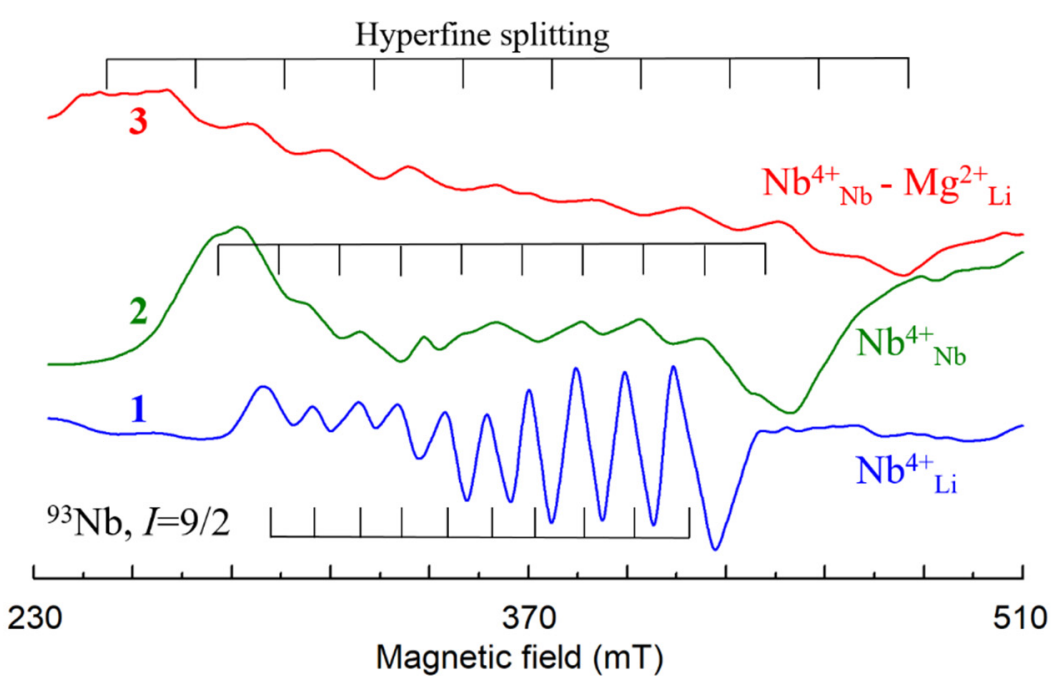

(a)

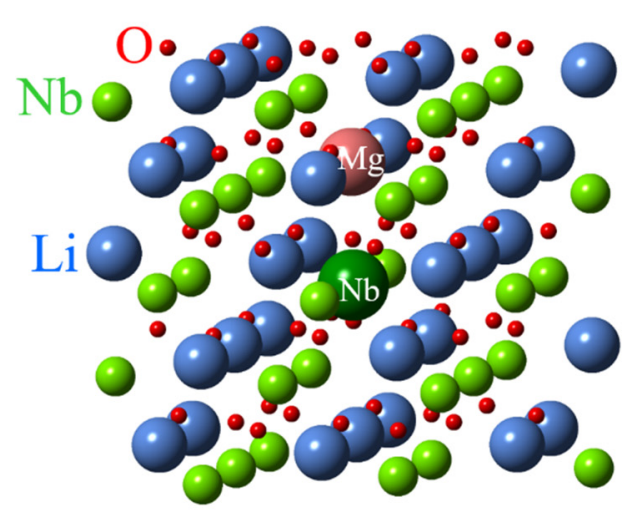

(b)

Figure 24. (a) EPR spectra of $\mathrm{Nb}^{4+}$ centers in cLN (1) and cLN doped with 6 mol.\% Mg (2) and 10 mol.\% Mg (3), X band. (b) Model for axial $\mathrm{Nb}^{4+} \mathrm{Nb}-\mathrm{Mg}^{2+} \mathrm{Li}$ center.

$\mathrm{Ta}^{4+}\left(5 \mathrm{~d}^{1}\right)$. The isotope ${ }^{181} \mathrm{Ta}$ has $I=7 / 2$ and $100 \%$ natural abundance. The eight-line axial EPR spectrum with $g_{\|}=1.503$ and $g_{\perp}=1.172, A_{\|}=0.0023$, and $A_{\perp}=0.0234 \mathrm{~cm}^{-1}$ has been observed in $\mathrm{LiTaO}_{3}$ after reduction in argon and attributed to axial $\mathrm{Ta}^{4+} \mathrm{Li}$ [257]. Other ways to obtain $\mathrm{Ta}^{4+}$ are an irradiation of as-grown crystals with X-rays or optical bleaching of crystals that had been previously reduced [264]. A possible model for axial $\mathrm{Ta}^{4+}$ center is similar to the presented on Figure 25a.

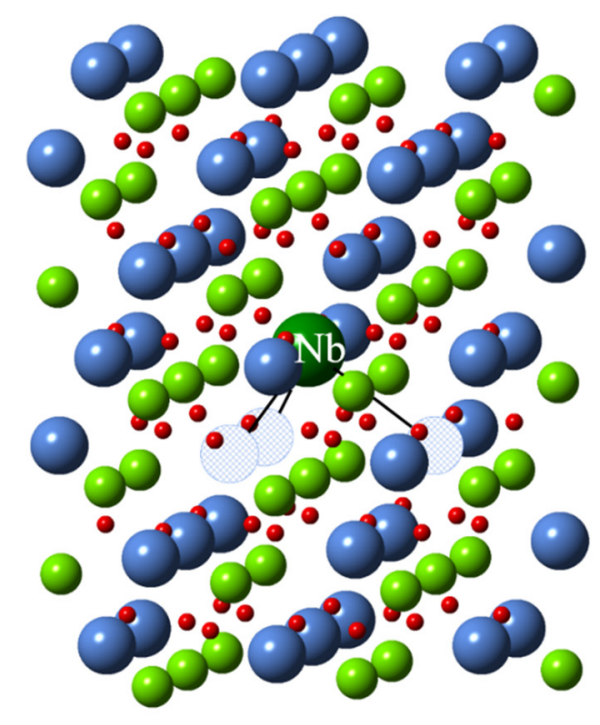

(a)

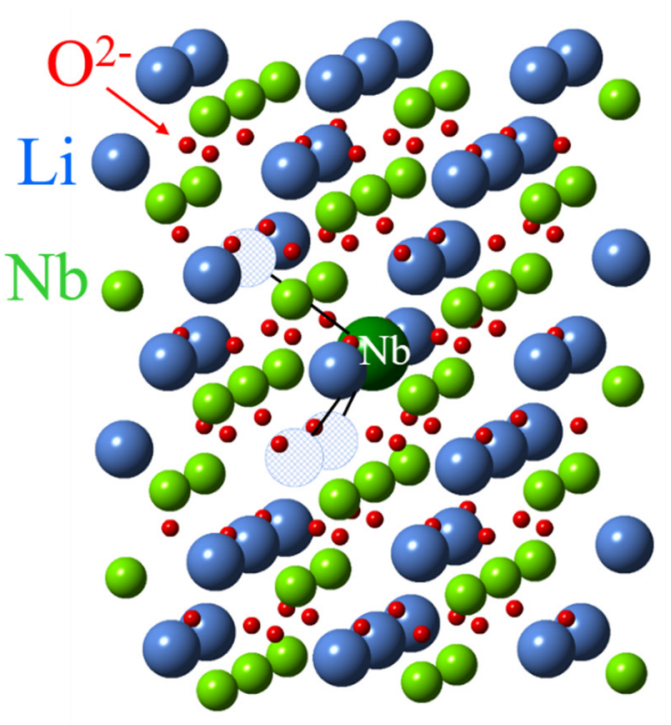

(b)

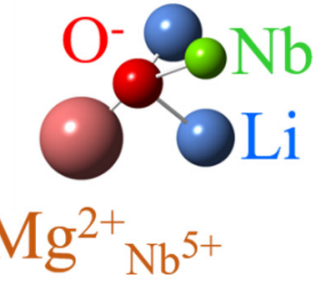

(c)

Figure 25. Models for $\mathrm{Nb}^{4+} \mathrm{Li}$ (large green ball) centers with three $\mathrm{v}_{\mathrm{Li}}$ in LN. Hatched circles represent lithium vacancies. (a) Axial center. (b) Low-symmetry center. (c) The center with $\mathrm{O}^{-}$near $\mathrm{Mg}^{2+}$ substituted for $\mathrm{Nb}^{5+}$.

$\mathbf{T b}^{4+}\left(4 \mathrm{f}^{7}\right)$. EPR study at $15 \mathrm{~K}$ revealed a signal of $g \approx 2.0$ appearing after UV irradiation with a simultaneous decrease in the $\mathrm{Fe}^{3+}$ signal intensity in near-stoichiometric $\mathrm{LiNbO}_{3}: \mathrm{Tb}$ and $\mathrm{LiNbO}_{3}: \mathrm{Tb}: \mathrm{Fe}$ [265]. This implies that the $\mathrm{Fe}^{3+}$ ions act as electron traps. Irradiation by UV light induced an absorption band extending from $\lambda \approx 650 \mathrm{~nm}$ to the absorption edge caused by the charge transfer from UV-sensitive absorption centers to $\mathrm{Fe}^{3+}$ ions via the conduction band. 
Other electron and hole traps. A trapped-hole center with $S=1 / 2$ was produced in $\mathrm{LiNbO}_{3}$ by ionizing radiation [266]. Its ESR spectrum contains at least 26 equally spaced lines with $1.54 \mathrm{mT}$ separation at $\mathbf{B} \mid \mathbf{|} \mathbf{z}$. This hyperfine pattern was explained as one "hole" interacting equally with three ${ }^{93} \mathrm{Nb}$ nuclei $(I=9 / 2$ and $100 \%$ abundant). The hole is equally shared by three equivalent oxygen ions adjacent to a cation vacancy. A center with 25 lines of hyperfine interaction with two ${ }^{7} \mathrm{Li}$ and two ${ }^{93} \mathrm{Nb}$ nuclei was ascribed to $\mathrm{O}^{-}$in regular $\mathrm{O}^{2-}$ site with unclear stabilizing factor for the hole trap [236].

An $\mathrm{OH}^{2-}$ ion was identified in undoped and weakly doped with $\mathrm{Mg} \mathrm{LN}$ samples after $\gamma$-irradiation and subsequent partial UV bleaching [109]. Specific hyperfine structure with ${ }^{93} \mathrm{Nb}$ was observed for a hole trap in LN doped with 6-8 mol.\% Mg. The center was attributed to $\mathrm{O}^{-}$near $\mathrm{Mg}^{2+}$ ion substituted for $\mathrm{Nb}^{5+}$ (Figure 25c) [263].

\section{Impurity Identification}

At an investigation of a sample grown from a melt with an addition of a paramagnetic spice in concentration $0.00 \mathrm{X}-0 . \mathrm{X}$ at.\%, which warrants that EPR signal significantly exceeds noise, it would be reasonable to expect EPR signal from this spice. Often, studied samples (especially, commercial ones) contain so-called non-controlled or trace impurities like $\mathrm{Cr}$, $\mathrm{Mn}, \mathrm{Fe}, \mathrm{Cu}$ etc. in a slightly smaller or comparable concentration. Fortunately, most paramagnetic impurities are already investigated by EPR/ENDOR techniques and their characteristics-electron and nuclear spins, zero-field splitting, hyperfine and quadrupole interactions, kinds of charge compensators and their locations, i.e., "passports" of the impurities-are known. Comparison of published and observed spectra (see, for instance, figures with EPR spectra and their angular dependencies above) allows to identify the impurities in films, epitaxial layers, and fibers, or to evaluate profile of impurity distribution in bulk samples. Spectra of LN/LT powders and ceramics can be simulated using determined spin-Hamiltonian parameters.

\section{Conclusions}

Very detailed information about structures of impurity defects (charge state, point symmetry, hyperfine interactions with neighbor nuclei, charge compensation mechanisms etc.) was obtained with the help of EPR and ENDOR.

The necessity of a charge compensation for non-isovalent substitution usually leads to the creation of families of electrically and magnetically non-equivalent impurity centers. The families of satellite centers exist due to the different relative locations of the impurity ion and its charge compensator. Two or more different centers were observed for $\mathrm{Co}^{2+}, \mathrm{Cr}^{3+}$, $\mathrm{Cu}^{2+}, \mathrm{Er}^{3+}, \mathrm{Fe}^{3+}, \mathrm{Gd}^{3+}, \mathrm{Mn}^{2+}, \mathrm{Nd}^{3+}, \mathrm{Yb}^{3+}$, and other ions. Since the relative concentrations of satellite centers are comparable with the concentration of the main center, both kinds of centers generally are equally responsible for many of the properties of LN/LT crystals, and they should both be taken into consideration, especially in non-stoichiometric crystals.

Several different mechanisms for a compensation of excessive charge of Me impurity were found:

- $\quad$ the compensation by nonstoichiometric defects $\left(\mathrm{v}_{\mathrm{Li}}, \mathrm{v}_{\mathrm{Nb}}\right)$ for small concentrations of $\mathrm{Me}_{\mathrm{Li}}$ in crystals,

- the partial self-compensation of charges of $\mathrm{Me}_{\mathrm{Li}}$ by $\mathrm{Me}_{\mathrm{Nb}}$ mainly for the $\mathrm{Me}_{\mathrm{Li}}$ concentration that exceeds the concentration of $\mathrm{v}_{\mathrm{Li}}$

- the partial compensation of $\mathrm{Me}_{\mathrm{Nb}}$ by interstitial $\mathrm{Li}^{+}$in $\mathrm{v}_{\mathrm{oct}}$,

- the compensation by other impurities ( $\mathrm{H}$, co-dopants like $\mathrm{Mg}$, $\mathrm{Zn}$, etc.).

The presence of non-stoichiometric defects is one of the reasons why LN tolerates a strong incorporation of dopants non-isovalent to $\mathrm{Li}^{+}$and $\mathrm{Nb}^{5+}$. As long as the impurity concentration [Me] is smaller than $\delta x_{C}=\left|50 \%-x_{C}\right|$, the number of intrinsic defects is large enough to compensate the corresponding charge excess. However, for stoichiometric or nearly stoichiometric samples with high impurity concentrations (when $[\mathrm{Me}]>\delta x_{C}$ ) and with the lack of charge compensators a decrease of the distribution coefficient of impurities is observed in comparison with congruent material. A further increase of the $[\mathrm{Me}] / \delta x_{C}$ 
ratio up to $[\mathrm{Me}]>>\delta x_{C}$ can result in a change of the charge compensation mechanism. This can reveal itself in the appearance of new impurity centers.

The charge compensation by $\mathrm{v}_{\mathrm{Li}}$ works well for most of the non-isovalent ions. Vacancies in the nearest neighborhood of $\mathrm{Me}_{\mathrm{Li}}$ decrease symmetry of centers from $\mathrm{C}_{3}$ to $\mathrm{C}_{1}$, whereas distant vacancies cause spectral line broadening. For $\mathrm{Me}^{3+} \mathrm{Nb} / \mathrm{Ta}$ in stoichiometric LN/LT the charge compensation by interstitial $\mathrm{H}^{+}$and $\mathrm{Li}^{+}{ }_{\mathrm{v}}$ ions was found. The interstitial $\mathrm{Li}^{+}{ }_{\mathrm{v}}$ should be considered as a concurrent charge compensation mechanism in VTE treated samples. The compensation of $\mathrm{Me}_{\mathrm{Nb}}$ by $\mathrm{Mg}_{\mathrm{Li}}, \mathrm{Zn}_{\mathrm{Li}}$ and other impurities occurs when the co-dopant concentration exceeds some threshold that depends on $\delta x_{C}$. Typically, the threshold is about $6-8 \%$ for congruent samples, but it is lower than $1 \%$ for nearly stoichiometric samples.

The use of stoichiometric or nearly stoichiometric crystals with $\delta x_{C} \approx 0$ presents many advantages for the investigation of impurity centers by spectroscopic techniques. The decreased concentration of intrinsic defects causes a tremendous narrowing of the spectral lines. This is accompanied with the increase of spectral resolution and sensitivity, facilitates the analysis of the spectra, and simplifies the interpretation of the data. However, together with the disappearance of intrinsic defects the satellite centers disappear also. For a detailed investigation of such additional centers, the crystals with high $x_{C} \approx 49.5-49.85 \%$ are more suitable than others: they have more narrow spectral lines than congruent samples, but the satellite centers are still present. Further study of nearly stoichiometric and stoichiometric LN and LT samples should help to eliminate some disagreements in published data and to clarify intimate details of structures of impurity defects in materials, which are important for both physics and applications.

Derived structures and obtained by EPR/ENDOR characteristics of Zeeman and zerofield splitting, quadrupole and hyperfine interactions of impurity electrons with own and surrounding nuclei can be reliable corner stones for modelling of the structures.

Author Contributions: V.G.G.--theorist (yin), and G.I.M.—experimentalist (yang) made inseparable complementary contributions. All authors have read and agreed to the published version of the manuscript.

Funding: The publishing fee is covered by V.G.Grachev, SimuMag, Bozeman, MT, USA.

Institutional Review Board Statement: Not applicable.

Informed Consent Statement: Not applicable.

Data Availability Statement: The data presented in this study are available on request from the corresponding author.

Conflicts of Interest: The authors declare no conflict of interest.

\section{References}

1. Räuber, A. Chemistry and Physics of Lithium Niobate. In Current Topics in Materials Science, 1st ed.; Kaldis, E., Ed.; North-Holland: Amsterdam, The Netherlands, 1978; Volume 1, pp. 481-601.

2. Volk, T.; Wöhlecke, M. Point defects in $\mathrm{LiNbO}_{3}$. In Lithium Niobate. Defects, Photorefraction and Ferroelectric Switching, 1st ed.; Hull, R., Osgood, R.M., Jr., Parisi, J., Warlimont, H., Eds.; Springer Series in Materials Science; Springer: Berlin/Heidelberg, Germany, 2009; Volume 115, pp. 1-50.

3. Ilyenkov, A.V.; Khiznyak, A.I.; Kreminskaya, L.V.; Soskin, M.S.; Vasnetsov, M.V. Birth and evolution of wave-front dislocations in a laser beam passed through a photorefractive $\mathrm{LiNbO}_{3}$ : Fe crystal. Appl. Phys. B 1996, 62, 465-471. [CrossRef]

4. Prokhorov, A.M.; Kuz'minov, Y.S. Physics and Chemistry of Crystalline Lithium Niobate; CRC Press: Boca Raton, FL, USA, 1990.

5. Wong, K.K. (Ed.) Properties of Lithium Niobate; EMIS Data Review Series No. 5; The Institution of Electrical Engineers, INSPEC: London, UK, 2002.

6. Toney, J.E. Lithium Niobate Photonics; Artech House Publishers: London, UK, 2015; pp. 1-265.

7. Streque, J.; Aubert, T.; Kokanyan, N.; Bartoli, F.; Taguett, A.; Polewczyk, V.; Kokanyan, E.; Hage-Ali, S.; Boulet, P.; Elmazria, O. Stoichiometric Lithium Niobate Crystals: Towards Identifiable Wireless Surface Acoustic Wave Sensors Operable up to $600{ }^{\circ} \mathrm{C}$. IEEE Sens. Lett. 2019, 3, 2501204. [CrossRef] 
8. Abrahams, S.C.; Reddy, J.M.; Bernstein, J.L. Ferroelectric lithium niobate. 3. Single crystal X-ray diffraction study at $24{ }^{\circ} \mathrm{C}$. J. Phys. Chem. Solids 1966, 27, 997-1012. [CrossRef]

9. Peterson, G.E.; Bridenbaugh, P.M.; Green, P. NMR Study of Ferroelectric $\mathrm{LiNbO}_{3}$ and $\mathrm{LiTaO}_{3}$. J. Chem. Phys. 1967, 46, 4009-4014. [CrossRef]

10. Vianden, R. Hyperfine techniques for defects studies. In Insulating Materials for Optoelectronics. New Developments; Agulló-López, F., Ed.; World Scientific Publishing: Singapore; Hackensack, NJ, USA; London, UK; Hong Kong, China, 1995; pp. 125-146.

11. Kling, A.; Soares, J.C.; da Silva, M.F. Channeling Investigation of Oxide materials for Optoelectronic Applications. In Insulating Materials for Optoelectronics. New Development; Agulló-López, F., Ed.; World Scientific Publishing: Singapore; Hackensack, NJ, USA; London, UK; Hong Kong, China, 1995; pp. 175-200.

12. Gog, T.; Marerlik, G. X-ray Standing Wave Determination of Lattice Positions of Impurities in Lithium Niobate. In Insulating Materials for Optoelectronics. New Developments; Agulló-López, F., Ed.; World Scientific Publishing: Singapore; Hackensack, NJ, USA; London, UK; Hong Kong, China, 1995; pp. 201-220.

13. Spaeth, J.-M.; Niklas, J.R.; Bartram, R.H. Structural Analysis of Point Defects in Solids: An Introduction to Multiple Magnetic Resonance Spectroscopy; Springer: Singapore, 1992; pp. 1-367.

14. Prieto, C. Influence of lithium niobate stoichiometry on the lattice position of $\mathrm{Nd}^{3+}$ in $\mathrm{Nd}: \mathrm{LiNbO}_{3}$. Opt. Mater. 1999, 12, 135-142. [CrossRef]

15. Lorenzo, A.; Jaffrezic, H.; Roux, B.; Boulon, G.; Garcia-Sole, J. Lattice location of rare-earth ions in LiNbO 3 . Appl. Phys. Lett. 1995, 67, 3735-3737. [CrossRef]

16. Lorenzo, A.; Loro, H.; Muñoz Santiuste, J.E.; Terrile, M.C.; Boulon, G.; Bausa, L.E.; Garcia Sole, J. RBS/channeling to locate active ions in laser materials: Application to rare earth activated $\mathrm{LiNbO}_{3}$. Opt. Mater. 1997, 8, 55-63. [CrossRef]

17. Rebouta, L.; Smulders, P.J.M.; Boerma, D.O.; Agullo-Lopez, F.; da Silva, M.F.; Soares, J.C. Ion-beam channeling yields of host and impurity atoms in $\mathrm{LiNbO}_{3}$ : Computer simulations. Phys. Rev. B 1993, 48, 3600-3610. [CrossRef]

18. Rebouta, L.; da Silva, M.F.; Soares, J.C.; Santos, M.T.; Dieguez, E.; Agulló-López, F. Ion-beam/channeling characterization of $\mathrm{LiNbO}_{3}$ : Interaction between impurity sites. Opt. Mater. 1995, 4, 174-178. [CrossRef]

19. Garcia Sole, J.; Petith, T.; Jaffrez, H.; Boulon, G. Lattice Location of the Non-Equivalent $\mathrm{Nd}^{3+}$ Ions in $\mathrm{LiNbO}_{3}: \mathrm{Nd}_{\text {and }} \mathrm{LiNbO}_{3}$ : MgO:Nd. Europhys. Lett. 1993, 24, 719-724. [CrossRef]

20. Vila, M.; de Bernabe, A.; Prieto, C. EXAFS determination of the Nd lattice position in $\mathrm{Nd}: \mathrm{LiNbO}_{3}$ : Influence of lithium niobate stoichiometry and Mg and Zn co-doping. J. Alloys Compd. 2001, 323-324, 331-335. [CrossRef]

21. Catlow, C.R.A.; Chadwick, A.V.; Cole, M.; Tomlinson, S.M. An EXAFS study of dopant substitution in $\mathrm{LiNbO}_{3}$ and $\mathrm{LiTaO}_{3}$. Radiat Eff. Defects Solids 1991, 119-121, 565-570. [CrossRef]

22. Bush, T.S.; Catlow, C.R.A.; Chadwick, A.V.; Cole, M.; Geatches, R.M.; Greaves, G.N.; Tomlinson, S.M. Studies of cation dopant sites in metal oxides by EXAFS and computer-simulation techniques. J. Mater. Chem. 1992, 2, 309-316. [CrossRef]

23. Prieto, C.; Zaldo, C. Determination of the lattice site of Fe in photorefractive $\mathrm{LiNbO}_{3}$. Solid State Commun. 1992, 83, 819-821. [CrossRef]

24. Zaldo, C.; Prieto, C. Lattice site of transition metal and rare-earth impurities in $\mathrm{LiNbO}_{3}$ single crystals: An exafs study. Ferroelectrics 1992, 134, 47-51. [CrossRef]

25. Corradi, G.; Chadwick, A.V.; West, A.R.; Cruickshankand, K.; Paul, M. On the substitution site of $\mathrm{Cr}$ and Fe in $\mathrm{LiNbO} 3$ : $\mathrm{An}$ exafs study. Radiat. Eff. Defects Solids 1995, 134, 219-222. [CrossRef]

26. Sanson, A.; Zaltron, A.; Argiolas, N.; Sada, C.; Bazzan, M.; Schmidt, W.G.; Sanna, S. Polaronic deformation at the Fe ${ }^{2+/ 3+}$ impurity site in Fe:LiNbO 3 crystals. Phys. Rev. B 2015, 91, 094109. [CrossRef]

27. Rebouta, L.; da Silva, M.F.; Soares, J.C.; Hage-Ali, M.; Stoquert, J.P.; Siffert, P.; Sanz-García, J.A.; Diéguez, E.; Agulló-López, F. Lattice Site of Iron in $\mathrm{LiNbO}_{3}\left(\mathrm{Fe}^{3+}\right)$ by the PIXE/Channelling Technique. Europhys. Lett. 1991, 14, 557-561. [CrossRef]

28. Gog, T.; Schotters, P.; Falta, J.; Materlik, G.; Grodzicki, M. The lattice position of Fe in Fe-doped LiNbO3. J. Phys. Condens. Matter 1995, 7, 6971-6980. [CrossRef]

29. Marques, J.G.; Kling, A.; Soares, J.C.; Rebouta, L.; da Silva, M.F.; Diéguez, E.; Agulló-López, F. Lattice site location of Hf in $\mathrm{LiNbO}_{3}$ : Influence of dopant concentration and crystal stoichiometry. Nucl. Instrum. Methods Phys. Res. B 1998, 136-138, 431-435. [CrossRef]

30. Mignotte, C. Determination of lattice site locations of erbium ions implanted into $\mathrm{LiNbO}_{3}$ single crystals after annealing at moderate and high temperature. Appl. Surf. Sci. 2001, 185, 11-26. [CrossRef]

31. Kovacs, L.; Rebouta, L.; Soaresh, J.C.; da Silva, M.F.; Hage-Ali, M.; Stoquert, J.P.; Siffert, P.; Sanz-Garcia, J.A.; Corradi, G.; Szaller,

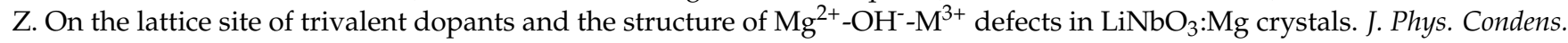
Matter 1993, 5, 781-794. [CrossRef]

32. Kling, A.; Soares, J.C.; da Silva, M.F.; Sanz-Garcia, J.A.; Dieguez, E.; Agullo-Lopez, F. Lattice site determination of Cr in low doped lithium niobate single crystals using PIXE/channeling. Nucl. Instrum. Methods Phys. Res. B 1998, 136-138, 426-430. [CrossRef]

33. Engelmann, H.; Mouahid, F.; Dezsi, I.; Molnar, B.; Gonser, U.; Siebert, D.; Dahlem, J.; Tuczek, F. Mössbauer and ESR study of $\mathrm{LiNbO}_{3}-\mathrm{Fe}_{2} \mathrm{O}_{3}$ for low $\mathrm{Fe}_{2} \mathrm{O}_{3}$ concentrations. Appl. Phys. A 1989, 48, 211-217. [CrossRef] 
34. Tomov, T.; Engelmann, H.; Dezci, I.; Gonser, U. Investigation of the ferroelectric phase transition in $\mathrm{LiNbO}_{3}$ : Fe by Mössbauer spectroscopy. Solid State Commun. 1989, 69, 41-44. [CrossRef]

35. Mignoni, S.; Fontana, M.D.; Bazzan, M.; Ciampolillo, M.V.; Zaltron, A.M.; Argiolas, N.; Sada, C. Micro-Raman analysis of Fe-diffused lithium niobate waveguides. Appl. Phys. B 2010, 101, 541. [CrossRef]

36. Kamińska, A.; Suchocki, A.; Kobyakov, S.; Arizmendi, L.; Potemski, M.; Teran, F.J. High-pressure and magneto-optical studies of Cr-related defects in the lithium-rich $\mathrm{LiNbO}_{3}: \mathrm{Cr}, \mathrm{Mg}$ crystal. Phys. Rev. B 2007, 76, 144117. [CrossRef]

37. Basun, S.; Kaplyanskii, A.; Kutsenko, A.; Dierolf, V.; Troester, T.; Kapphan, S.E.; Polgar, K. Optical characterization of Cr ${ }^{3+}$ centers in $\mathrm{LiNbO}_{3}$. Appl. Phys. B 2001, 73, 453-461. [CrossRef]

38. Sothe, H.; Rowan, L.G.; Spaeth, J.-M. Sites of $\mathrm{Fe}^{3+}$ impurities in a congruent $\mathrm{LiTaO}_{3}$ crystal. J. Phys. Condens. Matter 1989, 1, 3591-3600. [CrossRef]

39. Sothe, H.; Spaeth, J.-M. The site and local environment of $\mathrm{Fe}^{3+}$ in $\mathrm{LiNbO}_{3}$ investigated with ENDOR. J. Phys. Condens. Matter 1992, 4, 9901-9906. [CrossRef]

40. Spaeth, J.-M. Determination of atomic positions of point defects in solids by ENDOR. Appl. Magn. Reson. 1992, 3, $257-281$. [CrossRef]

41. Lerner, P.; Legras, C.; Dumas, J.P. Stoechiometrie des monocristaux de metaniobate de lithium. J. Cryst. Growth 1968, 3, $231-235$. [CrossRef]

42. Byer, R.L.; Young, J.F.; Feigelson, R.S. Growth of High-Quality $\mathrm{LiNbO}_{3}$ Crystals from the Congruent Melt. J. Appl. Phys. 1970, 41, 2320-2325. [CrossRef]

43. Malovichko, G.I.; Grachev, V.G.; Gabrielyan, V.T.; Kokanyan, E.P. Widths and intensities of ESR lines of iron-group impurities in nonstoichiometric lithium niobate crystals. Sov. Phys. Solid State 1986, 28, 1453-1458.

44. Iyi, N.; Kitamura, K.; Izumi, F.; Yamamoto, J.; Hayashi, T.; Asano, H.; Kimura, S. Comparative of defect structures in lithium niobate with different compositions. J. Solid State Chem. 1992, 101, 340-352. [CrossRef]

45. Holman, R.L. Processing of Crystalline Ceramics; Palmour, H., Davis, R.F., Eds.; Plenum: New York, NY, USA, 1978 ; p. 343.

46. Jundt, D.H.; Fejer, M.M.; Byer, R.L. Optical properties of lithium-rich lithium niobate fabricated by vapor transport equilibration. IEEE J. Quantum Electron. 1990, 26, 135-138. [CrossRef]

47. Bordui, P.F.; Norwood, R.G.; Bird, C.D.; Calvert, G.D. Compositional uniformity in growth and poling of large-diameter lithium niobate crystals. J. Cryst. Growth 1991, 113, 61-68. [CrossRef]

48. Bordui, P.F.; Norwood, R.G.; Jundt, D.H.; Fejer, M.M. Preparation and characterization of off-congruent lithium niobate crystals. J. Appl. Phys. 1992, 71, 875-879. [CrossRef]

49. Jundt, D.H.; Fejer, M.M.; Norwood, R.G.; Bordui, P.F. Composition dependence of lithium diffusivity in lithium niobate at high temperature. J. Appl. Phys. 1992, 72, 3468-3473. [CrossRef]

50. Fischer, C.; Kapphan, S.; Feng, X.-Q.; Cheng, N. Sharp R-lines in absorption and emission of $\mathrm{Cr}^{3+}$ in stoichiometric $(\mathrm{VTE}) \mathrm{LiNbO}_{3}$. Radiat. Eff. Defects Solids 1995, 135, 199-202. [CrossRef]

51. Furukawa, Y.; Sato, M.; Kitamura, K.; Yajima, Y.; Minakata, M. Optical damage resistance and crystal quality of $\mathrm{LiNbO}_{3}$ single crystals with various [Li]/[Nb] ratios. J. Appl. Phys. 1992, 72, 3250-3254. [CrossRef]

52. Kitamura, K.; Yamamoto, J.; Iyi, N.; Kirnura, S.; Hayashi, T. Stoichiometric $\mathrm{LiNbO}_{3}$ single crystal growth by double crucible Czochralski method using automatic powder supply system. J. Cryst. Growth 1992, 116, 327-332. [CrossRef]

53. Kitamura, K.; Furukawa, Y.; Iyi, N. Progress in single crystal growth of $\mathrm{LiNbO}_{3}$ using double crucible Czochralski method. Ferroelectrics 1997, 202, 21-28. [CrossRef]

54. Kitamura, K.; Furukawa, Y.; Ji, Y.; Zgonik, M.; Medrano, C.; Montemezzani, G.; Guenter, P. Photorefractive effect in LiNbO 3 crystals enhanced by stoichiometry control. J. Appl. Phys. 1997, 82, 1006-1009. [CrossRef]

55. Furukawa, Y.; Kitamura, K.; Suzuki, E.; Niwa, K. Stoichiometric $\mathrm{LiTaO}_{3}$ single crystal growth by double crucible Czochralski method using automatic powder supply system. J. Cryst. Growth 1999, 197, 889-895. [CrossRef]

56. Malovichko, G.I.; Grachev, V.G.; Yurchenko, L.P.; Proshko, V.Y.; Kokanyan, E.P.; Gabrielyan, V.T. Improvement of LiNbO 3 microstructure by crystal growth with potassium. Phys. Status Solidi (a) 1992, 133, K29-K33. [CrossRef]

57. Malovichko, G.I.; Grachev, V.G.; Kokanyan, E.; Schirmer, O.F.; Betzler, K.; Gather, B.; Jermann, F.; Klauer, S.; Schlarb, U. Characterization of stoichiometric $\mathrm{LiNbO}_{3}$ grown from melts containing $\mathrm{K}_{2} \mathrm{O}$. Appl. Phys. A 1993, 56, 103-108. [CrossRef]

58. Bermudez, V.; Dutta, P.S.; Serrano, M.D.; Dieguez, E. The effect of native defects on the domain structures of Fe-A case study by means of the addition of $\mathrm{MgO}$ and $\mathrm{K}_{2} \mathrm{O}$ to the congruent melt. J. Phys. Condens. Matter 1997, 9, 6097-6101. [CrossRef]

59. Polgar, K.; Peter, A.; Kovacs, L.; Corradi, G.; Szaller, Z. Growth of stoichiometric $\mathrm{LiNbO}_{3}$ single crystals by top seeded solution growth method. J. Cryst. Growth 1997, 177, 211-216. [CrossRef]

60. Balasanyan, R.N.; Vartanyan, E.S.; Gabrielyan, V.T.; Kazaryan, L.M. Method for Growing Lithium Niobate Single Crystals. Patent SU 845506 A1, 29 March 1979. Available online: https:/ / www.elibrary.ru/item.asp?id=41087794 (accessed on 27 February 2000).

61. Serrano, M.D.; Bermudez, V.; Arizmendi, L.; Dieguez, E. Determination of the Li/ $\mathrm{Nb}$ ratio in $\mathrm{LiNbO}_{3}$ crystals grown by Czochralski method with $\mathrm{K}_{2} \mathrm{O}$ added to the melt. J. Cryst. Growth 2000, 210, 670-675. [CrossRef]

62. Kokanyan, E.; Dieguez, E. New perspectives of lithium niobate crystals. J. Optoelectron. Adv. Mater. 2000, 2, $205-214$. 
63. Polgar, K.; Peter, A.; Foldvari, I.; Szaller, Z. Structural defects in flux-grown stoichiometric $\mathrm{LiNbO}_{3}$ single crystals. J. Cryst. Growth 2000, 218, 327-333. [CrossRef]

64. Polgár, K.; Péter, Á.; Földvári, I. Crystal growth and stoichiometry of $\mathrm{LiNbO}_{3}$ prepared by the flux method. Opt. Mater. 2002, 19, 7-11. [CrossRef]

65. Polgár, K.; Péter, Á.; Pöppl, L.; Ferriol, M.; Földvári, I. Chemical and thermal conditions for the formation of stoichiometric $\mathrm{LiNbO}_{3}$. J. Crystal Growth 2002, 237-239, 682-686. [CrossRef]

66. Grunskij, O.S.; Denisov, A.V.; Badmaev, T.V. A Method for Growing Doped Crystals of Lithium Niobate with a Composition close to Stoichiometric, and a Device for Its Implementation. Patent RU 2367730 C2, 29 November 2007. Available online: https: / / www.elibrary.ru/item.asp?id=37690005 (accessed on 20 September 2009).

67. Lengyel, K.; Péter, Á.; Kovács, L.; Corradi, G.; Pálfalvi, L.; Hebling, J.; Unferdorben, M.; Dravecz, G.; Hajdara, I.; Szaller, Z.; et al. Growth, defect structure, and THz application of stoichiometric lithium niobate. Appl. Phys. Rev. 2015, 2, 040601. [CrossRef]

68. Malovichko, G.; Grachev, V.; Schirmer, O. Interrelation of intrinsic and extrinsic defects-Congruent, stoichiometric, and regularly ordered lithium niobate. Appl. Phys. B 1999, 68, 785-793. [CrossRef]

69. Malovichko, G.I.; Grachev, V.G.; Schirmer, O.F.; Faust, B. New axial Fe ${ }^{3+}$ centers in stoichiometric lithium niobate crystals. J. Phys. Condens. Matter 1993, 5, 3971-3976. [CrossRef]

70. de Bernabe, A.; Prieto, C.; de Andres, A. Effect of stoichiometry on the dynamic mechanical properties of LiNbO 3 . J. Appl. Phys. 1995, 79, 143-148. [CrossRef]

71. Garret, M.H.; Mnushkina, I.; Furukawa, Y.; Kitamura, K.; Halliburton, L.E.; Giles, N.C.; Setzler, S.D. Photorefractive Properties of Iron-Doped Congruent Lithium Niobate, and Iron-Doped $\mathrm{K}_{2} \mathrm{O}$ Flux Grown Stoichiometric Lithium Niobate. Proceedings of 1997 Topical Meeting on Photorefractive Materials, Effects and Devices, Chiba, Japan, 11-13 June 1997.

72. Abdi, F.; Aillerie, M.; Bourson, P.; Fontana, M.D.; Polgar, K. Electro-optic properties in pure $\mathrm{LiNbO}_{3}$ crystals from the congruent to the stoichiometric composition. J. Appl. Phys. 1998, 84, 2251-2254. [CrossRef]

73. Choi, Y.N.; Choh, S.H.; Park, I.W.; Koh, E.K.; Kim, S.S. Characterization of Stoichiometry of $\mathrm{LiNbO}_{3}$ Crystals by EPR and Raman Scattering Measurements. J. Korean Phys. Soc. 1998, 32, S643.

74. Malovichko, G. Nonstoichiometry as a powerful tool for photorefractive material optimization. Lithium Niobate Crystals. In Advances in Photorefractive Materials, Effects and Devices; Andersen, P.E., Johansen, P.M., Pedersen, H.C., Petersen, P.M., Saffman, M., Eds.; Trends in Optics and Photonics; Optical Society of America: Washington, DC, USA, 1999; Volume 27. [CrossRef]

75. Malovichko, G.; Petersen, R.; Bäuman, C.; Grachev, V. Second axial Fe ${ }^{3+}$ center in stoichiometric lithium tantalate. J. Appl. Phys. 2006, 100, 023911. [CrossRef]

76. Razdobarin, A.G.; Basun, S.A.; Bursian, V.É.; Sochava, L.S.; Evans, D.R. A Fe[Nb]-Li center in stoichiometric LiNbO 3 crystals: Mechanism of formation. Phys. Solid State 2010, 52, 706-711. [CrossRef]

77. Schlarb, U.; Klauer, S.; Wesselmann, M.; Betzler, K. Determination of the Li/Nb ratio in lithium niobate by means of birefringence and Raman measurements. Appl. Phys. A 1993, 56, 311-315. [CrossRef]

78. Kling, A.; Marques, J.G.; Correia, J.G.; da Silva, M.F.; Dieguez, E.; Agullo-Lopez, F.; Soares, J.C. Study of structural differences between stoichiometric and congruent lithium niobate. Nucl. Instrum. Methods Phys. Res. B 1996, 113, 293-295. [CrossRef]

79. Kovacs, L.; Ruschhaupt, G.; Polgar, K.; Corradi, G.; Woehlecke, M. Composition dependence of the ultraviolet absorption edge in lithium niobate. Appl. Phys. Lett. 1997, 70, 2801-2803. [CrossRef]

80. Dravecz, G.; Kovács, L. Determination of the crystal composition from the $\mathrm{OH}^{-}$vibrational spectrum in lithium niobate. Appl. Phys. B 2007, 88, 305-307. [CrossRef]

81. Grachev, V.G. Visual EPR, Visual ENDOR Packages, Version 20.11. Available online: www.visual-epr.com (accessed on 1 June 2013).

82. CrystalMaker Program, Version 2.7.7; CrystalMaker Software Ltd.: Oxford, UK; Available online: www.crystalmaker.com (accessed on 31 December 2011).

83. Boysen, H.; Altorfer, F. A neutron powder investigation of the high-temperature structure and phase transition in $\mathrm{LiNbO}_{3}$. Acta Crystallogr. B 1994, 50, 405-414. [CrossRef]

84. Hsu, R.; Maslen, E.N.; du Boulay, D.; Ishizawa, N. Synchrotron X-ray Studies of $\mathrm{LiNbO}_{3}$ and LiTaO 3 . Acta Crystallogr. B 1997, 53, 420-428. [CrossRef]

85. Malovichko, G.; Cerclier, O.; Estienne, J.; Grachev, V.; Kokanyan, E.; Boulesteix, C. Lattice constants of K- and Mg-doped LiNbO3. Comparison with nonstoichiometric lithium niobate. J. Phys. Chem. Sol. 1995, 56, 1285-1289. [CrossRef]

86. Lehnen, H.; Boysen, H.; Frey, F.; Hewat, A.; Radaelli, P. A neutron powder investigation of the high-temperature structure and phase transition in stoichiometric $\mathrm{LiNbO}_{3}$. Zeitschrift für Kristallographie 1997, 212, 712-719. [CrossRef]

87. Malovichko, G.; Grachev, V.; Kokanyan, E.; Schirmer, O. Axial and low-symmetry centers of trivalent impurities in lithium niobate. Chromium in congruent and stoichiometric crystals. Phys. Rev. B 1999, 59, 9113-9125. [CrossRef]

88. Abrahams, S.C.; Hamilton, W.C.; Reddy, J.M. Ferroelectric lithium niobate. 4. Single crystal neutron diffraction study at $24{ }^{\circ} \mathrm{C}$. $J$. Phys. Chem. Solids 1966, 27, 1013-1018. [CrossRef]

89. Megaw, H.D. A note on the structure of lithium niobate, $\mathrm{LiNbO}_{3}$. Acta Crystallogr. A 1968, 24, 583-588. [CrossRef] 
90. Abrahams, S.C.; Levinstein, H.J.; Reddy, J.M. Ferroelectric lithium niobate. 5. Polycrystal X-ray diffraction study between $24^{\circ}$ and $1200{ }^{\circ}$ C. J. Phys. Chem. Solids 1966, 27, 1019-1026. [CrossRef]

91. Malovichko, G.; Grachev, V.; Okulov, S.; Kokanyan, E.; Henecker, F.; Hofstaetter, A.; Schirmer, O. EPR of Nd ${ }^{3+}$ in congruent and nearly stoichiometric lithium niobate. Phys. Status Solidi (b) 2005, 243, 1-7. [CrossRef]

92. Malovichko, G.; Bratus, V.; Munro, M.; Kokanyan, E.; Okulov, S.; Grachev, V. Multifrequency spectroscopy of laser active centers $\mathrm{Nd}^{3+}$ and $\mathrm{Yb}^{3+}$ in nearly stoichiometric $\mathrm{LiNbO}_{3}$. Phys. Status Solidi (c) 2007, 4, 1346-1351. [CrossRef]

93. Grachev, V.; Munro, M.; Kokanyan, E.; Malovichko, G. Determination of g-tensors of low-symmetry $\mathrm{Nd}^{3+}$ centers in LiNbO 3 by rectification of angular dependence of electron paramagnetic resonance spectra. J. Appl. Phys. 2015, 118, 044103. [CrossRef]

94. Blümel, J.; Born, E.; Metzger, T. Solid state NMR study supporting the lithium vacancy defect model in congruent lithium niobate. J. Phys. Chem. Solids 1994, 55, 589-593. [CrossRef]

95. Zotov, N.; Boysen, H.; Frey, F.; Metzger, T.; Born, E. Cation substitution models of congruent $\mathrm{LiNbO}_{3}$ investigated by $\mathrm{X}$-ray and neutron powder diffraction. J. Phys. Chem. Solids 1994, 55, 145-152. [CrossRef]

96. Leroux, C.; Nihoul, G.; Malovichko, G.; Grachev, V.; Boulesteix, C. High resolution electron microscopy investigation of correlated defects in non-stoichiometric lithium niobate. J. Phys. Chem. Solids 1998, 59, 311-319. [CrossRef]

97. Kim, S.; Gopalan, V.; Kitamura, K.; Furukawa, Y. Domain reversal and nonstoichiometry in lithium tantalate. J. Appl. Phys. 2001, 90, 2949-2963. [CrossRef]

98. Abrahams, S.C.; Marsh, P. Defect structure dependence on composition in lithium niobate. Acta Crystallogr. B 1986, 42, 61-68. [CrossRef]

99. Peterson, G.E.; Carnevale, A. ${ }^{93} \mathrm{Nb}$ NMR linewidths in nonstoichiometric lithium niobate. J. Chem. Phys. 1972, 56, 4648-4851. [CrossRef]

100. Araujo, R.M.; dos Santos Mattos, E.F.; Valerio, M.E.G.; Jackson, R.A. Computer Simulation of the Incorporation of $\mathrm{V}^{2+}, \mathrm{V}^{3+}, \mathrm{V}^{4+}$, $\mathrm{V}^{5+}$ and $\mathrm{Mo}^{3+}, \mathrm{Mo}^{4+}, \mathrm{Mo}^{5+}, \mathrm{Mo}^{6+}$ Dopants in $\mathrm{LiNbO}_{3}$. Crystals 2020, 10, 457. [CrossRef]

101. Kuzminov, Y.; Osiko, V.V. Disorder of stoichiometry in lithium niobate crystals. Cryst. Rep. 1994, 39, 471-476.

102. Fay, H.; Alford, W.J.; Dess, H.M. Temperature in $\mathrm{LiNbO}_{3}$ Crystals on Melt Composition. Appl. Phys. Lett. 1968, 12, 89. [CrossRef]

103. Suzuki, T. Oxygen partial pressure dependence of optical absorption in lithium niobate. J. Cryst. Growth 1996, 163, 403-410. [CrossRef]

104. Sweeney, K.L.; Halliburton, L.E.; Bryan, D.A.; Rice, R.R.; Gerson, R.; Tomaschke, H.E. Point defects in Mg-doped lithium niobate. J. Appl. Phys. 1985, 57, 1036-1044. [CrossRef]

105. Erdei, S.; Ainger, F.W. Trends in the growth of stoichiometric single crystals. J. Cryst. Growth 1997, 174, 293-300. [CrossRef]

106. Kovács, L.; Wohlecke, M.; Jovanović, A.; Polgár, K.; Kapphan, S. Infrared absorption study of the $\mathrm{OH}$ vibrational band in $\mathrm{LiNbO}_{3}$ crystals. J. Phys. Chem. Solids 1991, 52, 797-803. [CrossRef]

107. Engelsberg, M.; de Souza, R.E.; Pacobahyba, L.H.; do Nascimento, G.C. Structural determination of hydrogen site occupation in proton-exchanged $\mathrm{LiNbO}_{3}$ by nuclear magnetic resonance. Appl. Phys. Lett. 1995, 67, 359-361. [CrossRef]

108. Yevdokimov, S.V.; Yatsenko, A.V. Investigation of the Localization of $\mathrm{H}^{+}$Ions in Stoichiometric LiNbO 3 . Crystallogr. Rep. 2003, 48, 542-546. [CrossRef]

109. Rakitina, L.G.; Zaritskii, I.M.; Polgar, K. New hydrogen associated paramagnetic centre in LiNbO 3 . Appl. Magn. Reson. 1990, 1, 149-154. [CrossRef]

110. Rosa, J.; Polak, K.; Kubatova, J. ESR and optical studies of impurity centres in $\gamma$ - and X-irradiated LiNbO 3 . Phys. Status Solidi (b) 1982, 111, K85-K87. [CrossRef]

111. Corradi, G.; Polgar, K.; Bugai, A.A.; Grachev, V.G.; Deryugina, N.I.; Rakitina, L.M.; Zaritskii, I.M. Models of Ni ${ }^{+}$and Cu${ }^{2+}$ impurity centers in $\mathrm{LiNbO}_{3}$. Sov. Phys. Solid State 1986, 28, 739-748.

112. Zhang, H.-M.; Xiao, W.-B. Investigations on the EPR parameters and defect structures due to Jahn-Teller effect for the $\mathrm{Cu}^{2+}$ and $\mathrm{Ni}^{+}$centers in $\mathrm{LiNbO}_{3}$. J. Alloys Compd. 2018, 745, 586-591. [CrossRef]

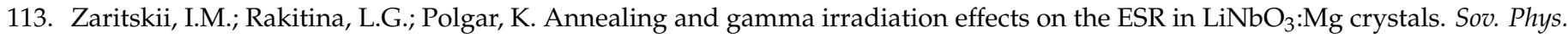
State Solid 1995, 37, 1073-1978.

114. Faust, B.; Müller, H.; Schirmer, O.F. Free small polarons in $\mathrm{LiNbO}_{3}$. Ferroelectrics 1994, 153, 297-302. [CrossRef]

115. Mirzakhanyan, A.A.; Petrosyan, A.K. EPR and optical absorption of $\mathrm{Co}^{2+}$ impurity ions in single crystal $\alpha-\mathrm{LiIO}_{3}$ and $\mathrm{LiNbO}_{3}$. Sov. Phys. Solid State 1986, 904-906, 1593-1595.

116. Donnerberg, H.J.; Shirmer, O.F. The paramagnetic properties of $\mathrm{Co}^{2+}$ in $\mathrm{LiNbO}_{3}$ and $\mathrm{LiTaO}_{3}$. Solid State Commun. 1987, 63, 29-32. [CrossRef]

117. Choi, Y.N.; Park, I.-W.; Kim, S.S.; Park, S.S.; Choh, S.H. Electron paramagnetic resonance studies of $\mathrm{Co}^{2+}$ ions in congruent and nearly stoichiometric $\mathrm{LiNbO}_{3}$ single crystals. J. Phys. Condens. Matter 1999, 11, 4723-4730. [CrossRef]

118. Grachev, V.G.; Hansen, K.; Meyer, M.; Kokanyan, E.P.; Malovichko, G.I. Substitution mechanisms and location of Co ${ }^{2+}$ ions in congruent and stoichiometric lithium niobate crystals derived from electron paramagnetic resonance data. Mater. Res. Express 2017, 4, 036204. [CrossRef]

119. Paul, M.; Tabuchi, M.; Weast, A.R. Defect Structure of Ni, Co-doped $\mathrm{LiNbO}_{3}$ and $\mathrm{LiTaO}_{3}$. Chem. Mater. 1997, 9, 3206-3214. [CrossRef] 
120. Mei, Y.; Wu, X.-X.; Zheng, W.-C. EPR parameters and defect structures for the $\mathrm{Co}^{2+}$ ions in $\mathrm{LiNbO}_{3}$ and $\mathrm{LiTaO}_{3}$ crystals. Spectrochim. Acta Part A Mol. Biomol. Spectrosc. 2008, 71, 714-719. [CrossRef]

121. Wu, S.-Y.; Lu, G.D.; Zhang, Z.H.; Wei, L.H.; Hu, Y.-X. Theoretical investigations of the local structures and spin Hamiltonian parameters for the trigonal $\mathrm{Co}^{2+}$ centers in $\mathrm{LiNbO}_{3}$ and $\mathrm{LiTaO}_{3}$. J. Alloys Compd. 2009, 1-2, 1-5. [CrossRef]

122. Setser, G.G. An Investigation by Electron Paramagnetic Resonance of the Jahn-Teller Effect in $\mathrm{LiNbO}_{3}: \mathrm{Ni}^{3+} \mathrm{and} \mathrm{LiNbO}_{3}: \mathrm{Cu}^{2+}$. Ph.D. Thesis, Rice University, Houston, TX, USA, 1974; pp. 1-237.

123. Palatnikov, M.N.; Sidorov, N.V.; Skiba, V.I.; Biryukova, I.V.; Serebryakov, Y.A.; Kravchenko, O.E.; Balabanov, Y.I.; Kalinnikov, V.T. Effects of nonstoichiometry and doping on the curie temperature and defect structure of lithium niobate. Inorg. Mater. 2000, 36, 489-493. [CrossRef]

124. Pape, M.; Reyher, H.-J.; Schirmer, O.F. Optically detected magnetic resonance of $\mathrm{Cu}, \mathrm{Fe}$ and $\mathrm{Mn}$ defects in LiNbO 3 . J. Phys. Condens. Matter 2005, 17, 6835-6847. [CrossRef]

125. Mirzakhanyan, A.A. Zero-field splitting of energy levels of $\mathrm{Ni}^{2+}$ ground state in $\alpha-\mathrm{LiIO}_{3}$ and $\mathrm{LiNbO}_{3}$. Sov. Phys. State Solid 1981, 23, 2452 .

126. Khalil, A.; Masaif, N.; Jennane, A.; Maaider, K. Substitution Mechanism of Ni:LiTaO, J. Mater. Environ. Sci. 2011, 2, 196-200.

127. Yang, Z.Y.; Rudowicz, C.; Yeung, Y.Y. Microscopic spin-Hamiltonian parameters and crystal field energy levels for the low $\mathrm{C}_{3}$ symmetry $\mathrm{Ni}^{2+}$ centre in $\mathrm{LiNbO}_{3}$ crystals. Physica B 2004, 348, 151-159. [CrossRef]

128. Petrov, M.P. Spectrum of Electron Paramagnetic Resonance of $\mathrm{Mn}^{2+}$ in ferroelectric $\mathrm{LiNbO}_{3}$. Sov. Phys. Solid State 1968, 10, 2574 .

129. Takeda, T.; Watanabe, A.; Sugihara, K. Spacing of the hyperfine sextet in $\mathrm{Mn}^{2+} \mathrm{ESR}$ in $\mathrm{LiNbO}_{3}$. Phys. Lett. A 1968, 27, 114-115. [CrossRef]

130. Danner, J.C.; Ranon, U.; Stamires, D.N. ESR of $\mathrm{Mn}^{2+}$ in ferroelectric $\mathrm{LiTaO}_{3}$ and $\mathrm{LiNbO}_{3}$ single crystals. Chem. Phys. Lett. 1968, 2, 605-606. [CrossRef]

131. Herrington, J.B.; Dischler, B.; Schneider, J. An EPR investigation of $\mathrm{Fe}^{3+}$ and $\mathrm{Mn}^{2+}$ in $\mathrm{LiNbO}_{3}$. Solid State Commun. 1972, 10, 509-511. [CrossRef]

132. Rexford, D.J.; Kim, Y.M. Electron-Spin Resonance Studies of Crystal Field Parameters in $\mathrm{Mn}^{2+}: \mathrm{LiNbO}_{3}$. J. Chem. Phys. 1972, 57, 3094-3098. [CrossRef]

133. Malovichko, G.I.; Grachev, V.G. Use of nuclear quadrupole splitting in determination of positions of iron group impurities in ferroelectric $\mathrm{LiNbO}_{3}$. Sov. Phys. Solid. State 1985, 27, 1678-1679.

134. Malovichko, G.I.; Grachev, V.G.; Lukin, S.N. EPR of axial and low symmetry $\mathrm{Cr}^{3+}, \mathrm{Fe}^{3+}$, and $\mathrm{Mn}^{2+}$ centers in $\mathrm{LiNbO}_{3}$. Sov. Phys. Solid State 1986, 28, 553-557.

135. Malovichko, G.I.; Karmazin, A.A.; Bykov, I.P.; Laguta, V.V.; Yarunichev, V.P. Electron spin resonance investigation of the temperature dependence of the axial crystal field parameters in $\mathrm{Mn}^{2+}$ and $\mathrm{Cr}^{3+}$ doped $\mathrm{LiNbO}_{3}$. Sov. Phys. Solid State 1983, 25, 2038-2041.

136. Park, I.W.; Choh, S.H.; Song, K.J. The hyperfine structure of $\mathrm{Mn}^{2+}$ in $\mathrm{LiNbO}_{3}$ and the sign of the second-order axial zero-field splitting. J. Korean Phys. Soc. 1993, 26, 77-80.

137. Park, I.-W. Three-fold Symmetry Effect on $\mathrm{Mn}^{2+}$ Centers in a $\mathrm{LiNbO}_{3}$ Crystal. J. Korean Magn. Res. Soc. 2008, 12, 103-110. [CrossRef]

138. Yeom, T.H.; Lee, S.H. Temperature Dependence of $\mathrm{Mn}^{2+}$ Paramagnetic Ion in a Stoichiometric $\mathrm{LiNbO}_{3}$ Single Crystal. J. Magn 2013, 18, 221-224. [CrossRef]

139. Corradi, G.; Söthe, H.; Spaeth, J.-M.; Polgar, K. Mn ${ }^{2+}$ defects in $\mathrm{LiNbO}_{3}$ : An electron nuclear double resonance (ENDOR) investigation of the $\mathrm{Mn}^{2+}$ site and the local disorder. J. Phys. Condens. Matter. 1990, 2, 6603-6618. [CrossRef]

140. Malovichko, G.; Grachev, V.; Hofstaetter, A.; Kokanyan, E.; Scharmann, A.; Schirmer, O. ENDOR study of $\mathrm{Cr}^{3+}$ centers substituting for lithium in lithium niobate. Phys. Rev. B 2002, 65, 224116. [CrossRef]

141. Grachev, V.; Malovichko, G. EPR, ENDOR, and optical-absorption study of $\mathrm{Cr}^{3+}$ centers substituting for niobium in Li-rich lithium niobate crystals. Phys. Rev. B 2000, 62, 7779-7790. [CrossRef]

142. Grachev, V.; Malovichko, G.; Schirmer, O. Structures of point defects in lithium niobate. Ukr. J. Phys. 2004, 49, 438-448.

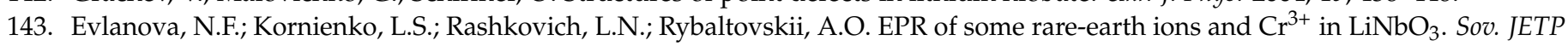
1967, 53, 1920-1926.

144. Burns, G.; O'Kane, D.F.; Title, R.S. Optical and Electron-Spin-Resonance Spectra of $\mathbf{Y b}^{3+}, \mathbf{N d}^{3+}$, and $\mathbf{C r}^{3+}$ in $\mathrm{LiNbO}_{3}$ and $\mathrm{LiTaO}_{3}$. Phys. Rev. 1968, 167, 314-318. [CrossRef]

145. Rexford, D.J.; Kim, Y.M.; Story, H.S. Electron-Spin resonance studies of $\mathrm{Cr}^{3+}$ in $\mathrm{LiNbO}_{3}$. J. Chem. Phys. 1970, 52, 860-863. [CrossRef]

146. Choh, S.H.; Kim, H.T.; Choh, H.K.; Han, C.S.; Choi, D.; Kim, J.N. Characterization of Stoichiometry of $\mathrm{LiNbO}_{3} \mathrm{Crystals}_{\text {by }} \mathrm{EPR}$ and Raman Scattering Measurements. Bull. Magn. Res. 1989, 11, 371.

147. Salley, G.M.; Basun, S.A.; Imbusch, G.F.; Kaplyanskii, A.A.; Kapphan, S.; Meltzer, R.S.; Happek, U. Chromium centers in LiNbO 3 revisited. J. Luminescence 1999, 83-84, 423-427. [CrossRef]

148. Grachev, V.; Malovichko, G.; Schirmer, O. Single, dimer and trimer chromium centers in lithium niobate. Ferroelectrics 1996, 185, 5-8. [CrossRef] 
149. Grachev, V.G.; Malovichko, G.I.; Troitskii, V.V. Investigation of the charge compensation mechanisms of $\mathrm{Cr}^{3+}$ ions in $\mathrm{LiNbO}_{3}$ by EPR and ENDOR methods. Sov. Phys. Solid State 1987, 29, 349-350.

150. Siu, G.G.; Zhao, M.-G. Electron-spin-resonance studies of Cr-ion pairs in $\mathrm{LiNbO}_{3}$ : Cr ${ }^{3+}$. Phys. Rev. B 1991, 43, 13575-13578. [CrossRef] [PubMed]

151. Corradi, G.; Sothe, H.; Spaeth, J.-M.; Polgar, K. Electron spin resonance and electron-nuclear double-resonance investigation of a new $\mathrm{Cr}^{3+}$ defect on an $\mathrm{Nb}$ site in $\mathrm{LiNbO}_{3}: \mathrm{Mg}$ :Cr. J. Phys. Condens. Matter 1991, 3, 1901-1908. [CrossRef]

152. Corradi, G.; Sothe, H.; Spaeth, J.-M.; Polgar, K. ENDOR for characterizing transition metal centres in LiNbO 3 . Radiat. Eff. Defects Solids 1991, 119-121, 583-587. [CrossRef]

153. Corradi, G.; Söthe, H.; Spaeth, J.-M.; Polgar, K. Local environment of $\mathrm{Mn}^{2+}$ and $\mathrm{Cr}^{3+}$ centres in $\mathrm{LiNbO}_{3}$ : Discussion of recent ENDOR results. Ferroelectrics 1992, 125, 295-299. [CrossRef]

154. Diazcaro, J.; Garcia-Sole, J.; Bravo, D.; Han, T.P.J.; Jaque, F.; Henderson, B. EPR and infrared absorption study in MgO Co-Doped $\mathrm{LiNbO}_{3}$ crystals. Ferroelectr. Lett. Sect. 1997, 23, 27-35. [CrossRef]

155. Thiemann, O.; Corradi, G.; Reyher, H.-J. ODMR-investigations of transition metals in $\mathrm{LiNbO}_{3}$. Ferroelectrics 1992, 125, 283-288 [CrossRef]

156. Camarillo, E.; Garcia-Sole, J.; Cusso, F.; Agullo-Lopez, F.; Sanz-Garcia, J.A.; Han, T.P.J.; Jaque, F.H.; Henderson, B. Polarization spectroscopy of $\mathrm{Cr}^{3+}$ ions in $\mathrm{LiNbO}_{3}$ single crystals: Effect of $\mathrm{Mg}^{2+}$ ions. Chem. Phys. Lett. 1991, 185, 505-510. [CrossRef]

157. Camarillo, E.; Tocho, J.; Vergara, I.; Dieguez, E.; Garcia-Sole, J.; Jaque, F. Optical bands of $\mathrm{Cr}^{3+}$ induced by $\mathrm{Mg}^{2+}$ ions in $\mathrm{LiNbO}_{3}: \mathrm{Cr}, \mathrm{Mg}$. Phys. Rev. B 1992, 45, 4600-4604. [CrossRef]

158. Martin, A.; Lopez, F.J.; Agullo-Lopez, F. Cr ${ }^{3+}$ in pure and Mg-doped $\mathrm{LiNbO}_{3}$ : Analysis of the EPR and optical spectra. J. Phys. Condens. Matter 1992, 4, 847-853. [CrossRef]

159. Macfarlane, P.I.; Holliday, K.; Nicholls, J.F.H.; Henderson, B. Characterization of $\mathrm{Cr}^{3+}$ centres in $\mathrm{LiNbO}_{3}$ using fluorescence line narrowing. J. Phys. Condens. Matter. 1995, 7, 9643-9656. [CrossRef]

160. Diaz-Caro, J.; Garcia-Sole, J.; Bravo, D.; Sanz-Garcia, J.A.; Lopez, F.J.; Jaque, F. MgO codoping-induced change in the site distribution of $\mathrm{Cr}^{3+}$ ions in $\mathrm{LiNbO}_{3}$. Phys. Rev. B 1996, 54, 13042-13046. [CrossRef] [PubMed]

161. Diaz-Caro, J.; Garcia-Sole, J.; Martinez, J.L.; Henderson, B.; Jaque, F.; Han, T.P.J. Redistribution of $\mathrm{Cr}^{3+}$ defect centres in $\mathrm{LiNbO}_{3}$ crystals: The MgO effect. Opt. Mater. 1998, 10, 69-77. [CrossRef]

162. Torchia, G.A.; Martinez Matos, O.; Vaveliuk, P.; Tocho, J.O. Influence of the electron-lattice coupling for $\mathrm{Cr}^{3+}$ ions in $\mathrm{Nb}^{5+}$ site into congruent co-doped $\mathrm{LiNbO}_{3}: \mathrm{Cr}^{3+}: \mathrm{ZnO}$ crystal. Solid State Commun. 2003, 127, 535-539. [CrossRef]

163. Ahn, S.W.; Rudowicz, C.; Choh, S.H.; Han, S.Y. EPR study of two $\mathrm{Cr}^{3+}$ defect centers in $\mathrm{LiTaO}_{3}$ single crystals. J. Korean Phys. Soc. 1997, 30, 99-102.

164. Ahn, S.W.; Kim, J.S.; Choh, S.H.; Yeom, T.H. An Induced $\mathrm{Cr}^{3+}$ Center in gamma-Irradiated LiTaO 3 . J. Korean Phys. Soc. 1994, 27, 535-538.

165. Loyo-Menoyo, M.; Keeble, D.J.; Furukawa, Y.; Kitamura, K. Electron paramagnetic resonance of $\mathrm{Cr}^{3+}$ in near-stoichiometric $\mathrm{LiTaO}_{3}$. J. Appl. Phys. 2005, 97, 123905. [CrossRef]

166. Bourson, P.; Malovichko, G.; Ridah, A.; Kokanyan, E. Effect of chromium concentration on site selective luminescence in nearly stoichiometric lithium niobate crystals. Ferroelectrics 1996, 155, 273-276. [CrossRef]

167. Lhomme, F.; Bourson, P.; Fontana, M.D.; Malovichko, G.; Aillerie, M.; Kokanyan, E. Luminescence of Cr ${ }^{3+}$ in lithium niobate: Influence of the chromium concentration and crystal composition. J. Phys. Condens. Matter 1998, 10, 1137-1146. [CrossRef]

168. Lhomme, F.; Bourson, P.; Moncorge, R.; Burlot, R.; Fontana, M.D.; Aillerie, M.; Boulon, G.; Malovichko, G. New study of the $720-750 \mathrm{~nm}$ range in the emission spectra of $\mathrm{LiNbO}_{3}: \mathrm{Cr}^{3+}$ crystals with different compositions. Radiat. Eff. Defects Solids 1999, 150, 259-263. [CrossRef]

169. Kaminska, A.; Suchocki, A.; Grinberg, M.; Garcia-Sole, J.; Jaque, F.; Arizmendi, L. High-pressure spectroscopy of LiNbO 3 :MgO, $\mathrm{Cr}^{3+}$ crystals. J. Lumin. 2000, 87-89, 571-573. [CrossRef]

170. Salley, G.M.; Basun, S.A.; Kaplyanskii, A.A.; Meltzer, R.S.; Polgar, K.; Happek, U. Chromium centers in stoichiometric LiNbO 3 . J. Lumin 2000, 87-89, 1133-1135. [CrossRef]

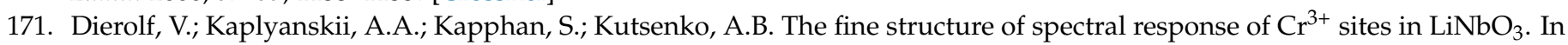
Radiat. Eff. Defects Solids; 2001; Volume 155, pp. 241-246. [CrossRef]

172. Basun, S.A.; Salley, G.M.; Kaplyanskii, A.A.; Gallagher, H.G.; Polgar, K.; Lu, L.; Happek, U. A novel luminescent center in $\mathrm{LiNbO}_{3}: \mathrm{Cr}: \mathrm{Mg}$ crystals. J. Lumin. 1999, 83-84, 435-439. [CrossRef]

173. Lhomme, F.; Bourson, P.; Boulon, G.; Guyot, Y.; Fontana, M.D. Comparative analysis of the $\mathrm{Cr}^{3+}$ centre spectroscopic properties in $\mathrm{LiNbO}_{3}$ crystals from congruent to nearly stoichiometric compositions. Eur. Phys. J. AP 2002, 20, 29-40. [CrossRef]

174. Han, T.P.J.; Jaque, F.; Bermudez, V.; Dieguez, E. Luminescence of the $\mathrm{Cr}^{3+} \mathrm{R}$-lines in pure and $\mathrm{MgO}$ co-doped near stoichiometric $\mathrm{LiNbO}_{3}: \mathrm{Cr}$ crystals. Chem. Phys. Lett. 2003, 369, 519-524. [CrossRef]

175. Han, T.P.J.; Jaque, F. Optical stability of the $\mathrm{Cr}^{3+}$ centres in codoped stoichiometric and congruent $\mathrm{LiNbO}$ : $\mathrm{Cr}: \mathrm{Mg}$. Opt. Mater. 2007, 29, 1041-1043. [CrossRef]

176. Kaczmarek, S.M.; Lukasiewicz, T.; Pracka, I.; Jablonski, R.; Boulon, G.; Kaczmarek, B.; Warchol, S. Radiation defects in Dy ${ }^{3+}$ doped $\mathrm{LiNbO}_{3}$ single crystals. J. Alloys Compd. 1998, 275-277, 105-108. [CrossRef] 
177. Jablonski, R.; Pracka, I.; Swirkowicz, M. Electron spin resonance spectra of $\mathrm{Nd}^{3+}, \mathrm{Dy}^{3+}, \mathrm{Er}^{3+}$ and $\mathrm{Yb}^{3+}$ in $\mathrm{LiNbO}_{3}$. In Solid State Crystals: Growth and Characterization, Proceedings of the XII Conference on Solid State Crystals: Materials Science and Applications, Zakopane, Poland, 7-11 October 1996; SPIE: Bellingham, WA, USA, 1997. [CrossRef]

178. Milori, D.M.B.P.; Moraes, I.J.; Hernandes, A.C.; de Souza, R.R.; Li, M.S.; Terrile, M.C.; Barberis, G.E. Optical and ESR study of Er ${ }^{3+}$ in $\mathrm{LiNbO}_{3}$. Phys. Rev. B 1995, 51, 3206-3209. [CrossRef] [PubMed]

179. Nolte, T.; Pawlik, T.; Spaeth, J.-M. EPR study of $\mathrm{Er}^{3+}$ in congruent $\mathrm{LiNbO}_{3}$. Solid State Commun. 1997, 104, 535-539. [CrossRef]

180. Bodziony, T.; Kaczmarek, S.M. EPR study of low symmetry Er centers in congruent lithium niobate. Phys. Status Solidi (b) 2008, 245, 998-1002. [CrossRef]

181. Kaczmarek, S.M.; Bodziony, T. Low symmetry centers in $\mathrm{LiNbO}_{3}$ doped with $\mathrm{Yb}$ and Er. J. Non-Cryst. Solids 2008, 354, 4202-4210. [CrossRef]

182. Bodziony, T.; Kaczmarek, S.M. Temperature dependence of the EPR spectra and optical measurements of $\mathrm{LiNbO}_{3}$ : Er, Tm single crystal. J. Alloys Compd. 2009, 468, 581-585. [CrossRef]

183. Bodziony, T.; Kaczmarek, S.M.; Kruk, R. Low temperature magnetic measurements of $\mathrm{LiNbO}_{3}$ single crystal weakly doped with Er and codoped with Tm ions. J. Spectrosc. Dyn. 2011, 1, 1-8.

184. Vrable, I.; Malovichko, G.; Grachev, V.; Meyer, M. EPR/ENDOR Studies of Erbium Centers in Stoichiometric Lithium Niobate Crystals. In Proceedings of the 49th Rocky Mountain Conference on Analytical Chemistry, Breckenridge, CO, USA, 22-26 July 2007; Abstract C 143. p. 71. Available online: http:/ / rockychem.com/links/past-conferences.html (accessed on 1 March 2007).

185. Malovichko, G.; Grachev, V.; Jorgensen, J.; Meyer, M.; Munro, M.; Todt, B.; Vrable, I.; Kokanyan, E.; Bratus, V.; Okulov, S. Magnetic resonance study of non-equivalent centers created by $4 \mathrm{f}$-ions in congruent and stoichiometric lithium niobate. MRS Online Proc. Libr. 2008, 1111, 103. [CrossRef]

186. Mackova, A.; Groetzschel, R.; Eichhorn, F.; Nekvindova, P.; Spirkova, J. Characterization of Er:LiNbO 3 and $\mathrm{APE}_{\mathrm{E}} \mathrm{Er}: \mathrm{LiNbO}_{3}$ by RBS-channeling and XRD techniques. Surf. Interface Anal. 2004, 36, 949-951. [CrossRef]

187. Gog, T.; Griebenow, M.; Materlik, G. X-ray standing wave determination of the lattice location of Er diffused into LiNbO 3 . Phys. Lett. A 1993, 181, 417-420. [CrossRef]

188. Rebouta, L.; da Silva, M.F.; Soares, J.C.; Serrano, D.; Diéguez, E.; Agulló-López, F.; Tornero, J. Nonaxial sites for Er in LiNbO3. J. Appl. Phys. Lett. 1997, 70, 1070-1072. [CrossRef]

189. Malovichko, G.; Vrable, I.; Meyer, M.; Kokanyan, E.; Grachev, V. Ordering magnetic moments of Er ${ }^{3+}$ in ferroelectric lithium niobate. In Proceedings of the International Conference "Oxide Materials for Electronic Engineering-Fabrication, Properties and applica\$tion" (OMEE-2014), Lviv, Ukraine, 26-30 May 2014; pp. 35-36.

190. Gill, D.M.; Wright, J.C.; McCaughan, L. Site characterization of rare-earth-doped $\mathrm{LiNbO}_{3}$ using total site selective spectroscopy. J. Appl. Phys. Lett. 1994, 64, 2483-2485. [CrossRef]

191. Gill, D.M.; McCaughan, L.; Wright, J.C. Spectroscopic site determinations in erbium-doped lithium niobate. Phys. Rev. B 1996, 53, 2334-2344. [CrossRef] [PubMed]

192. Muntoz, J.A.; Cantelar, E.; Sanz-garcia, J.A.; Duchowicz, R.; Serrano, D.; Dieguez, E.; Lifante, G.; Cusso, F. Site-selective spectroscopy of $\mathrm{Er}^{3+}$ and $\mathrm{Er}^{3+} \mathrm{Yb}^{3+}$ doped stoichiometric and congruent lithium niobate. Radiat. Eff. Defects Solids 1999, 150, 221-225. [CrossRef]

193. Dierolf, V.; Koerdt, M. Combined excitation-emission spectroscopy of $\mathrm{Er}^{3+}$ ions in stoichiometric $\mathrm{LiNbO}_{3}$ : The site selectivity of direct and up conversion excitation processes. Phys. Rev. B 2000, 61, 8043-8048. [CrossRef]

194. Dierolf, V.; Kutsenko, A.B.; Ostendorf, A.; von der Osten, W.; Sohler, W.; Suche, H. Site-selective spectroscopy of $\mathrm{Er}^{3+}: \mathrm{Ti}^{3} \mathrm{LiNbO}_{3}$ waveguides. Appl. Phys. B 2001, 72, 803-810. [CrossRef]

195. Dierolf, V.; Kutsenko, A.B.; Sandmann, C.; Troester, T.; Corradi, G. High-resolution site selective optical spectroscopy of rare earth and transition metal defects in insulators. J. Lumin. 2000, 87-89, 989-991. [CrossRef]

196. Dierolf, V.; Sandmann, C. Combined excitation emission spectroscopy of defects for site-selective probing of ferroelectric domain inversion in lithium niobate. J. Lumin. 2007, 125, 67-79. [CrossRef]

197. Bravo, D.; Martin, A.; Lopez, F.J. A new centre of $\mathrm{Er}^{3+}$ in $\mathrm{MgO}$ or $\mathrm{ZnO}$ co-doped $\mathrm{LiNbO}_{3}$ single crystals. Solid State Commun. 1999, 112, 541-544. [CrossRef]

198. Mehran, F.; Scott, B.A. Electron paramagnetic resonance of $\mathrm{LiNbO}_{3}: \mathrm{Fe}^{3+}$. Solid State Commun. 1972, 11, 15-19. [CrossRef]

199. Towner, H.H.; Kim, Y.M.; Story, H.S. EPR studies of crystal field parameters in $\mathrm{Fe}^{3+}$ : $\mathrm{LiNbO}_{3}$. J. Chem. Phys. 1972, 56, 3676-3679. [CrossRef]

200. Dikantova, Z. EPR study of impurities centers in $\mathrm{LiNbO}_{3}$. Acta Phys. Slov. 1973, 23, 245-250.

201. Keune, W.; Date, S.K.; Gonser, U.; Bunzel, H. Mossbauer effect study of $\mathrm{Fe}^{57}$ doped $\mathrm{LiNbO}_{3}$ and $\mathrm{LiTaO}_{3}$. Ferroelectrics 1976, 13, 443-445. [CrossRef]

202. Kurz, H.; Krätzig, E.; Keune, W.; Engelmann, H.; Gonser, U.; Dischler, B.; Räuber, A. Photorefractive centers in LiNbO 3 , studied by optical-, Mössbauer- and EPR-methods. Appl. Phys. 1977, 12, 355-368. [CrossRef]

203. Grachev, V.G.; Malovichko, G.I. Determination of the point symmetry of defects in crystals exhibiting structural phase transitions, using the temperature dependencies of the EPR spectra. Impurities in $\mathrm{LiNbO}_{3}$. Sov. Phys. Solid State 1985, $27,686-689$.

204. Pfannes, H.D.; Putzka, A.; Sampaio, J.F. Electronic structure and spin relaxation of Fe(III) in $\mathrm{LiNbO}_{3}$. Hyperfine Interact. 1986, 28, 785-788. [CrossRef] 
205. Jablonski, R.; Kaczmarek, S.M.; Praska, I.; Surma, B.; Swirkowicz, M.; Lukasiewicz, T. ESR and optical measurements of LiNbO 3 and $\mathrm{LiTaO}_{3}$ single crystals doped with ions of the first transition series. Spectrochim. Acta A 1998, 54, 1701-1709. [CrossRef]

206. Yeom, T.H.; Choh, S.H. Magnetic Resonance Investigations of $\mathrm{LiNbO}_{3}$ and $\mathrm{LiTaO}_{3}$ Single Crystals. J. Korea Phys. Soc. 1998, 32, S672-S674.

207. Santana, R.C.; Terrile, M.C.; Hernandes, A.C.; Andreeta, M.R.B.; Barberis, G.E. Electron spin resonance study of Fe ${ }^{3+}$ in $\mathrm{LiNbO}_{3}$ single crystals: Bulk and fibres. Solid State Commun. 1997, 103, 61-64. [CrossRef]

208. Keeble, D.J.; Loyo-Menoyo, M.; Furukawa, Y.; Kitamura, K. Electron paramagnetic resonance of $\mathbf{F e}^{3+}$ in $\mathbf{L i N b O}_{3}$. Phys. Rev. B 2005, 71, 224111. [CrossRef]

209. Agullò-López, F.; Müller, K.A. Superposition Model Calculations for $\mathrm{Fe}^{3+}$ in $\mathrm{LiNbO}_{3}$. Cryst. Latt. Def. Amorph. Mater. 1987, 15, 89.

210. Zhao, M.G.; Chiu, M. Substitution site of the $\mathrm{Fe}^{3+}$ impurity in crystalline LiNbO 3 . Phys. Rev. B 1994, 49, 12556-12558. [CrossRef]

211. Wang, H.; Kuang, X.Y.; Die, D.; Tan, X.-M.; Yang, X. EPR spectra and local lattice structure of Fe ${ }^{3+}$ impurity ions in ferroelectric $\mathrm{LiNbO}_{3}$. Chem. Phys. 2006, 330, 212-215. [CrossRef]

212. Wang, H.; Kuang, X.Y.; Die, D.; Yang, X.; Zhou, K.-W. EPR investigation of substitution position for $\mathrm{Fe}^{3+}$ in $\mathrm{LiNbO}_{3}: \mathrm{Fe}^{3+}$ system. Physica B 2005, 367, 53-60. [CrossRef]

213. Yeom, T.H.; Chang, Y.M.; Choh, S.H.; Rudowicz, C. Experimental and Theoretical Investigation of Spin-Hamiltonian Parameters for the Low Symmetry $\mathrm{Fe}^{3+}$ Centre in $\mathrm{LiNbO}_{3}$. Phys. Status Solidi (b) 1994, 185, 409-415. [CrossRef]

214. Xue, D.; He, X. Dopant occupancy and structural stability of doped lithium niobate crystals. Phys. Rev. B 2006, $73,064113$. [CrossRef]

215. Zhang, Z.; Xue, D. Local Lattice Structure and Dopant Occupancy Of Doped Lithium Niobate Crystals. Mod. Phys. Lett. B 2009, 23, 3687-3694. [CrossRef]

216. Basun, S.A.; Bursian, V.E.; Evans, D.R.; Kaplyanskii, A.A.; Razdobarin, A.G.; Sochava, L.S. Ferroelectric-Specific Stark Effect in Stoichiometric $\mathrm{LiNbO}_{3}: \mathrm{Fe}$ at Room Temperature. Phys. Rev. Lett. 2008, 100, 057602. [CrossRef]

217. Grachev, V.G.; Petersen, R.T.; Kokanyan, E.P.; Schirmer, O.F.; Malovichko, G.I. Structural analysis of the dominant axial Fe ${ }^{3+}$ center in $\mathrm{LiNbO}_{3}$ crystal by electron nuclear double resonance. J. Appl. Phys. 2016, 120, 193901. [CrossRef]

218. Boker, A.; Donnerberg, H.; Schirmer, O.F.; Feng, X. Two sites of $\mathrm{Fe}^{3+}$ in highly Mg-doped LiNBO 3 . J. Phys. Condens. Matter 1990, 2, 6865-6868. [CrossRef]

219. Volk, T.R.; Rubinina, N.M.; Pryalkin, V.I.; Krasnikov, V.V.; Volkov, V.V. Optical and non-linear optical investigations in $\mathrm{LiNbO}_{3}: \mathrm{Mg}$ and $\mathrm{LiNbO}_{3}: \mathrm{Zn}$. Ferroelectrics 1990, 109, 345-350. [CrossRef]

220. Yeom, T.H.; Lee, S.H.; Choh, S.H.; Choi, D. Electron paramagnetic resonance study of Fe ${ }^{3+}$ in $\mathrm{LiNbO}_{3}: \mathrm{Mg}: \mathrm{Fe}$ crystal. J. Korean Phys. Soc. 1998, 32, S647.

221. Malovichko, G.I.; Grachov, V.G.; Kokanyan, E.P. Low-symmetry Fe-Mg complexes in LiNbO 3 :Mg. Ferroelectrics 1992, 125, $289-294$. [CrossRef]

222. Grachev, V.; Malovichko, G.; Kokanyan, E. Optimization of lithium niobate for advanced applications by variation of extrinsic and intrinsic defect subsystems. Ferroelectrics 2001, 258, 131-140. [CrossRef]

223. Volk, T.; Wöhlecke, M.; Rubinina, N.; Razumovskii, N.V.; Jermann, F.; Fischer, C.; Böwer, R. LiNbO 3 with the damage-resistant impurity indium. Appl. Phys. A 1995, 60, 217-225. [CrossRef]

224. Volk, T.R.; Rubinina, N.M. Non photorefractive impurities in lithium niobate: Magnesium and zinc. Sov. Phys. Solid State 1991, 33, 674-680.

225. Vazhenin, V.A.; Guseva, V.B.; Artyomov, M.Y.; Route, R.K.; Fejer, M.M.; Byer, R.L. Fine structure of the electron paramagnetic resonance spectrum of $\mathrm{Fe}^{3+}$ centres in $\mathrm{LiTaO}_{3}$. J. Phys. Condens. Matter 2003, 15, 275-280. [CrossRef]

226. Loyo-Menoyo, M.; Keeble, D.J.; Furukawa, Y.; Kitamura, K. Electron paramagnetic resonance of Fe ${ }^{3+}$ in near-stoichiometric $\mathrm{LiTaO}_{3}$. J. Phys. Condens. Matter 2004, 16, 9047-9057. [CrossRef]

227. McDonald, P.F.; Tam, C.P.; Mok, Y.W. EPR Gd ${ }^{3+}$ in $\mathrm{LiNbO}_{3}$. J. Chem. Phys. 1972, 56, 1007-1008. [CrossRef]

228. Dischler, B.; Herrington, J.R.; Räuber, A.; Schneider, J.; Urban, W. An EPR study of different $\mathrm{Gd}^{3+}$ centers in $\mathrm{LiNbO}_{3}$. Solid State Communs. 1973, 12, 737-740. [CrossRef]

229. Park, I.-W.; Kim, M.; Choh, S.H.; Kim, J.N. EPR study of Gd ${ }^{3+}$ Paramagnetic Centers in Congruent LiNbO 3 Single Crystal. New Phys. (Korean Phys. Soc.) 1994, 34, 464-469.

230. Bonardi, C.; Carvalho, R.A.; Basso, H.C.; Terrile, M.C.; Cruz, G.K.; Bausa, L.E.; Sole, J.G. Magnetic circular dichroism of Nd ${ }^{3+}$ and $\mathrm{Yb}^{3+}$ ions in $\mathrm{LiNbO}_{3}$ crystals. J. Chem. Phys. 1999, 111, 6042-6046. [CrossRef]

231. Camarillo, E.; Hernandez, J.; Garcia Sole, J.; Caldino, U.; Munoz Santiuste, J.E.; Loro, H.; Voda, M.; Jaque, F.; Murrieta, H. Nd ${ }^{3+}$ centres induced by $\mathrm{ZnO}$ or $\mathrm{MgO}$ codoping $\mathrm{LiNbO}_{3}$. J. Phys. Condens. Matter 1995, 7, 96359641. [CrossRef]

232. Ziling, K.K.; Nadolinnii, V.A.; Shashkin, V.V. Sov.: Reports of AS of USSR. Inorg. Mater. 1980, 16, 701.

233. Juppe, S.; Schirmer, O.F. EPR Ti ${ }^{3+}$ in $\mathrm{LiNbO}_{3}$. Phys. Lett. A 1986, 117, 150-155. [CrossRef]

234. Rakitina, L.G.; Zaritskii, I.M.; Corradi, G.; Polgar, K. Mechanisms of broadening of ESR lines of polaron centers in LiNbO 3 : Ti subjected to irradiation and heat treatments. Sov. Phys. Solid State 1990, 32, 654-660.

235. Thiemann, O.; Donnerberg, G.H.; Wöhlecke, M.; Schirmer, O. Vibronic structure, energy level, and incorporation mechanism of $\mathrm{Ti}^{3+}$ in $\mathrm{LiNbO}_{3}$ and $\mathrm{LiTaO}_{3}$. Phys. Rev. B 1994, 49, 5845-5851. [CrossRef] 
236. Corradi, G.; Polgar, K.; Zaritskii, I.M.; Rakitina, L.G.; Deryugina, N.I. Defect formation under $\gamma$-irradiation and heat treatment in pure and doped $\mathrm{LiNbO}_{3}$ monocrystals. Sov. Phys. State Solid 1989, 31, 115-122.

237. Corradi, G.; Zaritskii, I.M.; Hofstaetter, A.; Polgar, K.; Rakitina, L.G. $\mathrm{Ti}^{3+}$ on Nb site: A paramagnetic Jahn-Teller center in vacuum-reduced $\mathrm{LiNbO}_{3}: \mathrm{Mg}$ :Ti single crystals. Phys. Rev. B 1998, 58, 8329-8337. [CrossRef]

238. Corradi, G. $\mathrm{Nb}^{4+}$ Polaron and $\mathrm{Ti}^{3+}$ Shallow Donor Jahn-Teller Centers in $\mathrm{LiNbO}_{3}$ Systems. In Defects and Surface-Induced Effects in Advanced Perovskites; Borstel, G., Krumins, A., Millers, D., Eds.; NATO Science Series (Series 3. High Technology); Springer: Dordrecht, The Netherlands; Boston, MA, USA; London, UK, 2000; Volume 77, pp. 89-100. [CrossRef]

239. Corradi, G.; Meyer, M.; Kovács, L.; Polgar, K. Gap levels of $\mathrm{Ti}^{3+}$ on $\mathrm{Nb}$ or Li sites in $\mathrm{LiNbO}_{3}$ :(Mg):Ti crystals and their effect on charge transfer processes. Appl. Phys. B 2004, 78, 607-614. [CrossRef]

240. Corradi, G.; Meyer, M.; Polgár, K. Bipolarons localised by Ti dopants in reduced $\mathrm{LiNbO}_{3}$ crystals double-doped by Ti and Mg. Phys. Status Solidi (c) 2005, 2, 132-135. [CrossRef]

241. Bonardi, C.; Magon, C.J.; Vidoto, E.A.; Terrile, M.C.; Bausa, L.E.; Montoya, E.; Bravo, D.; Martin, A.; Lopez, F.J. EPR spectroscopy of $\mathrm{Yb}^{3+}$ in $\mathrm{LiNbO}_{3}$ and $\mathrm{Mg}: \mathrm{LiNbO}_{3}$. J. Alloys Compd. 2001, 323, 340-343. [CrossRef]

242. Dohnke, I.; Trusch, B.; Klimm, D.; Hulliger, J. A study of influence of ytterbium and impurities on lattice parameters and phase transition temperature of Czochralski grown LiNbO . J. Phys. Chem. Solids 2004, 65, 1297-1305. [CrossRef]

243. Bodziony, T.; Kaczmarek, S.M. New low symmetry centres of $\mathrm{Yb}^{3+}$ impurities in lithium niobate single crystal. Opt. Mater. 2007, 29, 1440-1446. [CrossRef]

244. Bodziony, T.; Kaczmarek, S.M. EPR and optical study of coupled $\mathrm{Yb}^{3+}$ ion pairs in weakly doped $\mathrm{LiNbO}_{3}: \mathrm{Yb}_{\mathrm{b}}$ single crystal. Res. Chem. Intermed. 2007, 33, 885-899. [CrossRef]

245. Bodziony, T.; Kaczmarek, S.M.; Rudowicz, C. Temperature dependence of the EPR lines in weakly doped $\mathrm{LiNbO}_{3}: \mathrm{Yb}-\mathrm{Possible}$ evidence of Yb3+ ion pairs formation. Physica B 2008, 403, 207-218. [CrossRef]

246. Bodziony, T.; Kaczmarek, S.M.; Hanuza, J. EPR and optical studies of $\mathrm{LiNbO}_{3}: \mathrm{Yb}$ and $\mathrm{LiNbO}_{3}: \mathrm{Yb}$, Pr single crystals. J. Alloys Compd. 2008, 451, 240-247. [CrossRef]

247. Bodziony, T.; Kaczmarek, S.M.; Kruk, R. Magnetic properties of $\mathrm{LiNbO}_{3}$ single crystals weakly doped by $\mathrm{Yb}$ and/or codoped by Pr. Rev. Adv. Mater. Sci. 2010, 23, 1-7.

248. Malovichko, G.; Grachev, V.; Kokanyan, E.; Schirmer, O. EPR, NMR and ENDOR study of intrinsic and extrinsic defects in disordered and regularly ordered lithium niobate crystals. Ferroelectrics 2000, 239, 357-366. [CrossRef]

249. Malovichko, G.; Bratus, V.; Grachev, V.; Kokanyan, E. Electron paramagnetic resonance and electron-nuclear double resonance study of nonequivalent $\mathrm{Yb}^{3+}$ centers in congruent and nearly stoichiometric lithium niobate. Phys. Status Solidi (b) 2009, 246, 215-225. [CrossRef]

250. Xu, H.; Lee, D.; He, J.; Sinnott, S.B.; Gopalan, V.; Dierolf, V.; Phillpot, S.R. Stability of intrinsic defects and defect clusters in $\mathrm{LiNbO}_{3}$ from density functional theory calculations. Phys. Rev. B 2008, 78, 174103. [CrossRef]

251. Xu, H.; Chernatynskiy, A.; Lee, D.; Sinnott, S.B.; Gopalan, V.; Dierolf, V.; Phillpot, S.R. Stability and charge transfer levels of extrinsic defects in $\mathrm{LiNbO}_{3}$. Phys. Rev. B 2010, 82, 184109. [CrossRef]

252. Xu, H.; Lee, D.; Sinnott, S.B.; Dierolf, V.; Gopalan, V.; Phillpot, S.R. Structure and diffusion of intrinsic defect complexes in LiNbO 3 from density functional theory calculations. J. Phys. Condens. Matter 2010, 22, 135002. [CrossRef]

253. Vyalikh, A.; Zschornak, M.; Köhler, T.; Nentwich, M.; Weigel, T.; Hanzing, J.; Zaripov, R.; Vavilova, E.; Gemming, S.; Brendler, E.; et al. Analysis of the defect clusters in congruent lithium tantalate. Phys. Rev. Mater. 2018, 2, 013804. [CrossRef]

254. Zhang, Q.-R.; Feng, X.-Q. Defect structures and the MgO-doping-level-threshold effect on the optical absorption of reduced MgO-doped lithium niobate. Phys. Rev. B 1991, 43, 12019-12024. [CrossRef] [PubMed]

255. Schirmer, O.F.; Thiemann, O.; Wohlecke, M. Defects in $\mathrm{LiNbO}_{3}$-I. experimental aspects. J. Phys. Chem. Solids 1991, 52, 185-200. [CrossRef]

256. Schirmer, O.F.; Imlau, M.; Merschjann, C.; Schoke, B. Electron small polarons and bipolarons in LiNbO 3 . J. Phys. Condens. Matter 2009, 21, 123201. [CrossRef] [PubMed]

257. Schirmer, O.F.; von der Linde, D. Two photon and x-ray induced $\mathrm{Nb}^{4+}$ and $\mathrm{O}^{-}$small polarons in LiNbO 3 . Appl. Phys. Lett. 1978, 33, 35-38. [CrossRef]

258. Ketchum, J.L.; Sweeney, K.L.; Halliburton, L.E.; Armington, A.F. Vacuum annealing effects in lithium niobate. Phys. Lett. A 1983, 94, 450-453. [CrossRef]

259. Sweeney, K.L.; Halliburton, L.E. Oxygen vacancies in lithium niobate. Appl. Phys. Lett. 1983, 43, 336-338. [CrossRef]

260. Halliburton, L.E.; Sweeney, K.L.; Chen, C.Y. Electron spin resonance and optical studies of point defects in lithium niobate. Nucl. Instrum. Methods Phys. Res. B 1984, 1, 344-347. [CrossRef]

261. Dutt, D.A.; Feigl, F.J.; DeLeo, G.G. Optical absorption and electron paramagnetic resonance studies of chemically reduced congruent lithium niobate. J. Phys. Chem. Solids 1990, 51, 407-415. [CrossRef]

262. Müller, H.; Schirmer, O.F. Microscopic structure of $\mathrm{Nb}_{\mathrm{Li}}$ related defects in reduced undoped $\mathrm{LiNbO}_{3}$. Ferroelectrics 1992,125 , 319-324. [CrossRef]

263. Zaritskii, I.M.; Rakitina, L.G.; Corradi, G.; Polgar, K.; Bugai, A.A. A new trapped-hole radiation defect in heavily Mg-doped $\mathrm{LiNbO}_{3}$. J. Phys. Condens. Matter 1991, 3, 8457-8465. [CrossRef]

264. Halliburton, L.E.; Sweeney, K.L.; Kappers, L.A. Self-trapped electrons in lithium tantalate. Phys. Lett. A 1986, 116, 81-84. [CrossRef] 
265. Lee, M.; Gyoo Kim, I.; Takekawa, S.; Furukawa, Y.; Uchida, Y.; Kitamura, K.; Hatano, H. Electron paramagnetic resonance investigation of the photochromic effect in near-stoichiometric $\mathbf{L i N b O}_{3}$ with applications to holographic storage. J. Appl. Phys. 2001, 89, 5311. [CrossRef]

266. Miki, T.; Hantehzadeh, M.R.; Halliburton, L.E. A new trapped-hole center in irradiated $\mathrm{LiNbO}_{3}$. J. Phys. Chem. Solids 1989, 50, 1003-1007. [CrossRef] 